Copyright

by

Swagata Das

2011 
The Thesis Committee for Swagata Das

Certifies that this is the approved version of the following thesis:

Distribution Fault Location Using Short-circuit Fault Current Profile Approach

\begin{abstract}
APPROVED BY SUPERVISING COMMITTEE:
\end{abstract}

Supervisor:

Surya Santoso

W. Mack Grady 


\title{
Distribution Fault Location using Short-circuit Fault Current Profile Approach
}

by

Swagata Das, B.Tech.

\author{
Thesis \\ Presented to the Faculty of the Graduate School of \\ The University of Texas at Austin \\ in Partial Fulfillment \\ of the Requirements \\ for the Degree of
}

Master of Science in Engineering

The University of Texas at Austin

May 2011 


\section{Dedication}

This work is dedicated to my loving parents and grandparents. 


\section{Acknowledgements}

I wish to thank and express my sincere gratitude to my advisor, Professor Surya Santoso for giving me an opportunity to work on this project and for his continuous support and encouragement since I joined graduate school in Fall 09. Working under him has been an incredible learning experience and his positive feedback, guidance and encouragement have helped keep me focused during my research.

I am also thankful to W. Mack Grady for his academic guidance and having kindly agreed to read a draft of this thesis.

I also wish to extend my warmest thanks to Electric Power Research Institute for providing the actual distribution power quality and circuit data for this study.

I sincerely thank Neeraj Karnik and Saurabh Kulkarni for the help that they provided for improving the short-circuit fault current profile approach used in this study. And finally, many thanks to Mohit Singh, Alicia Allen, Won Jin Cho and Duehee Lee for their help and support.

May 2011 


\section{Statement of Originality and Academic Integrity}

I certify that I have completed the online ethics training modules, particularly the Academic Integrity Module [1], of the University of Texas at Austin - Graduate School. I fully understand, and I am familiar with the University policies and regulations relating to academic integrity and the academic policies and procedures [2].

I attest that this thesis is the result of my own original work and efforts. Any ideas of other authors, whether or not they have been published or otherwise disclosed, are fully acknowledged and properly referenced.

I acknowledge the thoughts, direction and supervision of my research advisor, Professor Surya Santoso. I give him consent to use the materials presented herein for publication, instructional and research activities.

[1] The University of Texas at Austin - Graduate School's online ethics training on academic integrity, http://www.utexas.edu/ogs/student_services/ethics/academic.html [Completed 04/27/2011]

[2] The Catalog of The University of Texas at Austin, General Information, 2010-201, Appendix C, Section 11-402, http://registrar.utexas.edu/docs/catalogs/gi/ut-cataloggi1011.pdf 


\begin{abstract}
Distribution Fault Location using Short-circuit Fault Current Profile Approach
\end{abstract}

\author{
Swagata Das, MSE \\ The University of Texas at Austin, 2011
}

Supervisor: Surya Santoso

Popularly used impedance-based methods need voltage and current waveform as well as line impedance per unit length to estimate distance to fault location. For a nonhomogenous system with different line configuration, these methods assume that the system is homogenous and use the line impedance of the most frequently occurring line configuration. Load present in the system before fault is an important parameter which affects fault location accuracy. Impedance-based methods like Takagi and positivesequence method assume that the load is lumped beyond the fault point which may not be true for a typical distribution system. As a result, accuracy of the impedance-based methods in estimating distance to fault is affected. Another short-coming of impedancebased methods are that they are unable to identify the branch in which the fault may be located. 
To minimize these errors, this thesis proposes a short-circuit fault current profile approach to complement impedance-based algorithms. In the short-circuit fault current profile approach, circuit model of the distribution feeder is used to place faults at every bus and the corresponding short-circuit fault current is plotted against reactance or distance to fault. When a fault occurs in the distribution feeder, fault current recorded by relay is extrapolated on the current profile to get location estimates. Since the circuit model is directly used in building the current profile, this approach takes into account load and non-uniform line impedance. Using the estimates from short-circuit fault current profile approach and impedance-based methods, the path on which the fault is located is identified. Next to improve fault location estimates, a median value of the estimates is computed. The median is a more robust estimate since it is not affected by outliers.

The strategy developed above is tested using modified IEEE 34 Node Test Feeder and validated against field data provided by utilities. For the IEEE 34 Node Test Feeder, it is observed that the median estimate computed from impedance-based methods and the short-circuit fault current profile approach is very close to the actual fault location. Error in estimation is within 0.58 miles. It was also observed that if a 0.6 mile radius is built around the median estimate, the fault will lie within that range. Now the IEEE 34 Node Test Feeder represents a typical distribution feeder and has also been modeled to represent the worst case scenario, i.e. load current is around $51 \%$ of the fault current for the farthest bus. Hence the 0.6 mile radius around the median estimate will hold true for most distribution feeders and will be used when computing the fault range for field case events.

For the field events, it was seen that the actual faults indeed lie within the 0.6 mile radius built around the median estimate and the path of the fault location has also been accurately estimated. For certain events, voltage waveform was not useful for analysis. In viii 
such situations, short-circuit fault current profile alone could be used to estimate fault location. Error in estimation is within 0.1 miles, provided the circuit model closely represents the distribution feeder. 


\section{Table of Contents}

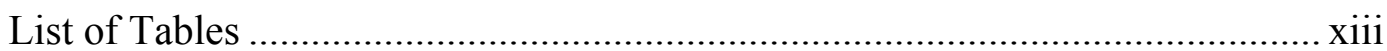

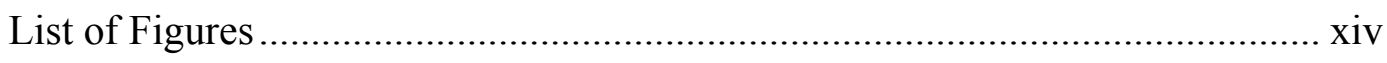

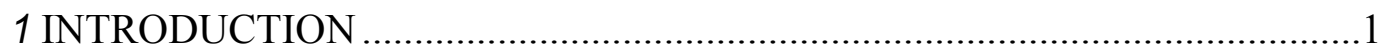

1.1 Background and Motivation .....................................................................

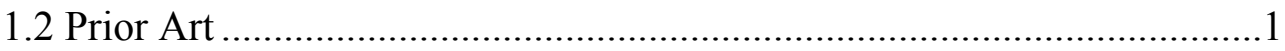

1.2.1 Impedance-based Approach ..........................................................

1.2.2 Short-circuit Fault Current Profile Approach …………...................3

1.3 Objective and Approach .......................................................................

1.4 Results of complementing Estimates from Impedance-based Methods using Short-circuit Fault Current Profile Approach ........................................6

1.5 Original Contribution ...........................................................................

1.6 Organization of the Thesis ...................................................................

2 REVIEW OF IMPEDANCE-BASED METHODS AND MODELING OF THE IEEE 34 NODE TEST FEEDER …………......................................10

2.1 Commonly used Impedance-based methods for Fault Location...............11

2.1.1 Positive-sequence Reactance Method...........................................12

2.1.2 Takagi Method ..........................................................................13

2.2 IEEE 34 Node Test Feeder ..............................................................14

2.2.1 Description of the IEEE 34 Node Test Feeder............................15

2.2.2 Time-domain modeling of IEEE 34 Node Test Feeder in PSCAD15

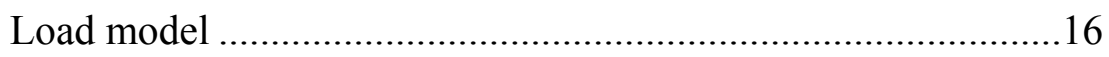

Shunt capacitor bank ............................................................... 17

Voltage regulators .....................................................................17

Transformers .........................................................................17

Overhead spacing model.............................................................18

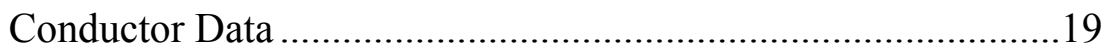

Overhead line impedance...........................................................19

Overhead shunt conductance ......................................................... 
2.2.3 Validation of the IEEE 34 Node Test Feeder 21

2.2.4 Modification of the IEEE 34 Node Test Feeder .......................22

2.2.5 Modeling of the IEEE 34 Node Test Feeder in OpenDSS.........23

Summary..... .23

3 SHORT-CIRCUIT FAULT CURRENT PROFILE APPROACH 24

3.1 Short-circuit fault current profile approach .....................................25

3.1.1 Strategy used in building the current profile...........................26

3.1.2 Graphical Interpretation of Fault Location using current profile28

3.1.3 Complementing Estimates from the Short-circuit Fault Current Profile Approach with Impedance-based Methods.....................29

Summary 29

4 APPLICATION OF SHORT-CIRCUIT FAULT CURRENT PROFILE APPROACH AND IMPEDANCE-BASED METHODS ON THE MODIFIED IEEE 34 NODE TEST FEEDER 31

4.1 Fault Location on the Modified IEEE 34 Node Test Feeder ..................32

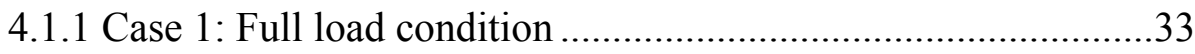

Impedance-based methods ....................................................33

Short-circuit fault current profile approach ..............................36

Complementing Estimates from Impedance-based Methods using Short-circuit Fault Current Profile Approach ....................42

4.1.2 Case 2: Zero Load .................................................................44

Impedance-based method....................................................44

Short-circuit Fault Current Profile Approach ...........................46

Complementing Estimates from Impedance-based Methods using Short-circuit Fault Current Profile Approach ...................49

Summary ..... .51

5 APPLICATION OF THE SHORT-CIRCUIT FAULT CURRENT PROFILE APPROACH AND IMPEDANCE-BASED METHODS ON FIELD DATA53

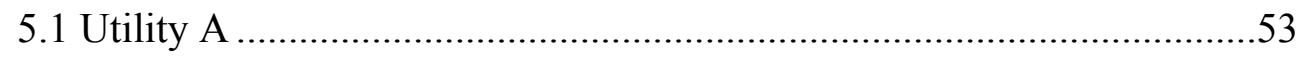

5.1.1 Estimation using Impedance-based Methods...........................57

5.1.2 Estimation using Short-circuit Fault Current Profile Approach .59 
5.1.3 Complementing Estimates from Impedance-based Methods using Short-circuit Fault Current Profile Approach ..............................61

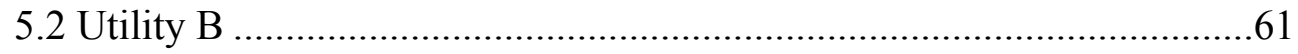

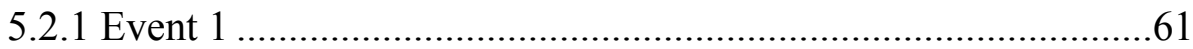

Short-circuit Fault Current Profile Approach ................................64

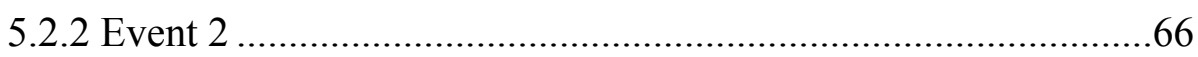

Short-circuit Fault Current Profile Approach ………………........68

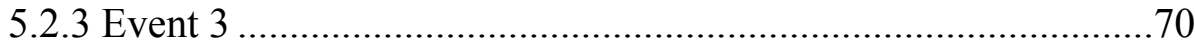

Short-circuit Fault Current Profile Approach ……………….......72

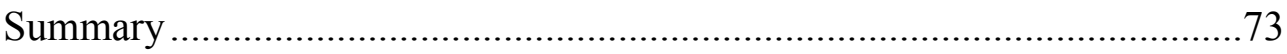

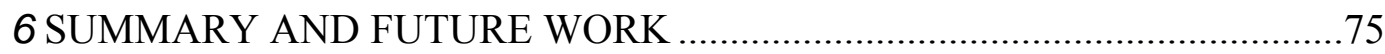

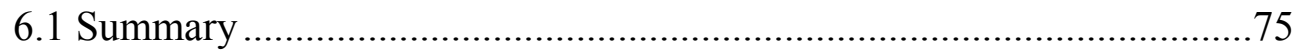

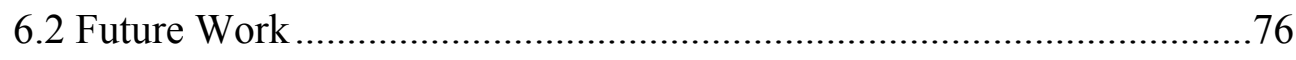

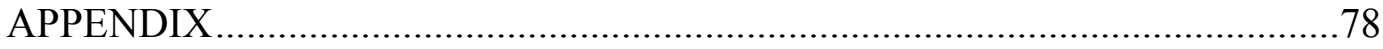

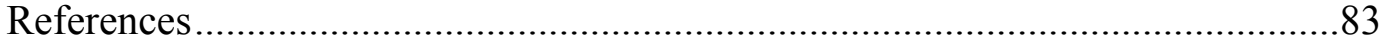

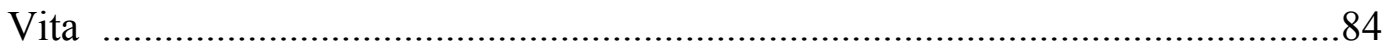




\section{List of Tables}

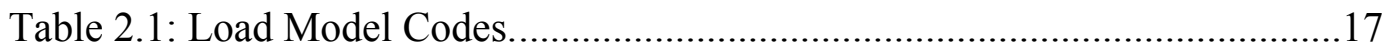

Table 2.2: Overhead Line Spacing............................................................. 18

Table 2.3: Conductor Data.............................................................................19

Table 4.1: Sequence Impedances of Five Different Line Configuration...............34

Table 4.2: Comparison of Actual versus the Estimated Positive-sequence Reactance to Fault using Impedance-based Methods.......................................36

Table 4.3: Comparison of Actual versus Estimated Positive-sequence Reactance to Fault using Short-circuit Fault Current Profile Approach.

Table 4.4: Computing Median of all Estimates. ................................................43

Table 4.5: Median Estimate is Close to the Actual Fault Location. .....................44

Table 4.6: Comparison of Actual versus the Estimated Positive-sequence Reactance to fault using Impedance-based Methods. ....................................45

Table 4.7: Estimated and Actual Reactance to Fault under Zero Load. ................47

Table 4.8: Computing Median of all Estimates. ...........................................50

Table 4.9: Error Percentage of the Median Estimate is Close to the Actual Fault

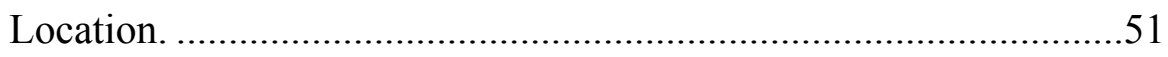

Table 5.1: Line Configuration Types in Utility A Circuit. .................................58

Table A.1: Line Segment Data of the Modified IEEE 34 Node Test Feeder. .......78

Table A.2: Spot Loads of the Modified IEEE 34 Node Test Feeder....................80

Table A.3: Distributed Loads of the Modified IEEE 34 Node Test Feeder. .........81 


\section{List of Figures}

Figure 2.1: One-line Diagram of a Typical Electrical System under Fault. ..........12

Figure 2.2: One-line Diagram of the IEEE 34 Node Test Feeder.........................15

Figure 2.3: Overhead Line Spacing in Feet. ...................................................18

Figure 3.1: IEEE 34 Node Test Feeder with Fault Current Profile along Every Branch and Lateral. .27

Figure 3.2: Graphically Interpreting Fault Location using Short-circuit Fault Current

Profile .28

Figure 3.3: Possible Fault Locations for Fault at Bus 854. .29

Figure 4.1: Fault Locations on the Test Feeder. 33

Figure 4.2: Possible Fault Location Estimates from Impedance-based Methods for a Fault at Bus 818. .35

Figure 4.3: Possible Fault Locations for a Fault at Bus 854, using Takagi Method.35

Figure 4.4: Paths for Short-circuit Fault Current Profile. .37

Figure 4.5: Fault Current Profile of Fault Current versus Positive-sequence Reactance to Fault under Peak Load Condition.

Figure 4.6: Illustrating Fault Location for a Fault Current of 2.38 kA..................39

Figure 4.7: Fault Current Exceeding Short-circuit Fault Current Profile Limit. ...40

Figure 4.8: Short-circuit Fault Current Profile Linearly Extended. .40

Figure 4.9: Illustration of the Error in Estimating Positive-sequence Reactance to Fault using Short-circuit Fault Current Profile. .42

Figure 4.10: Zero Load Fault Current Profile of Fault Current versus Positivesequence Reactance to Fault. 
Figure 4.11: Current Profile Extended for Fault Currents in Real World Exceeding Plot Limits 48

Figure 4.12: Comparison of Estimated versus Actual Positive-sequence Reactance to Fault under Zero Load. 49

Figure 5.1: Utility A Circuit in OpenDSS. 54

Figure 5.2: Voltage and Current Waveforms Recorded by the Relay During Fault.55 Figure 5.3: Fault Event Log of the Relay .55

Figure 5.4: The Faulted Lightning Arrestor. .56

Figure 5.5: Fault Location on the Distribution Feeder. ....................................57

Figure 5.6: Paths for Building the Fault Current Profile. ...................................60

Figure 5.7: Utility A Short-circuit Fault Current Profile.....................................60

Figure 5.8: Utility B Circuit Model in OpenDSS ..............................................62

Figure 5.9: Relay Records only Fault Current Waveforms. Voltage Waveforms are

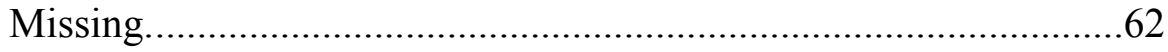

Figure 5.10: Relay Fault Log......................................................................63

Figure 5.11: Location of the Fault for Event 1...............................................63

Figure 5.12: Paths for Short-circuit Fault Current Profile..................................65

Figure 5.13: Short-circuit Fault Current Profile. ................................................66

Figure 5.14: Utility B Circuit Model in OpenDSS Indicating Fault Location. .....67

Figure 5.15: Relay Fault Log for Event 2 ..................................................67

Figure 5.16: SEL Relay records only Current Waveform. Voltage Waveform are

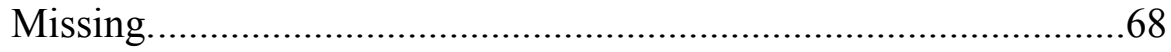

Figure 5.17: Fault Current magnitude of 1014 A does not Intersect the Current Profile .69

Figure 5.18: Short-circuit Fault Current Profile with Extrapolation..... .70 
Figure 5.19: Fault Location on the Circuit Model of the Distribution Feeder.......71

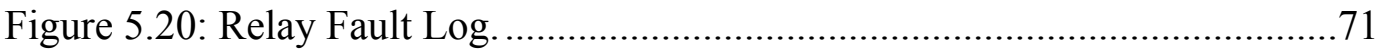

Figure 5.21: Relay Recording only Current Waveform. Voltage Waveform is

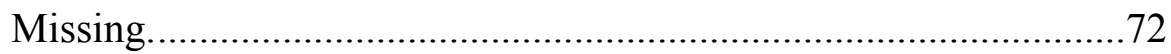

Figure 5.22: Illustrating Fault Location using the Current Profile. .......................73

Figure 6.1: Stand-alone fault location module components. ..............................77 


\section{$1_{\text {mrsomencrox }}$}

\subsection{BACKGROUND AND MotivATION}

Utility distribution systems are one of the key components in the generation and supply of electricity to the end-users. When a fault occurs in the distribution circuit, two of the most common power quality problems faced by customers are voltage sags and momentary interruptions due to operation of line protective devices [1]. Hence the utilities attempt to clear the fault as soon as possible to reduce outage time and thus increase the system reliability. Location of faults in a distribution system can be difficult to track down due to the topology of the feeder, presence of multiple branches and a large number of power apparatus in the feeder to mention just a few.

The work documented in this thesis attempts to improve fault location estimates when a single line-to-ground fault occurs in a distribution system and thus speed up the restoration process.

\subsection{PRIOR ART}

The common fault location practices used to determine fault locations in a distribution system are numerical methods, hardware based methods, customer calls, and line inspection [2]. Line inspection is labor intensive and time consuming. Hence numerical or hardware based methods are generally preferred by utilities, from which an estimate to the fault can be obtained.

Numerical based methods explicitly use voltage and current recorded by a relay or a power quality monitor at the monitoring station. An algorithm uses these voltage and current values to estimate the distance to fault. Hardware or microprocessor based devices such as fault indicators are effective in detecting faults in distribution systems 
[3]. With the advanced microprocessor technology, it not only detects fault currents, but also differentiates between a permanent and a temporary fault and alerts the system operator. Restoration time is expedited and temporary faults can be prevented from becoming an outage.

The goal of the current state of the art in fault location is to develop a commercial-grade fault-locating tool implemented in EPRI's PQView platform, which integrates both numerical and hardware based approaches [4], [5]. In this framework, fault location algorithms and system circuit models are integrated with the monitoring database. Fault events are distinguished from non-fault events and voltage and current data are used to provide a location estimate to the system operator.

The emphasis of this thesis is on fault location using numerical approaches. These approaches can be broadly classified into two types:

\subsubsection{Impedance-based Approach}

Impedance-based methods are popular among the utilities because they are straightforward to implement. They require the availability of voltage and current data captured when the fault is on the circuit. The fault data can be in the form of waveforms (time-series) or phasors (magnitude and phase angle quantities) recorded by a power quality monitor (PQM) or digital relay upstream from the fault location [4], [5], [6].

In addition to voltage and current data, impedance-based methods require knowledge of positive- and zero-sequence impedances of the distribution lines, i.e. $z_{1}$ (in $\Omega /$ mile) and $z_{0}$ given in $\Omega /$ mile. A distribution feeder is typically non-homogenous. Impedance-based methods assume that the system is homogenous and take the $z_{0}$ and $z_{1}$ values of the most commonly used line configuration [1], [3], [5]. 
Load plays an important role in fault location estimation. Impedance-based methods assume that the load is lumped beyond the fault point [7]. However, in a typical distribution system, loads may lie between the fault point and the monitoring location and hence this assumption does not hold true.

Another short-coming of the impedance-based methods is that they simply estimate the distance to the fault. No information regarding which branch or lateral the fault may be located in is available. Hence, given these requirements and assumptions, the accuracy of impedance-based methods are affected.

\subsubsection{Short-circuit Fault Current Profile Approach}

The short-circuit fault current profile approach requires the availability of prefault current and current magnitude measured during the occurrence of a fault. Utility may have the circuit model of the distribution feeder in CYMDIST, OpenDSS, ASPEN, FeederAll, DEW or any other distribution software. The circuit model is used to build a reference current profile of short-circuit fault current versus reactance or distance to the fault. When a fault occurs in the distribution feeder, fault current recorded by the relay in the real world is extrapolated on the current profile to get a location estimate [4], [8].

This approach is very simple to implement and attempts to move away from the impedance-based methods since they do not use line impedance values directly in its estimation. Unfortunately impedances are still present in the circuit model. However it does not make any system homogeneity assumption and hence avoids errors in estimation introduced because of this assumption. The circuit model of the distribution feeder is used directly in building the current profile and hence the load is also taken into account. As a result, this approach on short-circuit fault current profile approach appears to be promising. This is consistent with the results reported in [8]. 


\subsection{OBJECTIVE AND APPROACH}

The work presented in this thesis aims to improve fault location estimates when a single line-to-ground fault occurs in a utility distribution system, using data recorded by devices capable of making current and/or voltage measurements. To meet this objective, this work focuses on the short-circuit fault current profile approach. As seen from the previous Section, the short-circuit fault current profile approach minimizes the errors associated with impedance-based methods and appears to be promising for obtaining accurate estimates. Similar to the fault current profile approach, a voltage profile can also be built using fault voltage recorded by the relay and circuit model of the distribution feeder [4]. Estimates from both short-circuit fault current and voltage profiles can give a more accurate fault location. However this thesis focuses on fault location using only the current magnitude since voltage data during fault may be missing or unavailable.

The application of short-circuit fault current profile approach on a distribution feeder is challenging due to the complex topology of the feeder and has not been demonstrated in literature. This thesis aims to carry out an in-depth analysis of the shortcircuit fault current profile approach and discuss the strategy to be used when applying this approach on a complex distribution feeder. The goal is to improve fault location estimates, complement estimates from impedance-based methods as well as to identify the branch in which the fault may be located for a radial distribution feeder. The scope of the thesis is strictly for single line-to-ground faults since this type of fault is more common in a typical distribution system.

For the purpose of improving fault location estimates using estimates from both impedance-based methods and short-circuit fault current profile approach together, the following efforts were taken: 
- $\quad$ Review and implementation of impedance-based methods for estimating fault location using both voltage and current waveforms recorded by the relay. The faults were simulated using time-domain simulation model of the IEEE 34 Node Test Feeder as well as field events. The accuracy of the estimates was compared with actual fault location and the sources of estimation error were identified.

- Development of the short-circuit fault current profile for the IEEE 34 Node Test Feeder and utility distribution feeder case studies. A typical distribution feeder has many branches and laterals radiating out from the substation. In this thesis, it is strategized to develop the profile along every lateral and branch from the monitoring location. Hence, a typical current profile would consist of multiple sub-plots. To take into account the load current before fault, the current profile is built under different load conditions.

- Application of the short-circuit fault current profile approach to locate faults simulated in the time-domain model of the IEEE 34 Node Test Feeder as well as the field events. Prefault current magnitude recorded by the relay before the occurrence of the fault is used to choose the appropriate current profile. Fault current magnitude is interpolated on the profile to get location estimates. More than one estimate may be obtained. In such situations, the estimate which matches closely with that estimated by impedance-based methods is chosen. From the short-circuit fault current profile approach, the path on which the fault is located is identified. In certain cases, if the circuit model is not an accurate representation of the test feeder, fault current recorded by the relay exceeds the current profile plot limits. For getting an approximate estimate, the current profile is extended linearly till an intersection is obtained. 
- Fault location estimates are improved using estimates from both impedance-based methods and short-circuit fault current profile approach. Median value of the estimates from both approaches is computed. From the analysis conducted on the IEEE 34 Node Test Feeder, which is representative of a typical distribution feeder in the real world, it is seen that a 0.6 mile radius built around the median estimate contains the fault location. More than likely the fault is located in one of the equipment's. Hence, the utility should check the equipment lying in that range.

\subsection{RESUlTS OF COMPLEMENTING ESTIMATES FROM IMPEDANCE-BASED METHODS USing SHORT-Circuit FAult CuRRENT Profile APPRoACH}

The approach was developed using the modified IEEE 34 Node Test Feeder and validated against four field data events. For the IEEE 34 Node Test Feeder, the analysis was done under two different load conditions on the feeder, i.e. full and zero load conditions. It was observed that Takagi and positive-sequence methods gave accurate estimates when the fault was close to the relay location. The error increases with distance from the relay location. Estimation error when using Takagi method was within 0.58 miles from the fault location while positive-sequence method gave estimation error within 0.73 miles from the actual fault location. It was also observed that for a fault on the same bus, estimation error is higher when the feeder is under fully load condition. Also, any information pertaining to the branch in which the fault may be located in was not available.

The short-circuit fault current profile gave accurate estimates when the fault was close to the relay location. At the farthest laterals, the fault current recorded by the relay exceeded the current profile plot limits. When the profile was extended, an approximate positive-sequence reactance estimate was obtained. This reactance estimate however exceeded the total positive-sequence reactance of the feeder. In such situations, the 
farthest lateral is reported as the fault location. Error in estimation is within 1.9 miles. Such high estimation error is due to the fact that the circuit model of the test feeder in OpenDSS is not an accurate representation of the actual distribution test feeder, represented by PSCAD. Next, using estimates from impedance-based methods and shortcircuit fault current profile approach, the median value is computed. This estimate is close to the actual location of the fault. A 0.6 mile radius built around the median estimate is observed to contain the fault location. The path or the branch in which the fault may be located in is also identified. Now the IEEE 34 Node Test Feeder represents a typical distribution feeder and has also been modeled to represent the worst case scenario, i.e. load current is around $51 \%$ of the fault current for the farthest bus. Hence the 0.6 mile radius around the median estimate will hold true for most distribution feeders.

Next, the practicality of the approach was validated against four field events. For the first event, impedance-based method and the short-circuit fault current profile approach was used together to obtain a median estimate of 4.75 miles. It was predicted that the fault would be located in a rage of $4.75 \pm 0.6$ miles from the substation on path 1 . The actual fault was located 5.33 miles from the substation on path 1 . Hence using this approach, the location of the fault could be accurately estimated. For the next three events, the relay did not record the voltage waveforms. Hence, only short-circuit fault current profile approach can be used to estimate fault location. It was observed that for the second event, the current profile approach accurately estimates the fault location with an error of 0.1 mile. For the next two events however, the accuracy is affected since the distribution feeder is not correctly modeled in the circuit model. In fact the fault current recorded by the relay is less than the minimum short-circuit fault current of the circuit model. The approach should not be applied under such situations. 


\subsection{ORIginal CONTRIBUtion}

In this thesis, the shortcomings of impedance-based methods have been identified and illustrated with utility data. For minimizing the errors associated with impedancebased methods, an improved short-circuit fault current profile approach is developed and its application on a complex distribution feeder is demonstrated. It is proposed that estimates from the short-circuit fault current profile should be used to complement estimates from impedance-based methods. The approach is developed using IEEE 34 Node Test Feeder and validated against field event data.

The results and findings of the work developed in this report has been submitted and accepted for publication in the proceedings of the 2011 IEEE PES General Meeting [9].

\subsection{ORgAniZATION OF THE THESIS}

The work in the next few chapters is organized as follows:

In Chapter 2, the commonly used impedance-based methods like Takagi and positive-sequence reactance method are reviewed. The discussion of the methods is followed by their respective drawbacks and/or assumptions which contribute to loss of accuracy in estimating fault location. This chapter also discusses the significance of the IEEE 34 Node Test Feeder as an ideal test circuit and the modeling of the test feeder in PSCAD and OpenDSS.

Chapter 3 discusses the short-circuit fault current profile approach and its application on a complex distribution feeder. It also provides the guidelines for improving fault location estimates by using both impedance-based methods and shortcircuit fault current profile approach together.

In Chapter 4, the strategy developed in Chapter 3 is applied on the IEEE 34 Node Test Feeder. Single line-to-ground faults are simulated in the PSCAD model of the test 
feeder. Both impedance-based methods and the short-circuit fault current profile approach is used to estimate fault location under different load conditions of the test feeder (full load and zero load condition). Next, estimates from both methods are used to compute the median. This median estimate is found to be close to the actual fault location. A 0.5 to 0.6 mile radius is built around the median estimate and the fault is seen to lie within this range.

In Chapter 5, the strategy developed in Chapter 3 is validated against four field data provided by the utilities. Four events on two utility circuits are analyzed and the actual fault location is compared with the estimated location.

Chapter 6 discusses the summary and future work. 


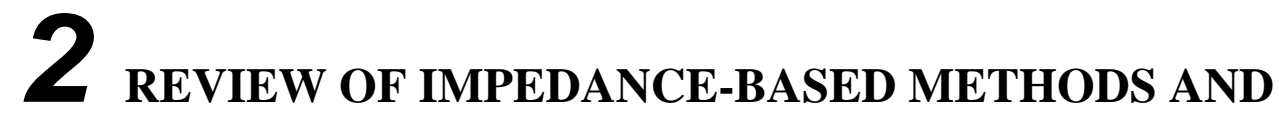 MODELING OF THE IEEE 34 NODE TEST FEEDER}

Impedance-based methods like Takagi and positive-sequence method are widely used to locate faults in a distribution system. These methods require voltage and current recorded by the relay at the monitoring location to estimate the distance or reactance to fault [2], [4], [5], [6]. Unfortunately, these methods do not use accurate models to represent the three-phase and the single-phase loads when deriving the expression for distance or reactance to fault. They assume that the load is lumped beyond the fault point [7]. However, when a fault occurs on the distribution feeder, loads may be present between the relay and the fault point. Hence, the lumped load assumption does not hold true and affects the accuracy of the location estimates.

Impedance-based methods also require line impedance per unit length when computing fault location. Utility systems are generally heterogeneous, i.e., pole configurations and line or wire sizes are not uniform. In such cases, impedance-based methods assume that the system is homogenous and use the line parameters of the most frequently occurring line configuration. This assumption of homogeneity introduces error in the estimation [2], [4].

Estimates from impedance-based methods do not clearly identify the branch or lateral in which the fault may be located. For example, consider a distribution feeder with multiple three-phase branches and laterals. Impedance-based methods estimate the distance to fault to be one mile. The fault may be located one mile from the relay location on any one of the laterals or branches. The utility has to rely on customer outage data or recloser operation to isolate the faulted branch or lateral. In this Chapter, a brief description of the most popular impedance-based methods is provided and the factors 
which directly affect the accuracy of estimation are identified. In effect, this Chapter lays down the foundation for the subsequent proposal of using short-circuit fault current profile approach along with impedance-based methods to improve fault location estimates and thus speed up the fault restoration process.

For conducting fault location study using short-circuit fault current profile approach and analyzing how estimates from this approach will complement estimates from impedance-based methods, a realistic test circuit is required on which comprehensive tests may be conducted. In this analysis, the circuit topology of the IEEE 34 Node Test Feeder has been adopted. This test feeder is an actual test feeder located in Arizona. It has multiple single-phase and three-phase laterals and a variety of components which make it an ideal system for fault location [10]. The test feeder however has low fault current and load current, which would not be useful for fault location analysis. Hence some modifications were necessary to increase the fault current and load current. In this Chapter, a brief description of the test feeder is followed by time domain modeling of the modified test feeder in PSCAD. The Chapter concludes with modeling of the modified test feeder in OpenDSS which would be used for the shortcircuit fault current profile approach in Chapter 4.

\subsection{COMMONLY USED IMPEDANCE-BASED METHODS FOR FAULT LOCATION}

Impedance-based methods require voltage and current phasors recorded by the relay during the fault. They also require positive- and zero-sequence line impedance per unit length ( $z_{1}$ and $z_{0}$ in $\Omega /$ mile) and prefault load current. Figure 2.1 illustrates the oneline diagram of a typical electrical system under faulted conditions. Impedance-based

methods will be used to determine the distance to fault $(d)$. A brief review of the commonly used impedance-based methods is given below: 


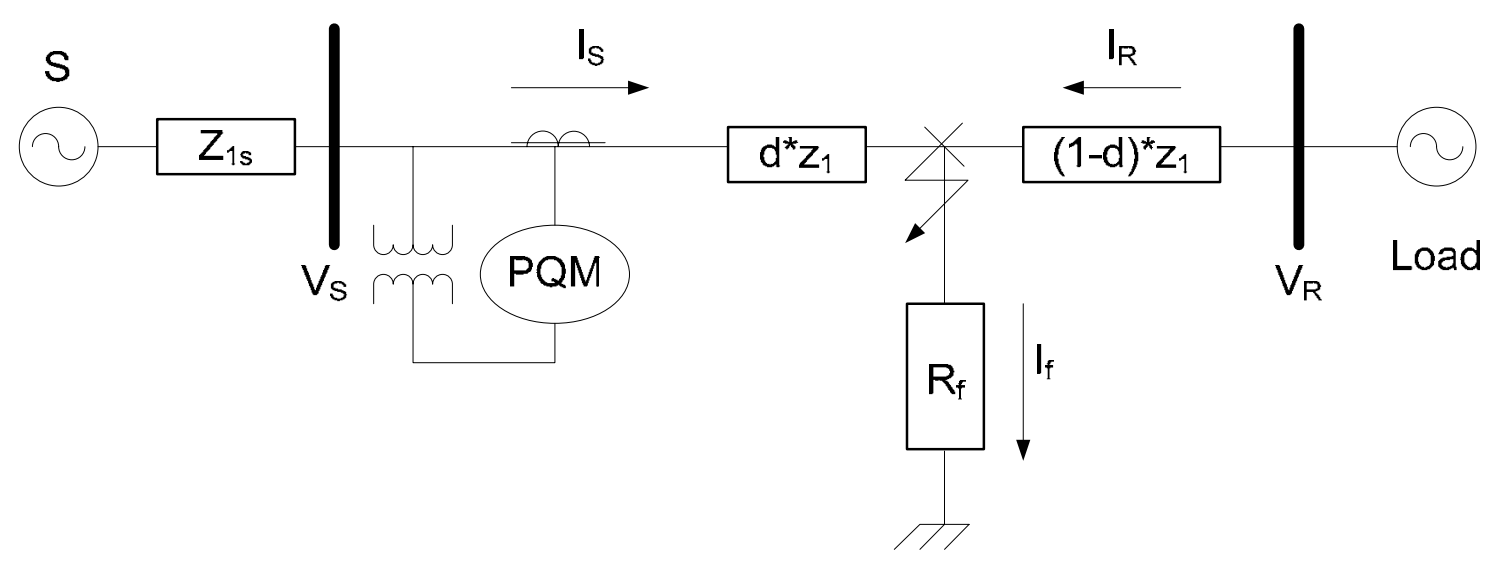

Figure 2.1: One-line Diagram of a Typical Electrical System under Fault.

\subsubsection{Positive-sequence Reactance Method}

The positive-sequence reactance method computes the positive-sequence reactance to fault and is given as follows [4], [6]:

$$
x_{1}=\operatorname{imag}\left(\frac{V_{S}}{I_{S}}\right)
$$

The current $I_{s}$ is given as,

$$
I_{S}=I+k I_{0}
$$

The factor $k$ is defined as,

$$
k=\frac{z_{0}-z_{1}}{z_{1}}
$$

The notations used are,

$V \quad=$ Fault voltage at the monitoring location, volts

$I=$ Faulted phase current recorded at the monitoring location, amperes

$I_{0} \quad=$ Zero-sequence fault current at the monitoring location, amperes

$\mathrm{Z}_{1} \quad=$ Positive-sequence line reactance, ohms $/ \mathrm{mile}$

$z_{0} \quad=$ Zero-sequence line reactance, $\mathrm{ohms} / \mathrm{mile}$

$x_{1}=$ Positive-sequence line reactance, ohms

In terms of distance to fault, Equation 2.1 can be written as, 


$$
d=\frac{\operatorname{imag}\left(\frac{V_{S}}{I_{S}}\right)}{x_{1}}
$$

Some of the drawbacks of this method are:

- $\quad$ This method assumes that the system load is lumped beyond the fault and models the load as a constant current load.

- It also assumes that $I_{s}$ and $I_{f}$ are in phase with each other, i.e. fault resistance is zero. For non-zero fault resistance however, phase difference between $I_{s}$ and $I_{f}$ will cause estimation errors.

- Uncertainty of line impedance parameters, especially the zero-sequence line impedance which is difficult to measure and may change with soil resistivity [2].

\subsubsection{Takagi Method}

Takagi method requires prefault current phasor. It improves upon the positivesequence reactance method by further minimizing effect of fault resistance and load current. It uses a superposition current $\left(I_{\text {sup }}\right)$ which is in phase with the fault current $I_{f}$ and is given as [4], [6], [11]:

$$
I_{\text {sup }}=I_{s}-I_{\text {pre }}
$$

Here, $I_{\text {pre }}$ is the prefault current in amperes. Using this superposition current, Takagi method computes the distance to fault $(d)$ as,

$$
I_{\text {sup }}=\frac{\operatorname{imag}\left(V_{s} \times I_{\text {sup }}^{*}\right)}{\operatorname{imag}\left(z_{1} \times I_{s} \times I_{\text {sup }}^{*}\right)}
$$

where * denotes the complex conjugate.

Some of the drawbacks of Takagi method are: 
- Takagi method assumes that the phase angle of $I_{s}$ is the same as $I_{f}$. This is true only for an ideal homogenous system. As the angle between $I_{s}$ and $I_{f}$ increase, error in fault location estimation increases.

- It assumes that the load is lumped beyond the fault point and models it as a constant current load model which may not be true for a distribution system.

- It uses actual line current rather than the residual current $\left(I_{A}+I_{B}+I_{C}\right)$ for line-toground faults. Using the residual current allows easier and more accurate load current reduction.

- Uncertainty in line impedance parameters. The zero-sequence line impedance depends on soil resistivity and hence is extremely difficult to measure accurately.

- Applying the Takagi method for a non-homogenous system or system with changing line configuration is extremely difficult. In such a situation, it is assumed that the system is homogenous and the line impedance parameters of the most frequently occurring line configuration are used.

\subsection{IEEE 34 NODE TEST FEEDER}

The IEEE's Distribution System Analysis Subcommittee has published data for four different radial distribution test feeders. Although these feeders cannot be considered typical, these feeders represent real world systems located at four locations of the North American Grid. To validate these test feeders, complete data set about the power flow and short-circuit current information are readily available, making them a useful benchmark [10].

For the analysis on fault location using short-circuit fault current profile approach in combination with impedance-based methods, the circuit topology of the IEEE 34 Node Test Feeder has been adopted. This test feeder is an actual test feeder in Arizona. Though 
not the largest amongst the other test feeders, this test feeder has a wide variety of components which make it an ideal system for fault location analysis.

\subsubsection{Description of the IEEE 34 Node Test Feeder}

Figure 2.2 shows the one-line diagram of the test feeder. The characteristics of this test feeder are as follows [10]:

- $\quad$ Nominal voltage of the test feeder is $24.9 \mathrm{kV}$

- $\quad$ Multiple single and three-phase laterals

- $\quad$ Long and lightly loaded

- Two in-line voltage regulators to regulate the voltage

- Unbalanced loading with "spot" and "distributed" load

- Shunt capacitors to improve the power factor

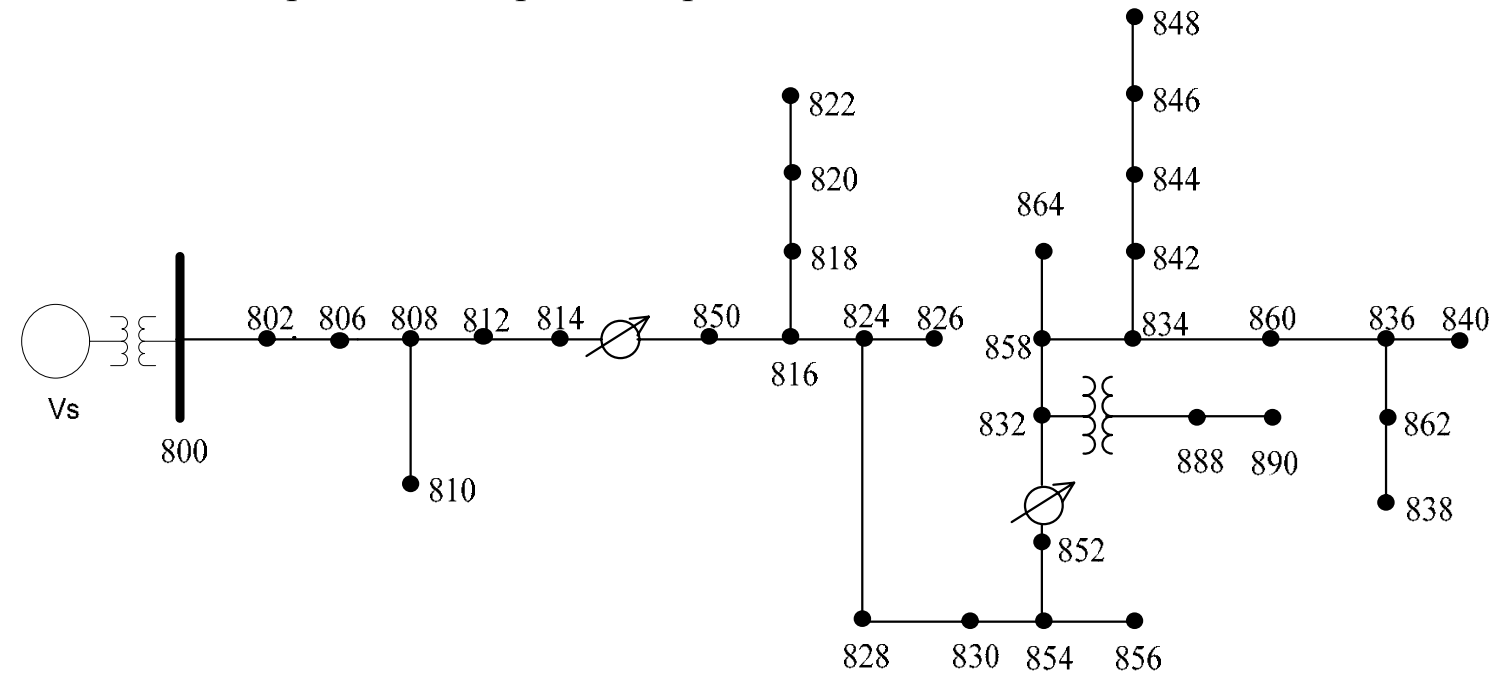

Figure 2.2: One-line Diagram of the IEEE 34 Node Test Feeder.

\subsubsection{Time-domain modeling of IEEE 34 Node Test Feeder in PSCAD}

The IEEE 34 Node Test Feeder is modeled in time domain using PSCAD simulation software. Modeling in time domain is used to generate voltage and current waveform similar to the waveforms captured by the power quality monitor or relay in the 
real world. In other words, it replicates actual faults occurring in the distribution feeder. The waveforms recorded by the relay in the model can be sampled to obtain the phasor quantities. Modeling in time-domain also allows for the simulation of both permanent and temporary faults. Modeling in steady state only allows simulation of permanent faults.

PSCAD simulation software is used for building the time-domain model since it is a fast, reliable, easy-to-use power system simulation software. It has a comprehensive library of components, interactive control inputs, meters and online plotting functions and has been widely adopted by utilities as a premier tool for transient simulation [12]. A brief description of the components present in the feeder are described below:

\section{Load model}

Spot loads are connected at a node. Distributed loads are modeled when load is uniformly distributed along the length of the feeder and is hence connected at the middle of the line segment. The loads are three-phase, two-phase or single-phase and connected in star or delta. The loads are modeled as constant complex power (PQ), constant current (I) and constant impedance (Z). Table 2.1 lists the codes used to describe the various loads.

Line-to-line connected single-phase loads have been given delta connection code, irrespective of whether the feeder is three-wire delta or four-wire system connected in wye. All the load data is specified in $\mathrm{kW}$ or in $\mathrm{kVAr}$. In case of constant current and constant impedance loads, $\mathrm{kW}$ and $\mathrm{kVAr}$ is converted by assuming rated voltage (1 pu). 
Table 2.1: Load Model Codes.

\begin{tabular}{|c|c|c|}
\hline Code & Connection & Model \\
\hline Y-PQ & Wye & Constant kW and kVar \\
\hline Y-I & Wye & Constant Current \\
\hline Y-Z & Wye & Constant Impedance \\
\hline D-PQ & Delta & Constant kW and kVar \\
\hline D-I & Delta & Constant Current \\
\hline D-Z & Delta & Constant Impedance \\
\hline
\end{tabular}

\section{Shunt capacitor bank}

Two three-phase capacitor banks are connected in star. They have been modeled as constant susceptance.

\section{Voltage regulators}

Two three-phase voltage regulators are connected to a specific line segment. Tap positions are determined by the following compensator circuit settings:

- $\quad$ Desired voltage level

- $\quad$ Bandwidth, assumed to be $2 \mathrm{~V}$

- $\quad$ Compensator resistance and reactance settings

- Turns ratio of the potential transformer feeding the compensator circuit

- Current rating of the primary of the transformer feeding the compensator circuit

\section{Transformers}

A three-phase step down transformer, connected in star-delta, is used to step down the voltage from $24.9 \mathrm{kV}$ to $4.16 \mathrm{kV}$ for a small section of the feeder. 


\section{Overhead spacing model}

Table 2.2 summarizes the spacing ID numbers and type for overhead lines in this model.

Table 2.2: Overhead Line Spacing.

\begin{tabular}{|c|c|}
\hline Spacing ID & Type \\
\hline 500 & Three-phase, 4 wire \\
\hline 510 & Single-Phase, 2 wire \\
\hline
\end{tabular}

For each spacing ID, Figure 2.3 shows the spacing distances between the phase and the neutral conductors.

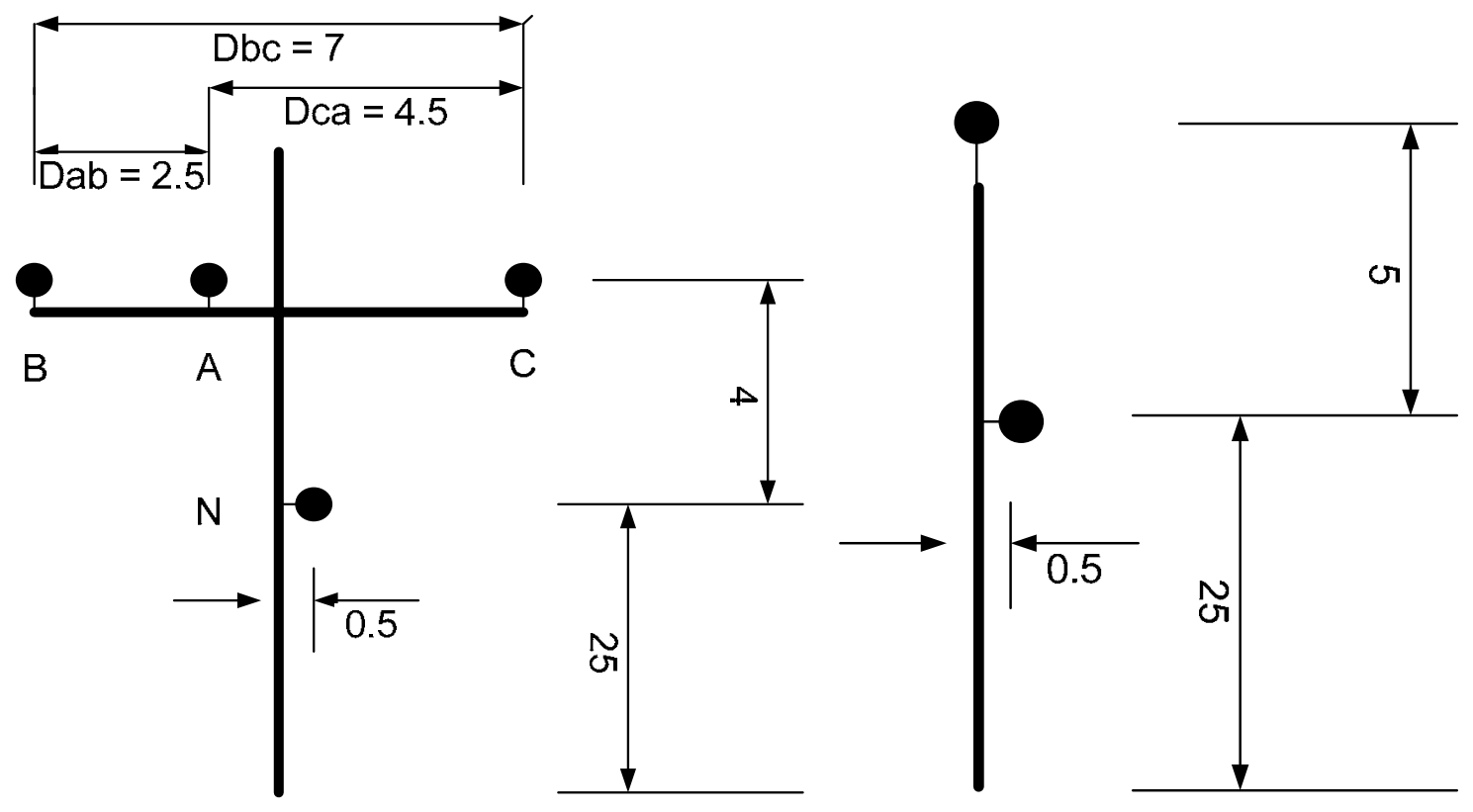

Figure 2.3: Overhead Line Spacing in Feet. 


\section{Conductor Data}

The conductor material used for phase and neutral are Aluminium Conductor Steel Reinforced (ACSR). Table 2.3 lists the characteristics of the different sizes of the same conductor.

Table 2.3: Conductor Data.

\begin{tabular}{|c|c|c|c|c|c|}
\hline Size & Stranding & Material & $\begin{array}{c}\text { Diameter } \\
\text { (inches) }\end{array}$ & $\begin{array}{c}\text { Geometric Mean } \\
\text { Radius (feet) }\end{array}$ & $\begin{array}{c}\text { RES } \\
(\Omega / m i l e)\end{array}$ \\
\hline $1 / 0$ & & ACSR & 0.398 & 0.00446 & 1.12 \\
\hline 2 & $6 / 1$ & ACSR & 0.316 & 0.00418 & 1.69 \\
\hline 4 & $6 / 1$ & ACSR & 0.25 & 0.00437 & 2.57 \\
\hline
\end{tabular}

\section{Overhead line impedance}

To compute the sequence line impedances, the concept of geometric mean distance (GMD) has been used. The geometric mean distance between phases is defined as [13]:

$$
\begin{aligned}
& D_{i j}=\sqrt[3]{D_{a b} \times D_{b c} \times D_{c a}} f t \\
& D_{i n}=\sqrt[3]{D_{a n} \times D_{b n} \times D_{c n}} f t
\end{aligned}
$$

From Equation (2.7) and (2.8), the various self and mutual line impedances can be determined as:

$$
\begin{aligned}
& z_{i i}=r_{i}+0.00158836 \times f+0.00202237 \times f \times\left(\ln \frac{1}{G M R_{i}}+7.6786+\frac{1}{2} \ln \frac{\rho}{f}\right) \Omega / m i \\
& z_{n n}=r_{n}+0.00158836 \times f+0.00202237 \times f \times\left(\ln \frac{1}{G M R_{n}}+7.6786+\frac{1}{2} \ln \frac{\rho}{f}\right) \Omega / m i \\
& z_{i j}=0.00158836 \times f+0.00202237 \times f \times\left(\ln \frac{1}{D_{i j}}+7.6786+\frac{1}{2} \ln \frac{\rho}{f}\right) \Omega / m i
\end{aligned}
$$




$$
\operatorname{zin}=0.00158836 \times f+0.00202237 \times f \times\left(\ln \frac{1}{D_{\text {in }}}+7.6786+\frac{1}{2} \ln \frac{\rho}{f}\right) \Omega / m i
$$

It is assumed that,

$$
\begin{array}{ll}
f & =\text { Frequency }=60 \mathrm{~Hz} \\
\rho & =\text { Earth resistivity }=100 \text { ohm-meter } \\
i, j & =\text { Phase conductors of the feeder } \\
n & =\text { Neutral Conductor } \\
G M R & =\text { Geometric mean radius of conductor }
\end{array}
$$

Equations (2.9) to (2.12) define a primitive impedance matrix of order $n$ cond $x$ ncond, where ncond is the number of conductors (phases and neutral) in the line segment. Application of Kron Reduction as given by Equation (2.13) results in the phase impedance matrix $Z_{a b c}[13]$,

$$
\left[Z_{a b c}\right]=\left[Z_{i j}\right]-\left[Z_{i n}\right] \times\left[Z_{n n}\right]^{-1} \times\left[Z_{n j}\right] \Omega / \text { mile }
$$

The phase impedance matrix $Z_{a b c}$ can be transformed into the sequence impedance matrix $Z_{012}$ with the help of Equation (2.14),

$$
\left[Z_{012}\right]=\left[A_{S}\right]^{-1} \times\left[Z_{a b c}\right] \times\left[A_{S}\right] \Omega / \text { mile }
$$

Here, the matrix $A_{s}$ is given by,

$$
\left[A_{S}\right]=\left[\begin{array}{ccc}
1 & 1 & 1 \\
1 & a^{2} & a \\
1 & a & a^{2}
\end{array}\right]
$$

where $a=1 \angle 120$.

\section{Overhead shunt conductance}

Method of conductors and their images is used to calculate the shunt capacitance of overhead lines. The self and mutual potential coefficients are defined as [13]

$$
P_{i i}=11.17689 \times \ln \frac{S_{i i}}{R D_{i}} \text { mile/ } \mu \mathrm{F}
$$




$$
P_{i j}=11.17689 \times \ln \frac{S_{i j}}{D_{i j}} \text { mile } / \mu \mathrm{F}
$$

where,

$S_{i i} \quad=$ Distance from conductor $i$ to its image $i$ ( $\left.\mathrm{ft}\right)$

$S_{i j} \quad=$ Distance of conductor $i$ to the image of conductor of conductor $j(\mathrm{ft})$

$D_{i j} \quad=$ Distance from conductor $i$ to conductor $j(\mathrm{ft})$

$R D_{i}=$ Radius of conductor $i(\mathrm{ft})$

$P_{i i} \quad=$ Self potential coefficient $($ mile $/ \mu \mathrm{F})$

$P_{i j} \quad=$ Mutual potential coefficient $($ mile $/ \mu \mathrm{F})$

For an overhead line of ncond conductors, the primitive potential coefficient matrix ( $\left.P_{\text {primitive }}\right)$ is constructed. Since the neutral is grounded, the matrix is reduced by Kron reduction, using Equation (2.18), to obtain phase potential co-efficient matrix $\left(P_{a b c}\right)[13]$,

$$
\left[P_{a b c}\right]=\left[P_{i j}\right]-\left[P_{i n}\right] \times\left[P_{n n}\right]^{-1} \times\left[P_{n j}\right]
$$

The inverse of $P_{a b c}$ will give the capacitance matrix $C_{a b c}$.

$$
\left[C_{a b c}\right]=\left[P_{a b c}\right]^{-1}
$$

Neglecting the shunt conductance, the phase shunt admittance matrix $y_{a b c}$ is given by Equation (2.20) as

$$
\left[y_{a b c}\right]=0+j \times \omega \times\left[C_{a b c}\right] \mu s / \text { mile }
$$

\subsubsection{Validation of the IEEE 34 Node Test Feeder}

The IEEE 34 node test feeder model was simulated in PSCAD and the voltage and power flow at every node was measured. The IEEE Power and Energy Society have archived the expected power flow solution at every node of the feeder. Hence, the measured power flow values were validated against the archived data. The power flow values were within $1 \%$ of the published data, indicating that the feeder has been modeled correctly and that the voltage regulator is performing as expected. 


\subsubsection{Modification of the IEEE 34 Node Test Feeder}

In the IEEE 34 Node Test Feeder, it was observed that the load current was low, around 40A (peak). Next, a single line-to-ground fault was placed at the farthest lateral and the fault current recorded by the relay at the substation was also very low, around 300A (peak).

Load current affects the accuracy of fault location estimates. Hence, such low levels of load current will not useful since location estimates will be hardly affected and no effective conclusions can be made. Also when the fault current at the farthest laterals is low, it is difficult to obtain accurate distance or reactance to the fault estimates for faults located at those remote locations. Hence to make the test circuit more useful for analysis, some modifications were implemented in the PSCAD model of the test feeder to increase load current and the fault current.

- $\quad$ At the substation, the ideal $24.9 \mathrm{kV}$ voltage source is replaced by a $115 \mathrm{kV}$ ideal voltage source stepped down to $24.9 \mathrm{kV}$ by a step-down transformer with a leakage reactance of $0.04 \mathrm{pu}$.

- $\quad$ Length of the main feeder (800-848) decreased from 35 miles to 9.54 miles.

- $\quad$ Length of the single-phase laterals is reduced to 1 to 3 miles as compared to 8 to 9 miles in the original model.

- $\quad$ Since the feeder length has been shortened, level of fault currents in the system has increased considerably. Fault currents range from $5 \mathrm{kA}$ (for faults closer to substation) to $970 \mathrm{~A}$ (for faults at maximum distance from substation).

- Loads present in the system are increased from $40 \mathrm{~A} /$ phase to $425 \mathrm{~A} /$ phase.

The dataset of the modified IEEE 34 Node Test Feeder has been included in the Appendix. 


\subsubsection{Modeling of the IEEE 34 Node Test Feeder in OpenDSS}

OpenDSS is a comprehensive simulation tool for electrical utility distribution systems. It supports all frequency domain analyses and has components like energy meter and monitor objects which can capture results accurately. The main advantage of OpenDSS is that it can be implemented both as a standalone EXE and as a COM object which can be driven by any application software like Matlab for analysis [14]. Hence in the short-circuit fault current profile approach, as seen in Chapter 4, OpenDSS has been used to model the modified IEEE 34 Node Test Feeder. This OpenDSS model would represent the circuit model available to the utilities and will be used to build the fault current profile.

\section{SUMMARY}

This Chapter describes two of the most popular impedance-based methods for fault location. These methods are easy to implement. However, as seen in this section, location estimates are subject to inaccuracy due to inadequate assumptions and inaccurate data applied to the fault locating algorithms [2]. In other words, this section paves the way for the development of the short-circuit fault profile approach developed in Chapter 3 and 4 . The short-circuit fault current profile approach minimizes most of the errors faced by impedance-based methods and when used along with impedance-based methods is expected to improve fault location estimates.

This Chapter also discusses the modeling of the IEEE 34 Node Test Feeder in PSCAD and OpenDSS simulation software. The test feeder has low levels of load current and fault current. Hence some modifications are necessary to the test feeder, to make it more useful for analysis. 


\section{SHORT-CIRCUIT FAULT CURRENT PROFILE APPROACH}

Chapter 2 reviews some of the drawbacks of impedance-based methods which introduce error in fault location estimates. To minimize the errors associated with impedance-based methods, a short-circuit profile approach can be used to complement impedance-based methods in improving the fault location estimates. This approach requires only fault current magnitude recorded by the relay, prefault current and circuit model of the distribution feeder [4], [8].

In the short-circuit fault current profile approach, circuit model of the distribution feeder is used to place single line-to-ground faults at every bus in the feeder. The simulated fault current recorded by the relay is stored and a current profile of short-circuit fault current against the distance or reactance to fault is pre-plotted and used as a reference. When a fault occurs in the distribution feeder, the real world fault current recorded by the relay is interpolated on the short-circuit fault current profile to get a location estimate [4], [8].

The short-circuit fault current profile attempts to minimize the errors associated with impedance-based methods. The circuit model is directly used in building the current profile and hence the non-homogeneity of the distribution feeder is taken into account. Load plays an important role in fault location estimation. Impedance-based methods assume that the load is lumped beyond the fault point, which introduces error in estimation. The short-circuit fault current profile approach considers load current by building fault current profiles for the system under different load conditions, for example, no load, light load and peak load condition. If the prefault current before fault is available, the appropriate current profile is chosen for fault location estimation. If the relay does not record prefault data, fifteen-minute demand data can also be used. Hence 
the short-circuit fault current profile approach is expected to be more accurate. Unlike the impedance-based methods, fault location using the short-circuit fault current profile approach also indicates which branch or lateral the fault is located in. This significantly speeds up the fault restoration process. In terms of ease of application, the short-circuit fault current profile approach is very simple and does not require any computational effort. Hence this approach can be directly used by field personnel to estimate a fault location.

A typical distribution feeder is complex consisting of multiple single-phase laterals and three-phase branches. Application of short-circuit fault current profile on such a feeder is challenging. Hence, this Chapter discusses the short-circuit fault current profile approach and the strategy to be used when applied on a typical distribution feeder with complex topology. A discussion is also provided as to how the estimates from this approach will be used to complement the estimates from the impedance-based methods.

\subsection{SHORT-CIRCUIT FAULT CURRENT PROFILE APPROACH}

The short-circuit fault current profile approach requires only fault current magnitude (no phase angle), prefault current, and circuit model of the distribution feeder to determine location of a fault. The circuit model closely represents the distribution feeder and is used to build a reference short-circuit fault current profile. Single line-to ground faults are placed at successive incremental distances from the relay in the circuit model. The corresponding short-circuit fault current measured by the relay is plotted against positive-sequence reactance or distance to fault from the relay location. Zerosequence reactance as an indicator is not preferred since zero-sequence line impedance depends on soil-resistivity, which is difficult to measure and may change. Moreover, the short-circuit fault current profile approach complements the estimates obtained from 
impedance-based methods. Impedance-based methods estimate either distance or positive-sequence reactance to fault. Hence to keep a common base, zero-sequence impedance is not used an indicator.

When a fault occurs in the distribution feeder, the fault current magnitude recorded by the relay is extrapolated on the fault current profile to get a positive-sequence reactance or distance estimate to the fault. Short-circuit fault current decreases with distance from the relay. Hence a typical short-circuit fault current profile is an exponentially decreasing curve, as shown in Figure 3.2. In what follows, the strategies used in building the current profile and interpretation of the results are discussed in details.

\subsubsection{Strategy used in building the current profile}

The short-circuit fault current profile is always built along one particular direction from the relay location to the end of the feeder. Now, it is simple to build a current profile for a single feeder length with no laterals and branches. However, generally distribution systems are radial and can be very complex. For example, consider the IEEE 34 Node Test feeder. Building a current profile for such a feeder is very challenging since it is difficult to determine along which feeder length the profile should be built. In this analysis, it has been strategized to build profiles along every lateral and branch, as shown in Figure 3.1. In a single plot, multiple fault current profiles would be plotted. This strategy would give accurate estimates since all the nodes or buses are taken into account.

Load current before fault plays an important role in determining the accuracy of fault location estimates. The load is taken into account by building current profiles for the system under incremental load conditions, for example no-load, light, and full load conditions. Prefault current magnitude recorded by the relay before fault or the fifteen 
minute demand data indicates the load level in the system before fault. This information is used to choose the appropriate current profile and then conduct fault location analysis.

To build the current profile for the system under light load conditions, for example half load, loads in the circuit model of the test feeder have to be switched off till the desired load level is achieved. From the prefault current recorded by the relay, no information regarding which loads have been switched off or on in the real world can be obtained. Only the load level can be determined. Hence different loads are switched off to obtain the desired load current in the circuit model. To determine whether this inaccuracy will affect the fault location estimates, a case study was performed on the IEEE 34 Node Test Feeder. A number of cases were taken in which half load condition was achieved by switching off different loads at different buses. In each case, for a fault at a particular bus, the total current seen by the relay at bus 812 varied in the range of a few amperes. Therefore, this inaccuracy in terms of distance to fault estimation will not lead to significant error.

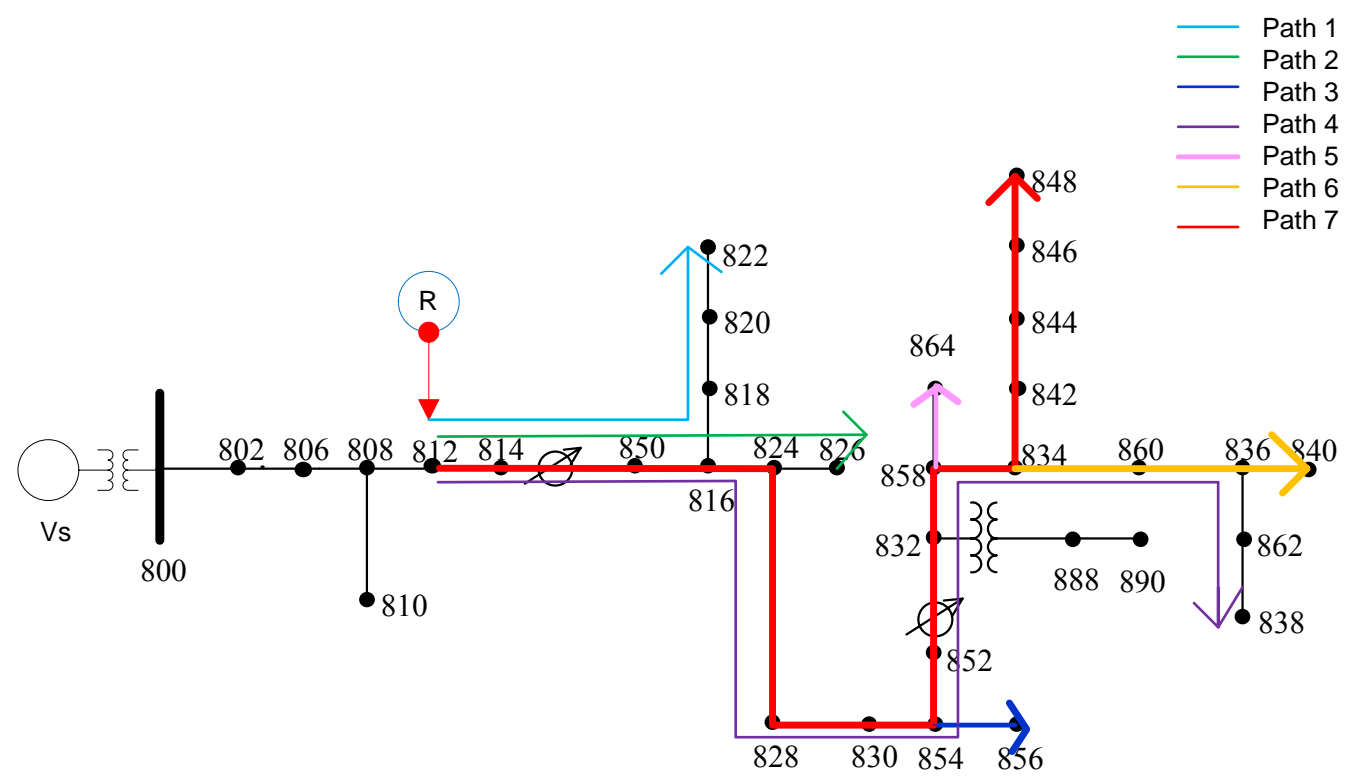

Figure 3.1: IEEE 34 Node Test Feeder with Fault Current Profile along Every Branch and Lateral. 


\subsubsection{Graphical Interpretation of Fault Location using current profile}

Short-circuit current profile for a typical distribution feeder would consist of multiple sub-profiles as shown in Figure 3.2. When fault current magnitude is extrapolated, multiple location estimates would be obtained and hence it is essential to understand how the results should be interpreted.

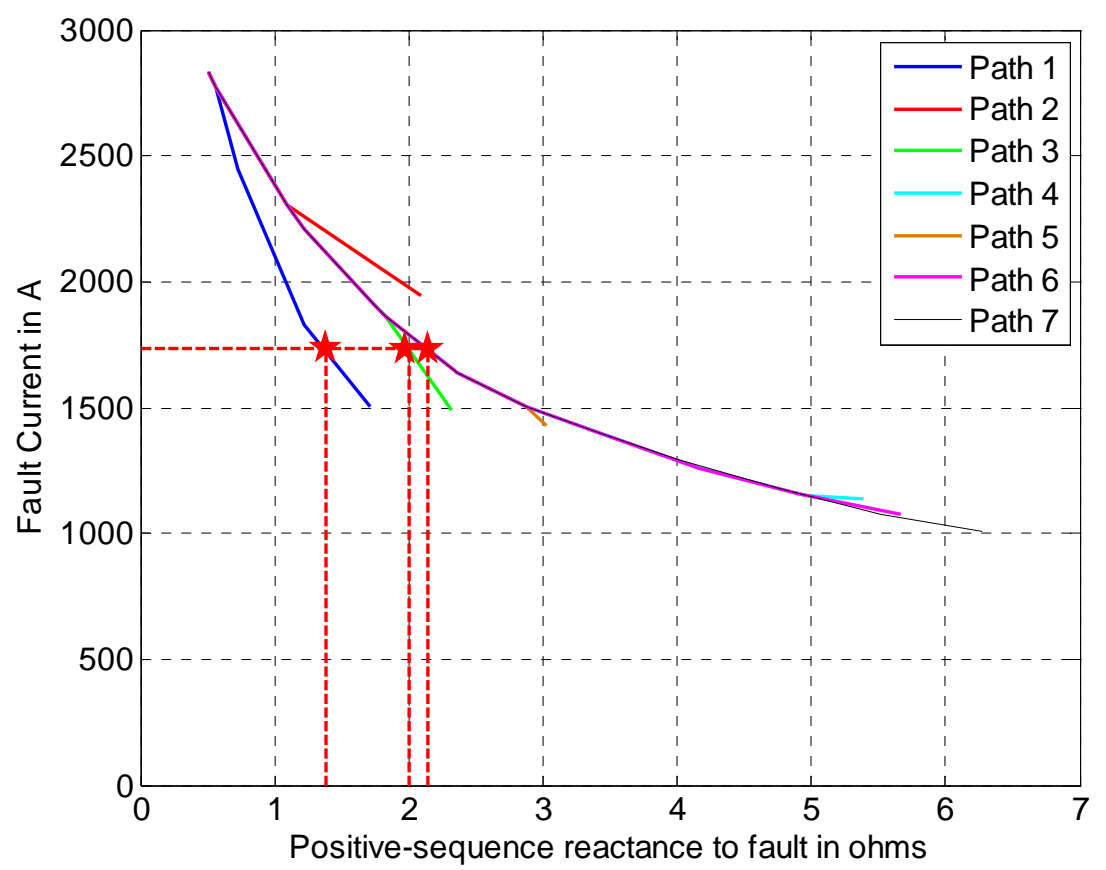

Figure 3.2: Graphically Interpreting Fault Location using Short-circuit Fault Current Profile.

For example, suppose that a fault occurs at bus 854 in the real world. The relay at bus 812 records a fault current magnitude of 1732.2 A. This magnitude when extrapolated on the profile intersects paths 1 at a positive-sequence reactance of $1.38 \Omega$, path 3 at a positivesequence reactance of $2 \Omega$ and paths $4,5,6$ and 7 at a positive-sequence reactance of 2.14 $\Omega$, as shown in Figure 3.2. The actual and estimated locations are shown in Figure 3.3. To narrow down the possible locations of the fault, utilities may apply an impedancebased algorithm. The estimate from short-circuit fault current profile approach which 
matches closely to that estimated from the impedance-based algorithm is chosen. The utility may also utilize customer outage report or recloser operation status to determine which location has the maximum probability of a fault.

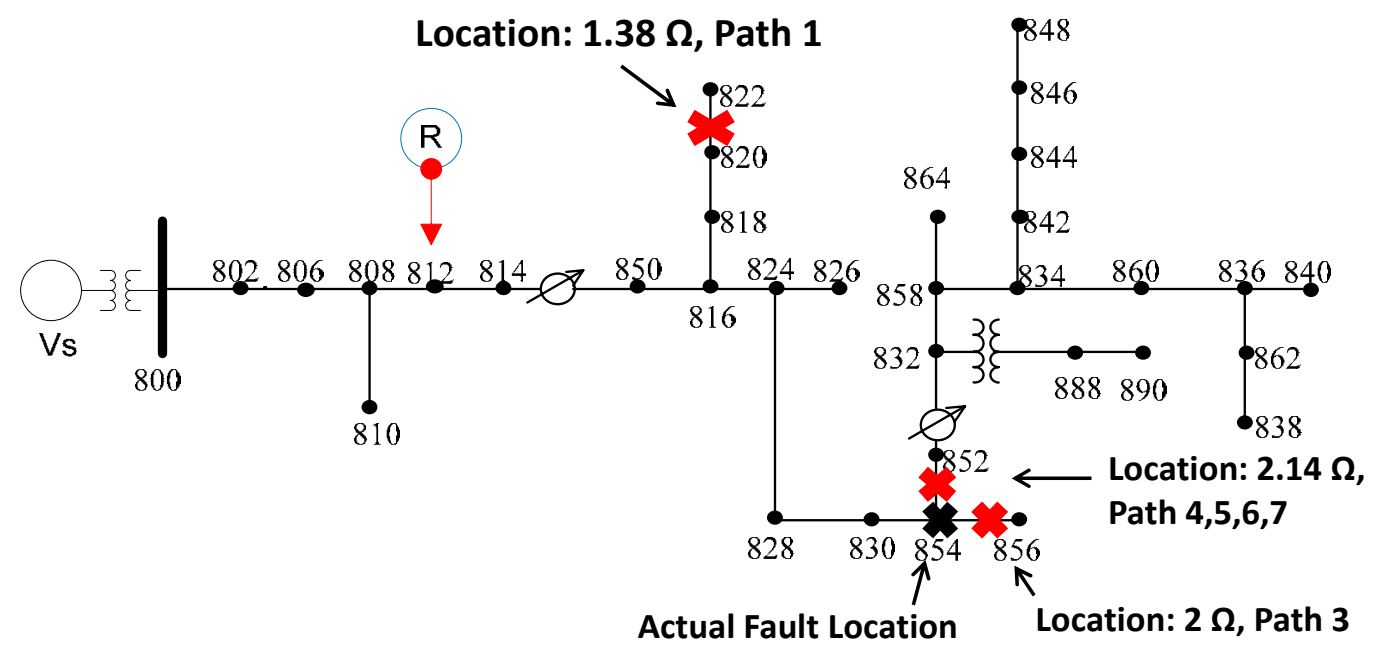

Figure 3.3: Possible Fault Locations for Fault at Bus 854.

\subsubsection{Complementing Estimates from the Short-circuit Fault Current Profile Approach with Impedance-based Methods}

From the previous subsection, impedance-based methods were used along with short-circuit fault current profile approach to determine the path or branch on which the fault may be located. This Section aims to improve the location estimate. Median value of the estimates from short-circuit fault current profile approach as well as the impedancebased methods are calculated. The median is a more robust estimate than the mean since it is not affected by the outliers.

\section{SUMMARY}

In this Chapter, the short-circuit fault current profile approach is discussed in details. When applying the approach on a distribution feeder with complex topology, the 
profile should be built unidirectionaly along every single lateral and branch. Multiple location estimates may be obtained when fault current recorded by relay in the real world is extrapolated on this profile. To narrow down the possible locations, estimates from impedance-based methods may be used. Utility can also use customer outage report or recloser operation. To improve fault location estimate, median value of estimates from short-circuit fault current profile approach as well as impedance-based methods is calculated and reported as the fault location estimate. 


\section{APPLICATION OF SHORT-CIRCUIT FAULT CURRENT PROFILE APPROACH AND IMPEDANCE-BASED METHODS ON THE MODIFIED IEEE 34 NODE TEST FEEDER}

Chapter 3 gives a brief description of the short-circuit fault current profile approach and how it can be used to complement impedance-based methods to improve fault location estimates. In this Chapter, the strategy is further developed using the circuit topology of the modified IEEE 34 Node Test Feeder. Faults are simulated in the PSCAD model under full load condition and zero load condition. Positive-sequence reactance to fault is estimated using both impedance-based methods and short-circuit fault current profile approach.

Under full load condition, impedance-based methods estimate the positivesequence reactance to fault accurately when faults are close to the relay location, i.e. load current is around $15 \%$ of the fault current. Error in estimation increases with distance from the substation, i.e. load current is around $50 \%$ of the fault current. Estimation error when using Takagi method is within 0.58 miles while estimation error when using positive-sequence reactance method is within 0.73 miles. When faults are simulated under zero load condition, the impedance-based methods are very close to the actual fault location, thus indicating the detrimental effect of load on accuracy of estimates. This analysis also illustrates that the impedance-based methods do not indicate which branch the fault may be located in.

The short-circuit fault current profile approach is built using the guidelines form Chapter 3 and accurately estimates fault location when faults are close to the monitoring location. For faults at the farthest laterals, the fault current recorded by the relay is lower than the current profile plot limits. To get an intersection, the current profile was linearly 
extended. However, the error in estimation is 1.9 miles or $31 \%$. Such high error percentages are due to the fact that the circuit model of the test feeder in OpenDSS is not an accurate representation of the actual distribution feeder represented by the PSCAD model.

Next, to improve fault location estimates, estimates from short-circuit fault current profile approach as well as impedance-based methods are used to compute a median estimate. This median estimate is very close to the actual fault location and error in estimation is within 0.58 miles. The path on which the fault is located was also identified. It was seen that if a 0.6 mile radius is built around this median estimate, the fault would be contained within that range.

\subsection{FAUlt Location ON THE MOdIFIEd IEEE 34 NODE TEST FEEDER}

The circuit topology of the IEEE 34 Node Test Feeder is ideal for fault location analysis since it is an actual feeder located in Arizona and hence represents the complexities of a real world distribution feeder. The rated voltage of the source is $115 \mathrm{kV}$ stepped down to $24.9 \mathrm{kV}$ by the substation transformer. The relay located at bus 812 monitors the system voltage and current at a sampling rate of 128 samples per cycle.

For the analysis on fault location using short-circuit fault current profile approach to complement impedance-based methods, single line-to-ground faults have been simulated in the PSCAD model of the modified test feeder at eight strategic locations, as shown in Figure 4.1. The PSCAD model is used to simulate faults occurring in the circuit and captures both voltage and current waveforms. It is used to replicate actual faults occurring in utility circuits and actual relays capturing voltage and current waveforms. In other words, this circuit is used to represent the actual or real world circuit so that faults can be simulated and populated at every bus of interest in the feeder. This of course 
cannot be done in the actual circuit. The time-domain PSCAD model developed in Chapter 2 is used for this purpose.

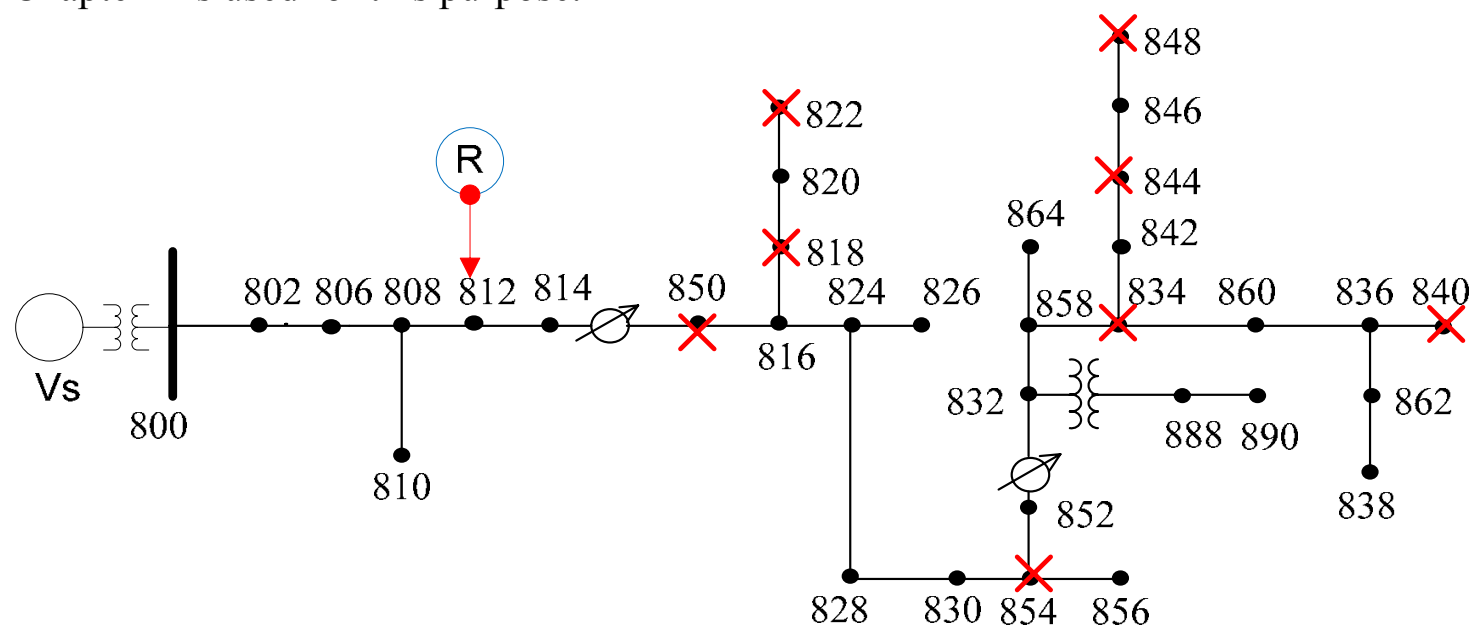

Figure 4.1: Fault Locations on the Test Feeder.

System load before fault affects fault location accuracy. To analyze the effect of load on the estimates, fault location is done for two cases:

- $\quad$ Full load

- Zero load

\subsubsection{Case 1: Full load condition}

Under the full load condition, load current in the system before fault is 425 A per phase. Single line-to-ground faults are simulated in the PSCAD model under full load condition. In the following subsections, fault location estimate will be calculated using impedance-based methods and short-circuit fault current profile approach.

\section{Impedance-based methods}

Using voltage and current measurements, Takagi and positive-sequence reactance methods are used to estimate distance to fault. Impedance-based methods need line impedance per unit length to determine fault location. Now the IEEE 34 Node Test 
Feeder has five different line configurations and they are summarized in Table 4.1. It is observed that line configuration 301 is the most widely used configuration and hence the sequence impedances of this configuration are used for estimation. Table 4.2 gives the positive-sequence reactance to fault estimates. The error percentages are calculated as:

$$
\text { Error }(\%)=\text { Absolute }\left(\frac{\text { Estimated reactance- Actual reactance }}{\text { Actual reactance }}\right) \times 100
$$

The estimates are accurate when faults are close to the monitoring location, i.e. load current is around $15 \%$ of the fault current. Estimation errors increase with distance from the relay location. At the farthest lateral, bus 848 , load current is $51 \%$ of the fault current and hence error in estimation is higher.

Table 4.1: Sequence Impedances of Five Different Line Configuration.

\begin{tabular}{|c|c|c|c|c|c|}
\hline Sequence & $\mathbf{3 0 0}$ & $\mathbf{3 0 1}$ & $\mathbf{3 0 2}$ & $\mathbf{3 0 3}$ & $\mathbf{3 0 4}$ \\
\hline $\mathbf{z}_{\mathbf{0}}$ & $1.749+j 2.372$ & $2.387+j 2.578$ & $0.9332+j 0.4952$ & $0.9332+j 0.4952$ & $0.6406+j 0.4737$ \\
\hline $\mathbf{Z}_{\mathbf{1}}$ & $1.120+j 0.833$ & $1.690+j 0.841$ & $0.9332+j 0.4952$ & $0.9332+j 0.4952$ & $0.6406+j 0.4737$ \\
\hline $\mathbf{Z}_{\mathbf{2}}$ & $1.120+j 0.833$ & $1.690+j 0.841$ & $0.9332+j 0.4952$ & $0.9332+j 0.4952$ & $0.6406+j 0.4737$ \\
\hline
\end{tabular}

As discussed in Chapter 2, impedance-based methods do not provide any information regarding which branch or lateral, the fault may be located. For example, consider the fault at bus 818. Takagi and positive-sequence method estimate the reactance to fault to be $0.82 \mathrm{ohms}$ and $0.83 \mathrm{ohms}$ respectively from the relay at bus 812 . As seen from Figure 4.2, these location estimates may be on the single-phase lateral 816822 or on the three-phase feeder $816-826$.

Consider another example of a single line-to-ground fault on bus 854. Fault current recorded by the relay at bus 812 is 1732.2 A. Takagi and positive-sequence 
methods estimate the reactance to fault to be 1.77 and 1.82 ohms respectively. For the Takagi estimates, Figure 4.3 shows the possible locations of the fault.

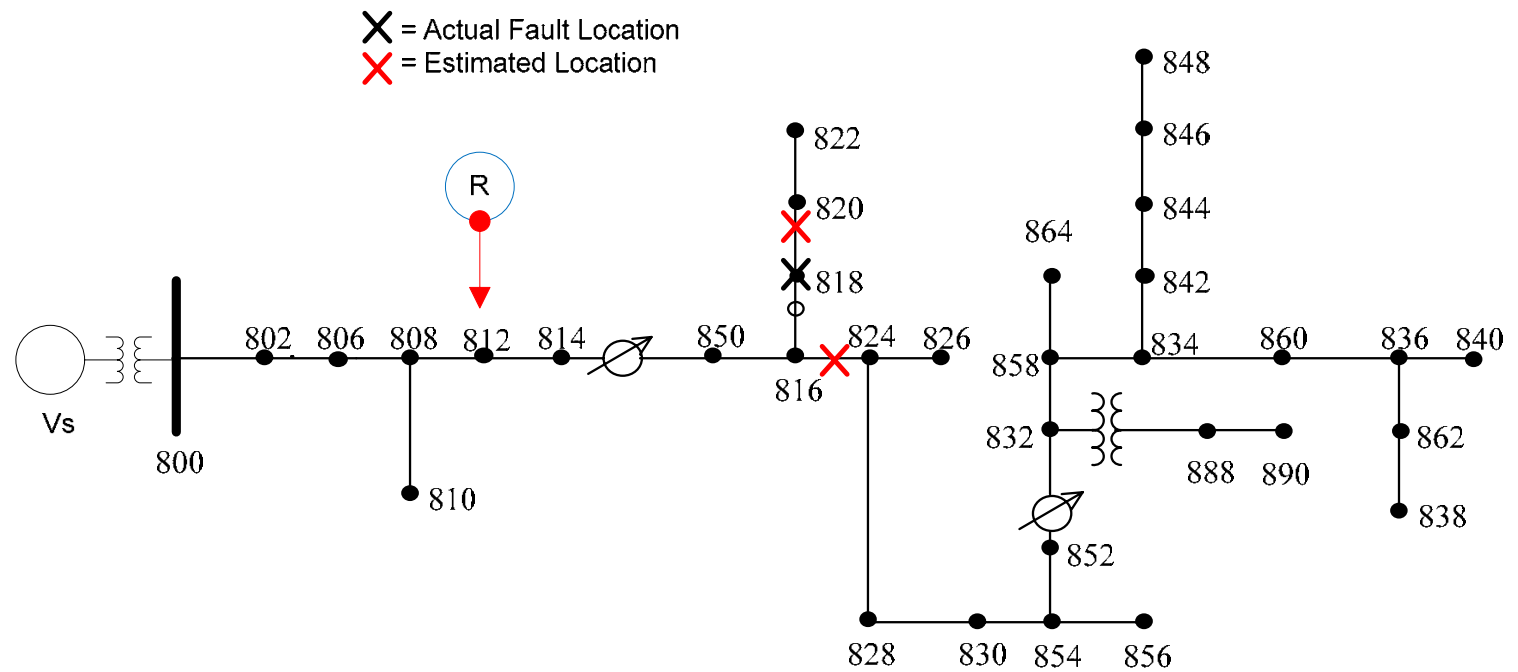

Figure 4.2: Possible Fault Location Estimates from Impedance-based Methods for a Fault at Bus 818 .

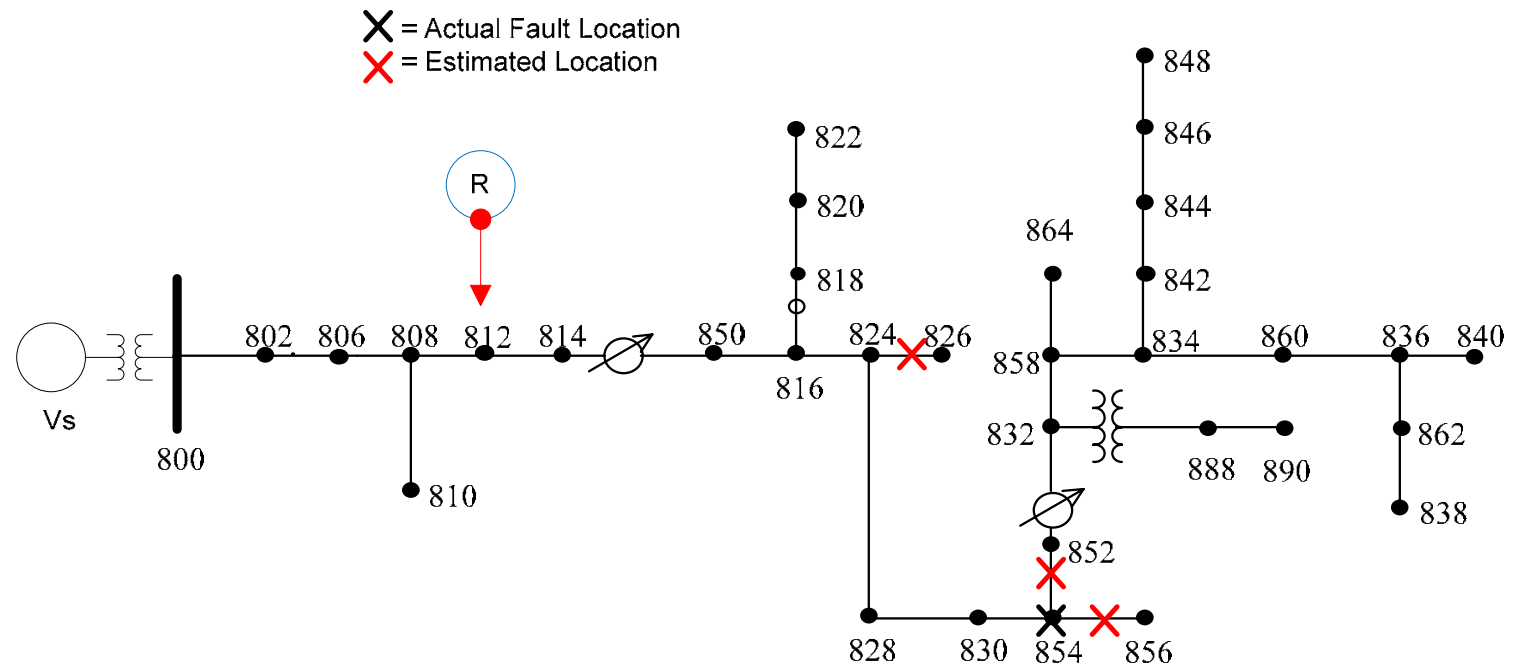

Figure 4.3: Possible Fault Locations for a Fault at Bus 854, using Takagi Method. 
Table 4.2: Comparison of Actual versus the Estimated Positive-sequence Reactance to Fault using Impedance-based Methods.

\begin{tabular}{|c|c|c|c|c|c|c|}
\hline \multirow{2}{*}{$\begin{array}{l}\text { Fault } \\
\text { Bus }\end{array}$} & \multirow{2}{*}{$\begin{array}{c}\text { Fault } \\
\text { Current } \\
\text { from } \\
\text { PSCAD } \\
\text { (kA) }\end{array}$} & \multirow{2}{*}{$\begin{array}{c}\text { Actual } \\
\text { Positive- } \\
\text { sequence } \\
\text { Reactance } \\
\text { to Fault } \\
\text { (ohms) }\end{array}$} & \multicolumn{4}{|c|}{$\begin{array}{c}\text { Estimated Positive-sequence Reactance } \\
\text { to Fault (ohms) }\end{array}$} \\
\hline & & & $\begin{array}{l}\text { Takagi } \\
\text { Method }\end{array}$ & $\begin{array}{c}\text { Error } \\
(\%)\end{array}$ & $\begin{array}{l}\text { Positive- } \\
\text { sequence } \\
\text { Method }\end{array}$ & $\begin{array}{l}\text { Error } \\
(\%)\end{array}$ \\
\hline 850 & 2.832 & 0.52 & 0.47 & 9.62 & 0.53 & 1.92 \\
\hline 818 & 2.3771 & 0.726 & 0.82 & 12.95 & 0.83 & 14.33 \\
\hline 822 & 1.3797 & 1.72 & 2.44 & 41.86 & 2.13 & 23.84 \\
\hline 854 & 1.7322 & 1.83 & 1.77 & 3.28 & 1.82 & 0.55 \\
\hline 834 & 1.1975 & 3.40 & 3.34 & 1.76 & 3.34 & 1.76 \\
\hline 844 & 0.9769 & 4.76 & 4.56 & 4.20 & 4.48 & 5.88 \\
\hline 840 & 0.8804 & 5.67 & 5.30 & 6.53 & 5.12 & 9.70 \\
\hline 848 & 0.8374 & 6.28 & 5.70 & 9.24 & 5.55 & 11.62 \\
\hline
\end{tabular}

\section{Short-circuit fault current profile approach}

For the short-circuit fault current profile approach, the current profile is built using the circuit model of the test feeder in OpenDSS, when the system is under full load condition. From the relay location, the feeder branches out into five single-phase laterals and two three-phase branches. Using the guidelines outlined in Chapter 3, short-circuit fault current profile is built along every lateral and branch in the OpenDSS circuit model of the feeder, as shown in Figure 4.4. Seven paths have been identified. Figure 4.5 shows the current profile of fault current versus positive-sequence reactance to fault. 


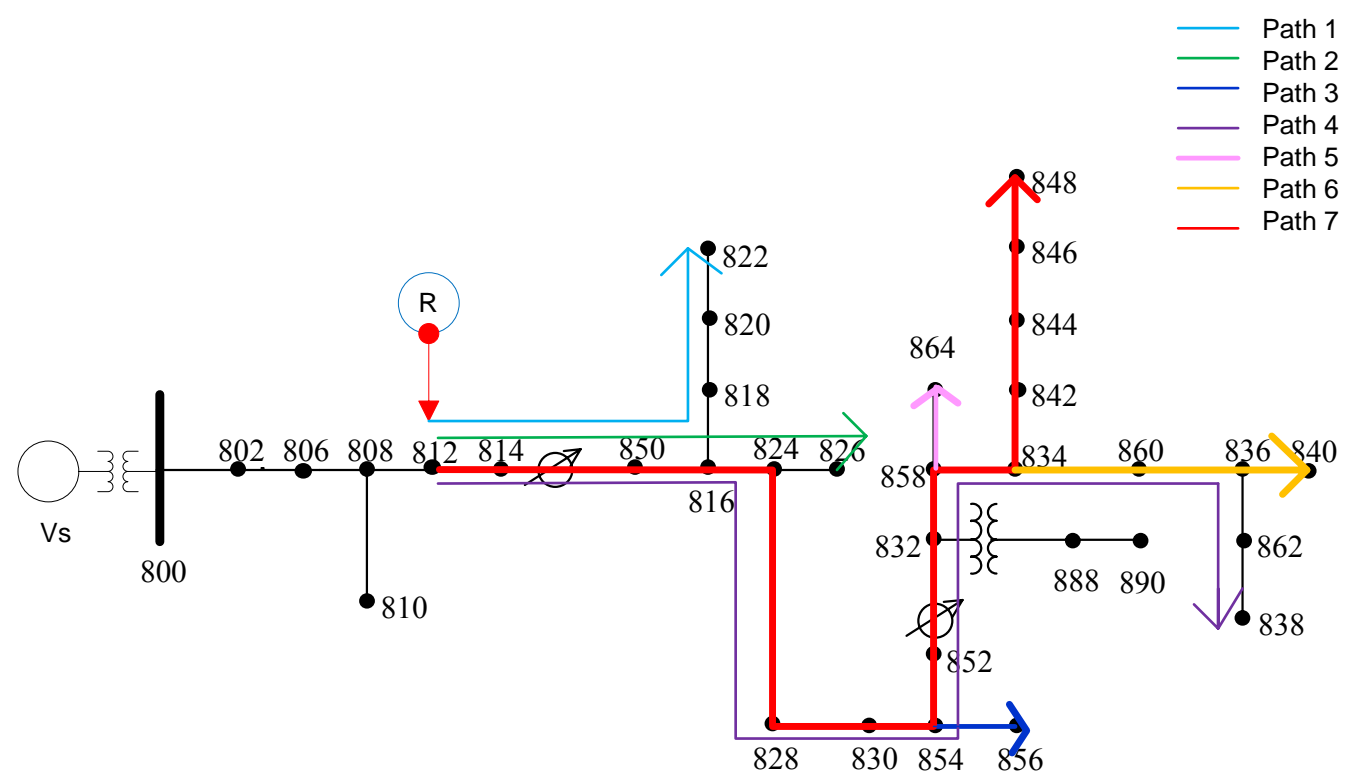

Figure 4.4: Paths for Short-circuit Fault Current Profile.

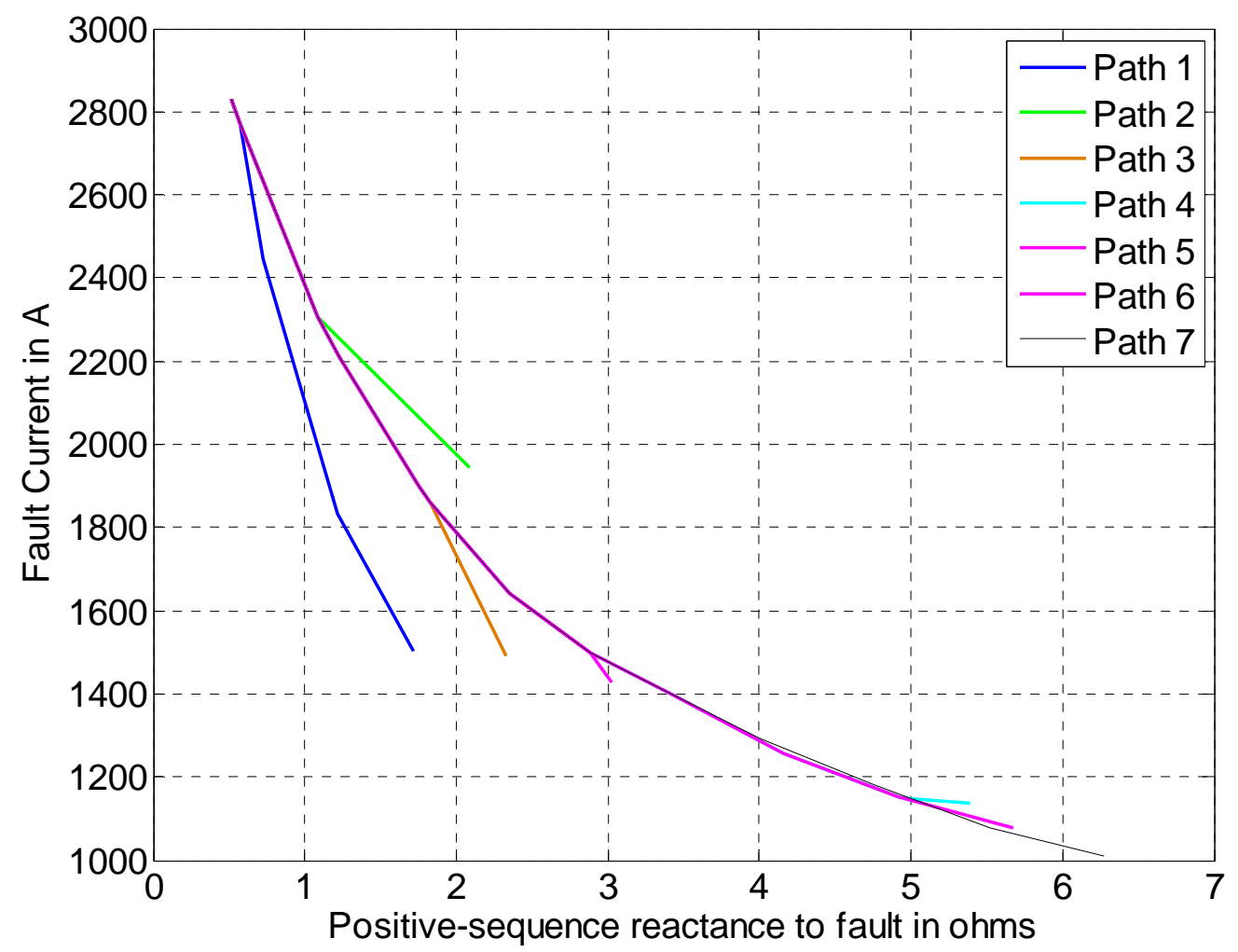

Figure 4.5: Fault Current Profile of Fault Current versus Positive-sequence Reactance to Fault under Peak Load Condition. 
In Table 4.3, the fault current magnitudes measured by the relay at bus 812 for each faulted bus is shown. Now, when these fault current magnitudes are extrapolated on the current profiles, multiple location estimates are obtained. To narrow down the estimates, estimates from impedance-based methods are used. Table 4.3 shows the estimate which matches closely with that estimated by impedance-based methods. The error percentage is also calculated with respect to that particular reactance estimate.

For example, consider fault on bus 818 . The fault current is 2377.1 A. When interpolated on the current profile, this fault current magnitude intersects the current profile at two points, i.e. path 1 at a positive-sequence reactance of 0.78 ohms and paths 4, 5, 6 and 7 at a positive-sequence reactance of $1.01 \mathrm{ohms}$. This is illustrated in Figure 4.6. Now from Table 4.2, Takagi method estimates the positive-sequence reactance to fault to be $0.82 \mathrm{ohms}$ and positive-sequence method estimates it to be $0.83 \mathrm{ohms}$. Hence, using the estimates from impedance-based methods, $0.78 \mathrm{ohms}$ along path 1 is reported as the fault location using short-circuit fault current profile approach. However there may be cases where impedance-based methods alone cannot narrow down the possible fault locations. In such situations, customer outage data or recloser operation data is used for isolating the possible branch in which the fault maybe located.

Short-circuit fault current profile approach along with impedance-based methods have correctly predicted the path on which the fault may be located in, as shown in Table 4.3. For example, suppose that a fault has occurred in bus 850 . It is predicted that the fault is located in paths $1,2,3,4,5,6$ and 7 . This means that the fault is located at a point common to all the seven paths.

For certain buses, particularly at the farthest laterals (for example bus 840 and 848), it was observed that the fault current magnitude recorded by the relay exceeds the OpenDSS plot limits. This is illustrated in Figure 4.7. Hence, to get an estimate or in 38 
other words, to get an intersection, the plots are linearly extended till an intersection is obtained. Linear extrapolation of the current profile is shown by the broken line seen in Figure 4.8. For example, consider bus 840 . The actual positive-sequence reactance from the relay at bus 812 to bus 840 is 5.67 ohms. For a fault at bus 840 , the fault current seen by the relay exceeds the plot limits and hence, by linear extrapolation of the profile, the estimated reactance is found to be $7.57 \mathrm{ohms}$. This estimate however exceeds the total reactance of the feeder. Under such circumstances, the repair personnel should investigate the area near the end of the feeder.

As seen from Table 4.3, fault location estimates for faults located close to the monitoring location are very accurate. Error percentage increases with distance from the monitoring location. Maximum error of $33 \%$ is observed. Figure 4.9 illustrate the deviation of the estimated reactance with respect to actual reactance to fault.

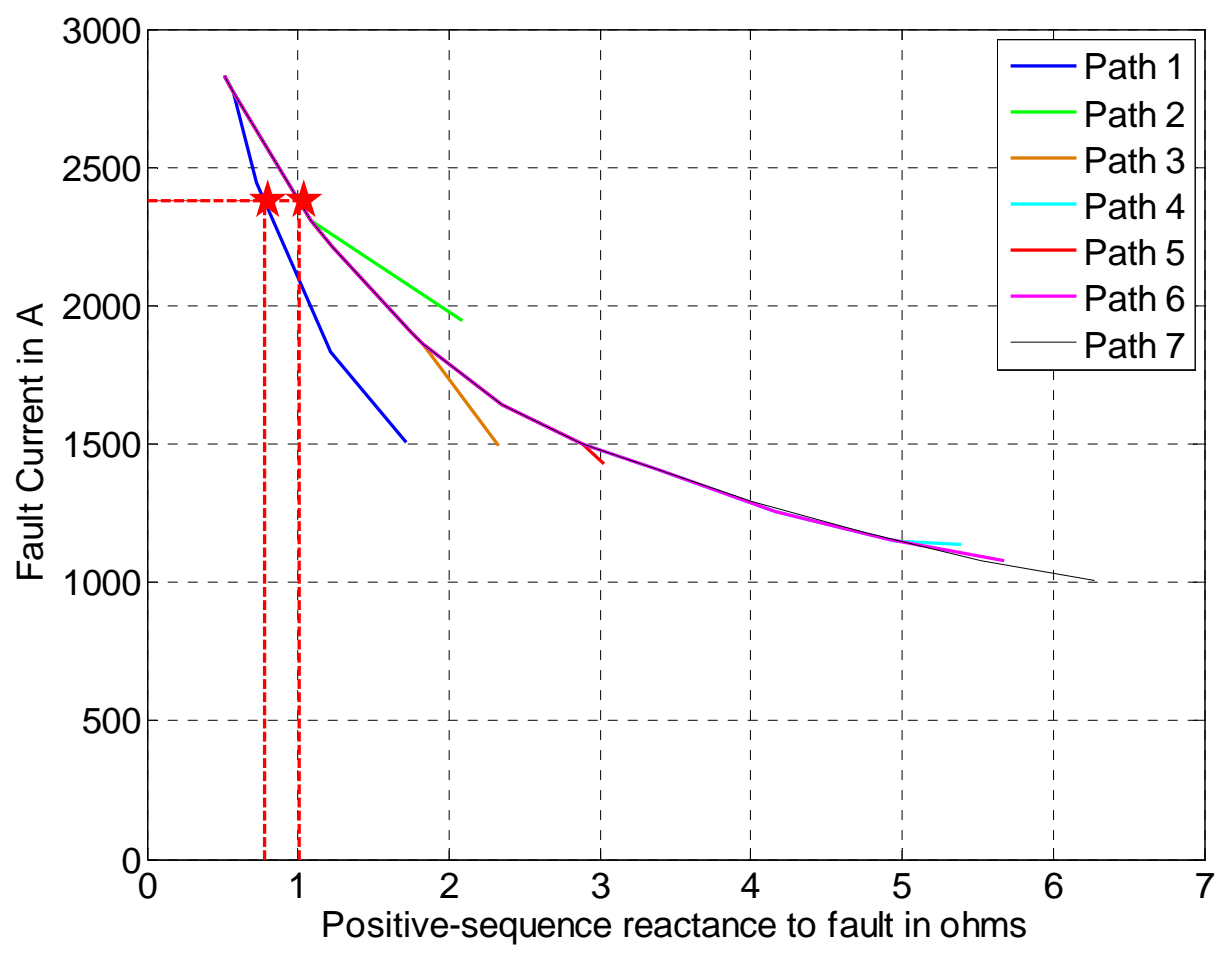

Figure 4.6: Illustrating Fault Location for a Fault Current of $2.38 \mathrm{kA}$. 


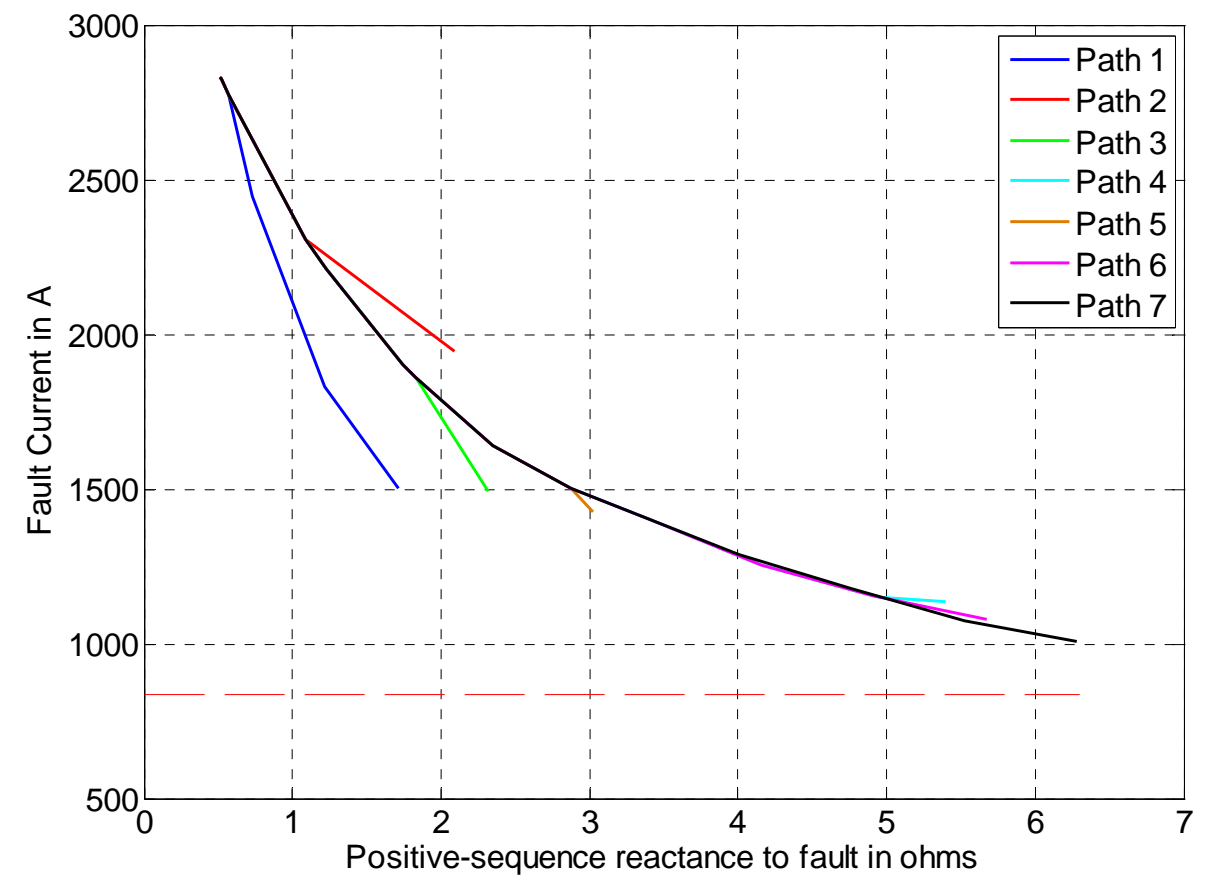

Figure 4.7: Fault Current Exceeding Short-circuit Fault Current Profile Limit.

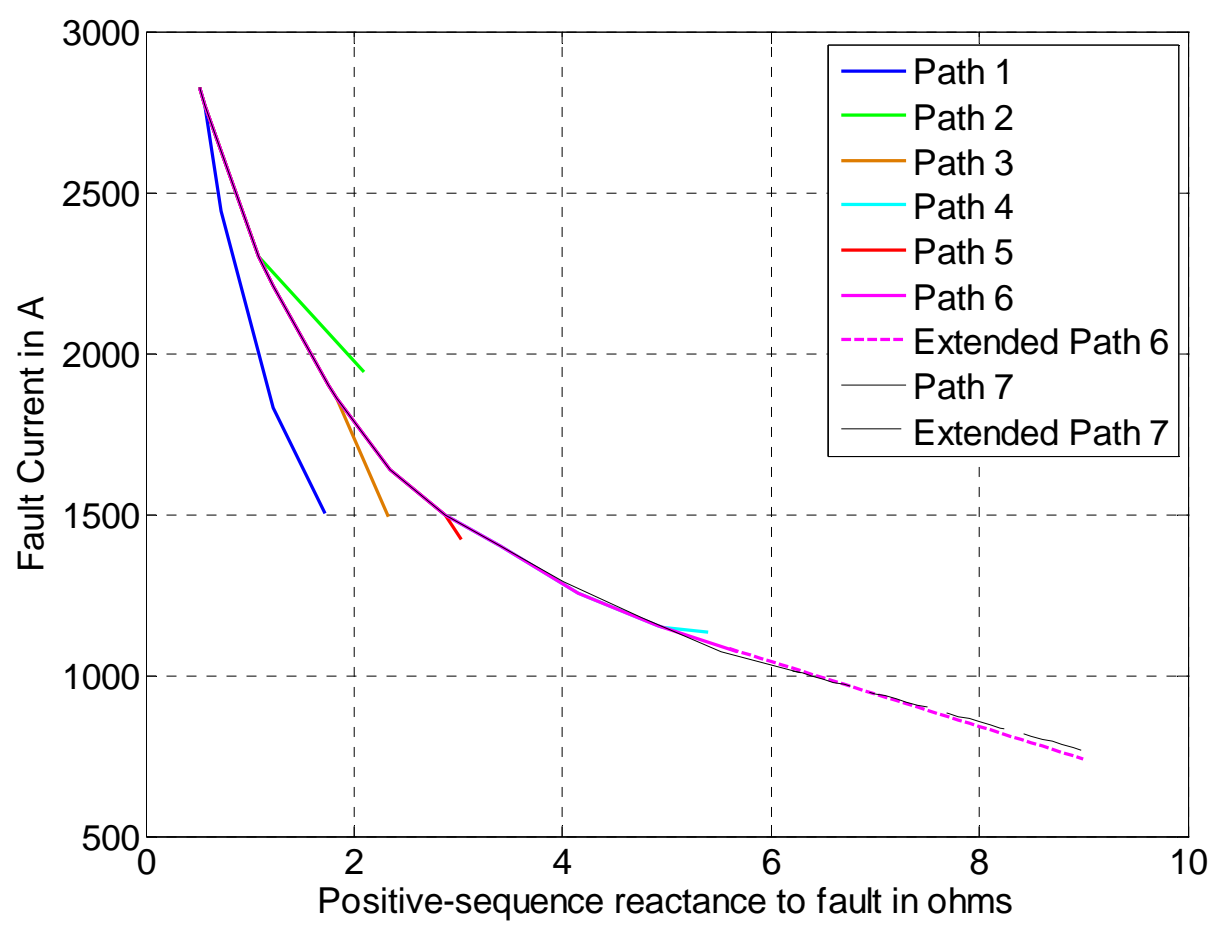

Figure 4.8: Short-circuit Fault Current Profile Linearly Extended. 
Table 4.3: Comparison of Actual versus Estimated Positive-sequence Reactance to Fault using Short-circuit Fault Current Profile Approach.

\begin{tabular}{|c|c|c|c|c|c|}
\hline $\begin{array}{c}\text { Fault } \\
\text { Bus }\end{array}$ & $\begin{array}{c}\text { Fault } \\
\text { Current } \\
\text { from } \\
\text { PSCAD } \\
\text { (kA) }\end{array}$ & $\begin{array}{c}\text { Actual } \\
\text { Positive- } \\
\text { sequence } \\
\text { Reactance to } \\
\text { fault } \\
\text { (ohms) }\end{array}$ & $\begin{array}{c}\text { Estimated } \\
\text { Positive- } \\
\text { sequence } \\
\text { Reactance to } \\
\text { fault (ohms) }\end{array}$ & $\begin{array}{c}\text { Error } \\
\text { (\%) }\end{array}$ & $\begin{array}{c}\text { Path of Fault } \\
\text { Location }\end{array}$ \\
\hline 850 & 2.832 & 0.52 & 0.51 & 1.92 & $1,2,3,4,5,7$ \\
\hline 818 & 2.3771 & 0.73 & 0.87 & 7.44 & 1 \\
\hline 822 & 1.3797 & 1.72 & 1.9 & 10.47 & 1 \\
\hline 854 & 1.7322 & 1.83 & 2.14 & 16.94 & $3,4,5,6,7$ \\
\hline 834 & 1.1975 & 3.40 & 4.6 & 35.29 & $4,6,7$ \\
\hline 844 & 0.9769 & 4.76 & 6.6 & 38.66 & 7 \\
\hline 840 & 0.8804 & 5.67 & 7.57 & 33.51 & 6 \\
\hline 848 & 0.8374 & 6.28 & 8.18 & 30.25 & 7 \\
\hline
\end{tabular}

The underlying cause for the error in estimation using current profiles is due to discrepancies between the test feeder circuit model available to the utility (OpenDSS) and the model used to generate the power quality monitor data (PSCAD). To check if the OpenDSS model is representative of the test feeder in PSCAD, a validation check was carried out. Single line-to-ground faults were placed at every bus in the PSCAD model as well as in the OpenDSS model of the test feeder. If the utility model (OpenDSS model) had closely represented the distribution feeder (PSCAD model), the fault currents of both the models should be very close. However, fault currents in OpenDSS are higher than the 
PSCAD model by around 200A, indicating that there were significant modeling errors. This gives rise to high error percentages.

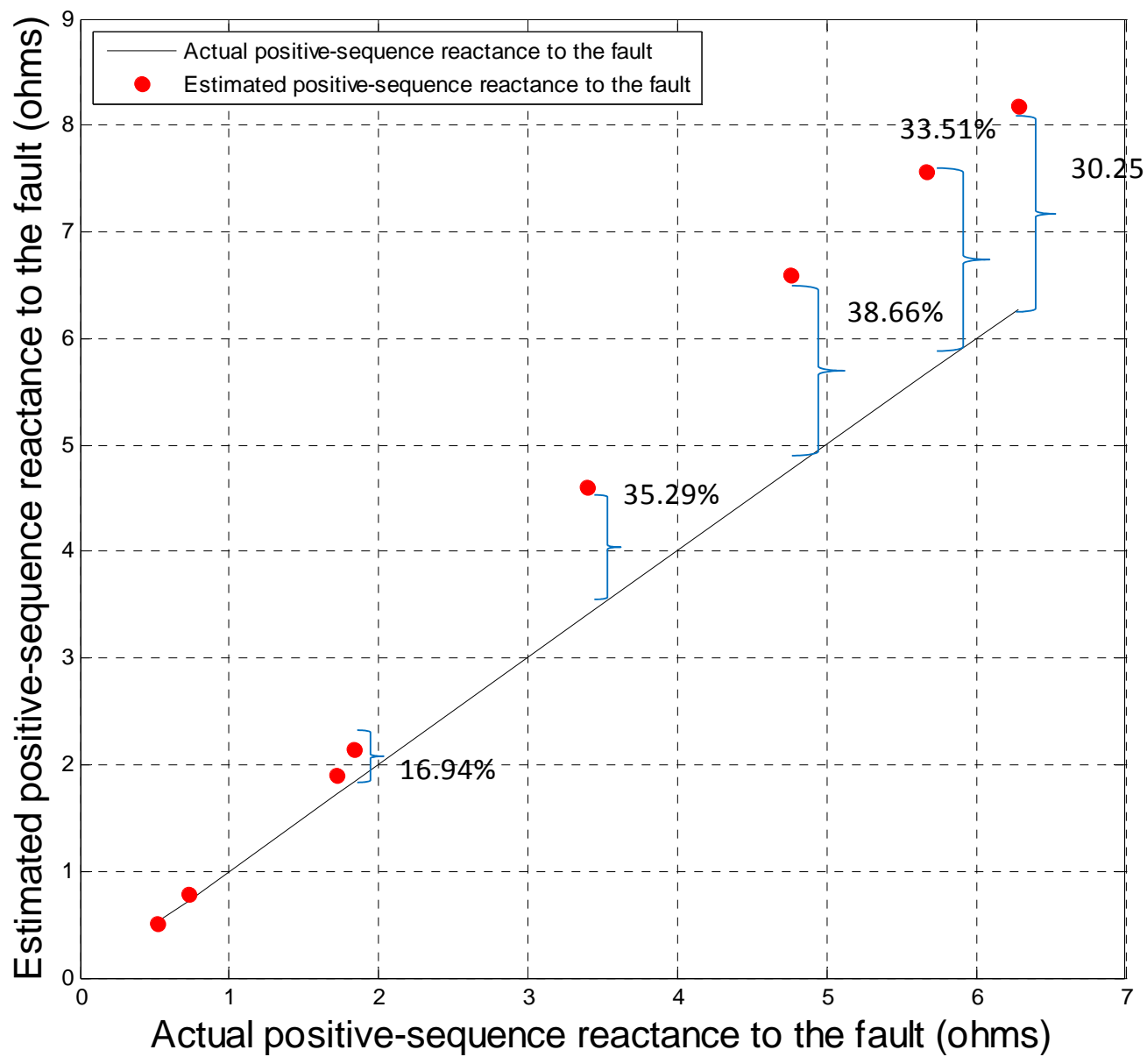

Figure 4.9: Illustration of the Error in Estimating Positive-sequence Reactance to Fault using Short-circuit Fault Current Profile.

\section{Complementing Estimates from Impedance-based Methods using Short-circuit Fault Current Profile Approach}

In this Section, reactance estimates using impedance-based methods are tabulated along with estimates obtained using short-circuit fault current profile approach, as shown in Table 4.4. Next the median value of all the estimates is calculated. The median is a more robust estimate than a mean since it is not affected by the outliers. 
Table 4.4: Computing Median of all Estimates.

\begin{tabular}{|c|c|c|c|c|c|}
\hline $\begin{array}{c}\text { Fault } \\
\text { Bus }\end{array}$ & $\begin{array}{c}\text { Actual } \\
\text { Positive- } \\
\text { sequence } \\
\text { Reactance } \\
\text { (ohms) }\end{array}$ & $\begin{array}{c}\text { Takagi } \\
\text { Method } \\
\text { (ohms) }\end{array}$ & $\begin{array}{c}\text { Positive- } \\
\text { sequence } \\
\text { Reactance } \\
\text { Method } \\
\text { (ohms) }\end{array}$ & $\begin{array}{c}\text { Short-circuit } \\
\text { Fault Current } \\
\text { Profile } \\
\text { (ohms) }\end{array}$ & $\begin{array}{c}\text { Median } \\
\text { (ohms) }\end{array}$ \\
\hline 850 & 0.52 & 0.47 & 0.53 & 0.51 & 0.51 \\
\hline 818 & 0.73 & 0.82 & 0.83 & 0.87 & 0.83 \\
\hline 822 & 1.72 & 2.44 & 2.13 & 1.9 & 2.13 \\
\hline 854 & 1.83 & 1.77 & 1.82 & 2.14 & 1.82 \\
\hline 834 & 3.40 & 3.34 & 3.34 & 4.6 & 3.34 \\
\hline 844 & 4.76 & 4.56 & 4.48 & 6.6 & 4.56 \\
\hline 840 & 5.67 & 5.30 & 5.12 & 7.57 & 5.30 \\
\hline 848 & 6.28 & 5.70 & 5.55 & 8.18 & 5.70 \\
\hline
\end{tabular}

As seen in Table 4.5, the median is found to be very close to the actual distance to the fault. A maximum error of 0.41 miles is observed. An upper and lower range can be identified by building a 0.6 mile radius around the median estimate. The fault will lie within that range, as seen from Table 4.5. In this way, the approach explained above can be effectively utilized to track down and locate faults. 
Table 4.5: Median Estimate is Close to the Actual Fault Location.

\begin{tabular}{|c|c|c|c|}
\hline $\begin{array}{c}\text { Fault } \\
\text { Bus }\end{array}$ & $\begin{array}{c}\text { Actual Positive- } \\
\text { sequence Reactance } \\
\text { (ohms) }\end{array}$ & $\begin{array}{c}\text { Median } \\
\text { (ohms) }\end{array}$ & $\begin{array}{c}\text { Error } \\
\text { (\%) }\end{array}$ \\
\hline 850 & 0.52 & 0.51 & 1.92 \\
\hline 818 & 0.73 & 0.83 & 14.33 \\
\hline 822 & 1.72 & 2.13 & 23.84 \\
\hline 854 & 1.83 & 1.82 & 0.55 \\
\hline 834 & 3.40 & 3.34 & 1.76 \\
\hline 844 & 4.76 & 4.56 & 4.20 \\
\hline 840 & 5.67 & 5.30 & 6.53 \\
\hline 848 & 6.28 & 5.70 & 9.24 \\
\hline
\end{tabular}

\subsubsection{Case 2: Zero Load}

All the loads in the distribution feeder are switched off. To obtain the power quality monitor data of the test feeder, faults have been simulated in the PSCAD model when the system is under zero load condition. As in the previous two subsections, positive-sequence reactance to fault will be computed using both impedance-based methods as well as short-circuit fault current profile approach.

\section{Impedance-based method}

Takagi and positive-sequence methods use voltage and current waveform recorded by the relay in the PSCAD model to compute positive-sequence reactance to 
fault. The results are summarized in Table 4.6. Error percentages are calculated using Equation 4.1.

Table 4.6: Comparison of Actual versus the Estimated Positive-sequence Reactance to fault using Impedance-based Methods.

\begin{tabular}{|c|c|c|c|c|c|c|}
\hline \multirow{2}{*}{$\begin{array}{l}\text { Fault } \\
\text { Bus }\end{array}$} & \multirow{2}{*}{$\begin{array}{c}\text { Fault } \\
\text { Current } \\
\text { from } \\
\text { PSCAD } \\
\text { (kA) }\end{array}$} & \multirow{2}{*}{$\begin{array}{c}\text { Actual } \\
\text { Positive- } \\
\text { sequence } \\
\text { Reactance to } \\
\text { Fault } \\
\text { (ohms) }\end{array}$} & \multicolumn{4}{|c|}{$\begin{array}{c}\text { Estimated Positive-sequence Reactance to } \\
\text { Fault (ohms) }\end{array}$} \\
\hline & & & $\begin{array}{l}\text { Takagi } \\
\text { Method }\end{array}$ & $\begin{array}{l}\text { Error } \\
(\%)\end{array}$ & $\begin{array}{l}\text { Positive- } \\
\text { sequence } \\
\text { Method }\end{array}$ & $\begin{array}{l}\text { Error } \\
(\%)\end{array}$ \\
\hline 850 & 2.7280 & 0.52 & 0.49 & 5.77 & 0.53 & 1.92 \\
\hline 818 & 2.2735 & 0.726 & 0.82 & 12.95 & 0.83 & 14.33 \\
\hline 822 & 1.1808 & 1.72 & 2.50 & 45.35 & 2.26 & 31.40 \\
\hline 854 & 1.6349 & 1.83 & 1.80 & 1.64 & 1.83 & 0.00 \\
\hline 834 & 1.0993 & 3.40 & 3.36 & 1.18 & 3.39 & 0.29 \\
\hline 844 & 0.8550 & 4.76 & 4.72 & 0.84 & 4.75 & 0.21 \\
\hline 840 & 0.7461 & 5.67 & 5.60 & 1.23 & 5.62 & 0.88 \\
\hline 848 & 0.6854 & 6.28 & 6.22 & 0.96 & 6.24 & 0.64 \\
\hline
\end{tabular}

This analysis clearly illustrates the effect load has on the fault location estimates.

For single line-to-ground faults on the same bus and using the same line parameters, it is seen that the location estimates under zero load condition are more accurate as compared to the full load condition. For example, consider the fault on bus 848 . Under full load condition, i.e. load current is $50 \%$ of the fault current, Takagi method estimates the positive-sequence reactance to fault at $5.7 \mathrm{ohms}$. Under zero load conditions, the same 
method estimates the positive-sequence reactance to fault as $6.22 \mathrm{ohms,}$ which is much closer to the actual positive-sequence reactance to fault of $6.28 \mathrm{ohms}$.

\section{Short-circuit Fault Current Profile Approach}

Zero load short-circuit fault current profile is built by switching off all the loads in the OpenDSS circuit model. Figure 4.10 shows the current profile of short-circuit fault current versus positive-sequence reactance to fault at zero load. As seen in the previous two cases, when fault current magnitude is extrapolated on the current profile, multiple location estimates are obtained. The estimates which match closely to that estimated by impedance-based methods are tabulated in Table 4.7.

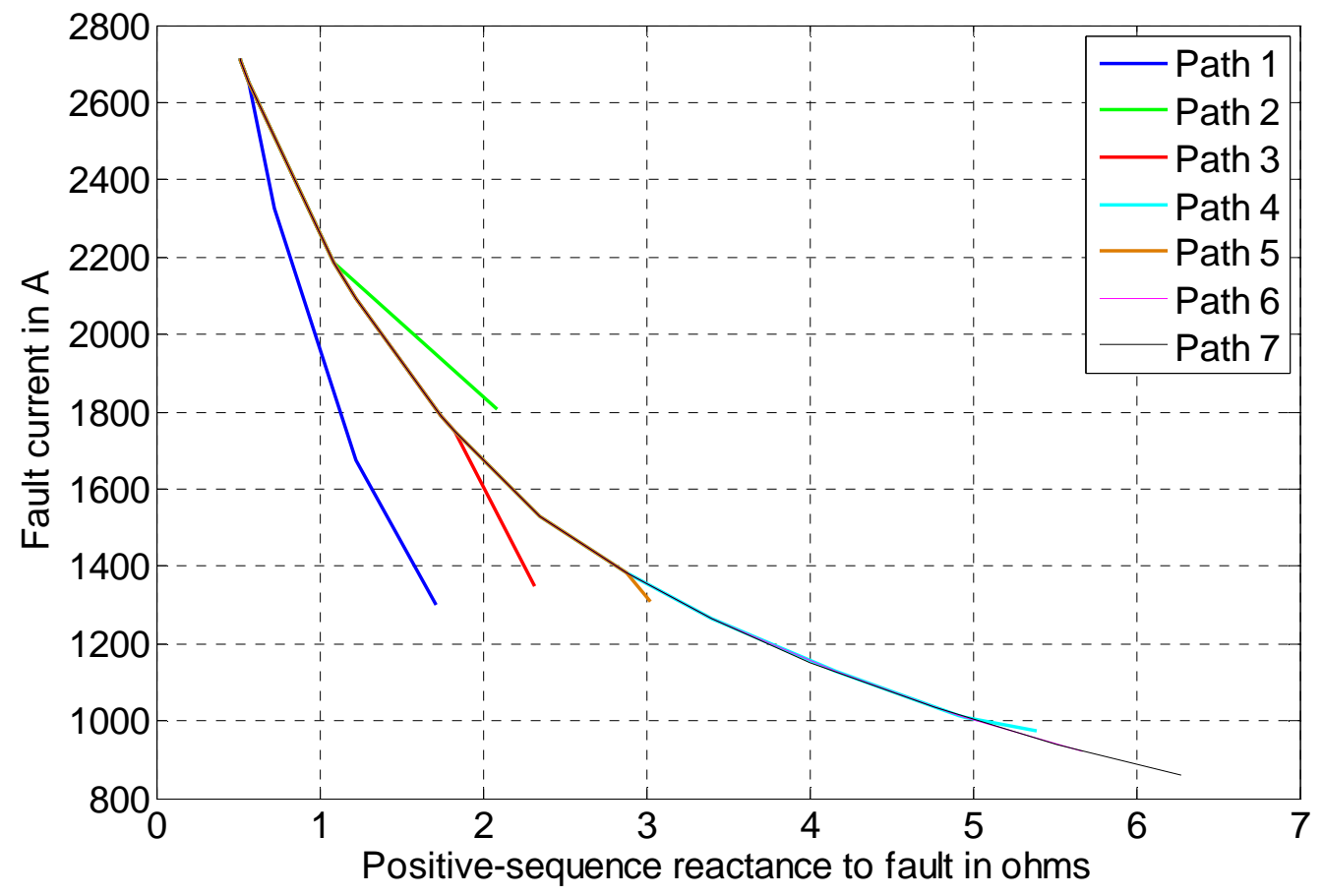

Figure 4.10: Zero Load Fault Current Profile of Fault Current versus Positive-sequence Reactance to Fault.

Again, due to inaccuracies in representing the test feeder (PSCAD model) accurately in the OpenDSS circuit model, fault currents at the farthest laterals (buses 822, 
840 and 848) recorded by the relay in the PSCAD model exceed the plot limits. To get a location estimate, the profiles have been linearly extended till an intersection is obtained, as shown in Figure 4.11. For example, consider bus 848. The actual positive-sequence reactance from the relay at bus 812 to bus 848 is 6.28 ohms. For a fault at bus 848 , the fault current recorded by the relay exceeds the plot limits and hence, by linear extrapolation of the profile, the estimated reactance is found to be $7.86 \mathrm{ohms}$. However, this estimate obtained exceeds the total reactance of the feeder. Under such circumstances, the repair personnel should investigate the area at the end of the feeder.

Table 4.7: Estimated and Actual Reactance to Fault under Zero Load.

\begin{tabular}{|c|c|c|c|c|c|}
\hline $\begin{array}{c}\text { Fault } \\
\text { Bus }\end{array}$ & $\begin{array}{c}\text { Fault } \\
\text { Current } \\
\text { from } \\
\text { PSCAD } \\
\text { (kA) }\end{array}$ & $\begin{array}{c}\text { Actual } \\
\text { Positive- } \\
\text { sequence } \\
\text { Reactance to } \\
\text { Fault } \\
\text { (ohms) }\end{array}$ & $\begin{array}{c}\text { Estimated } \\
\text { Positive- } \\
\text { sequence } \\
\text { Reactance to } \\
\text { Fault } \\
\text { (Ohms) }\end{array}$ & $\begin{array}{c}\text { Error } \\
\text { (\%) }\end{array}$ & $\begin{array}{c}\text { Path of } \\
\text { Fault } \\
\text { Location }\end{array}$ \\
\hline 850 & 2.7280 & 0.52 & 0.50 & 3.85 & $\begin{array}{c}1,2,3,4,7 \\
5,6,7\end{array}$ \\
\hline 818 & 2.2735 & 0.73 & 0.75 & 3.31 & 1 \\
\hline 822 & 1.1808 & 1.72 & 1.88 & 9.30 & 1 \\
\hline 854 & 1.6349 & 1.83 & 2.09 & 14.21 & $3,4,5,6,7$ \\
\hline 834 & 1.0993 & 3.40 & 4.33 & 27.35 & $4,6,7$ \\
\hline 844 & 0.8550 & 4.76 & 6.27 & 31.72 & 7 \\
\hline 840 & 0.7461 & 5.67 & 7.10 & 25.22 & 6 \\
\hline 848 & 0.6854 & 6.28 & 7.86 & 25.16 & 7 \\
\hline
\end{tabular}




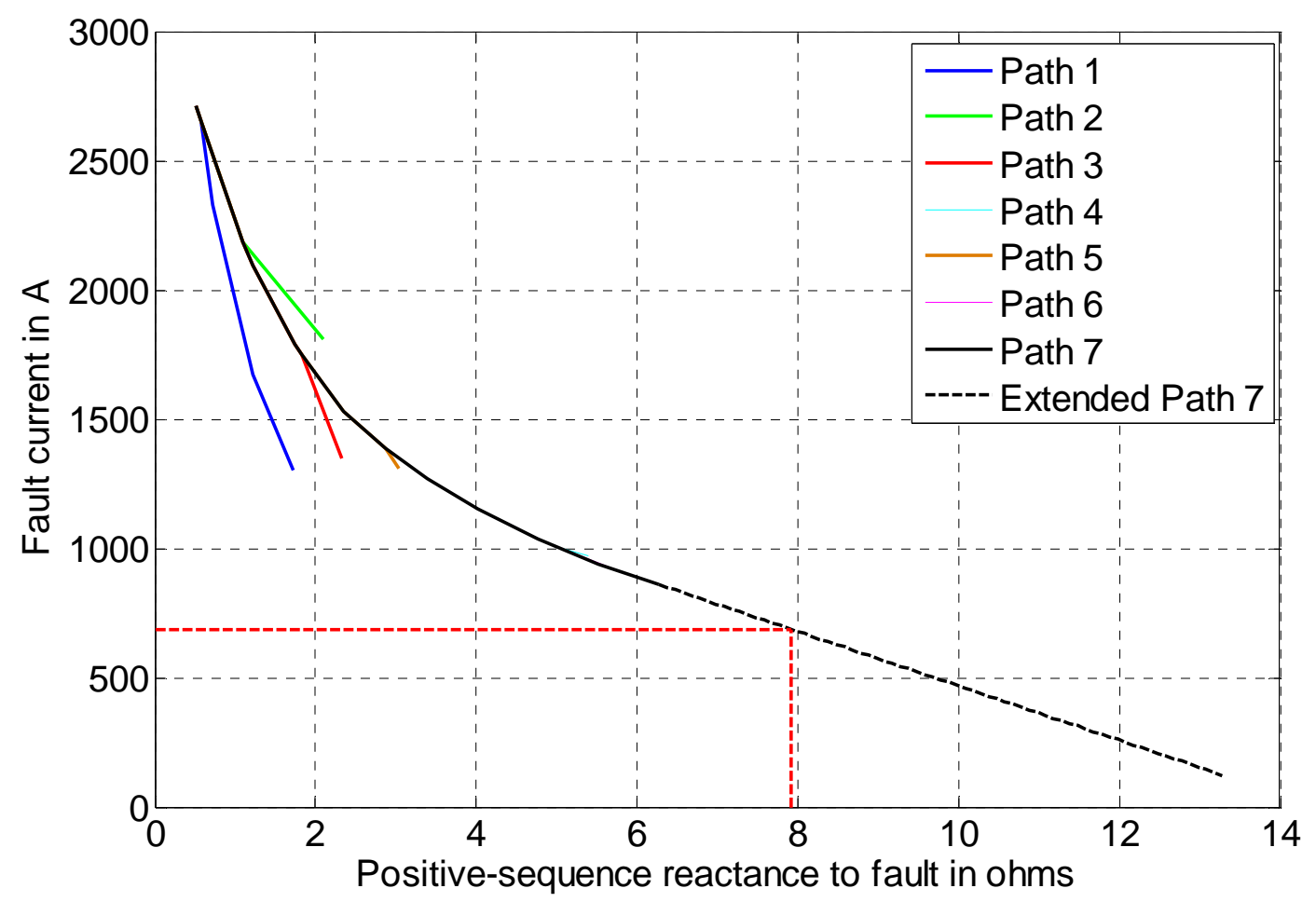

Figure 4.11: Current Profile Extended for Fault Currents in Real World Exceeding Plot Limits.

Figure 4.12 illustrate the error percentages. The error percentages increase with distance from the monitoring location. However, as compared to the peak load case, the error in estimation is lower. 


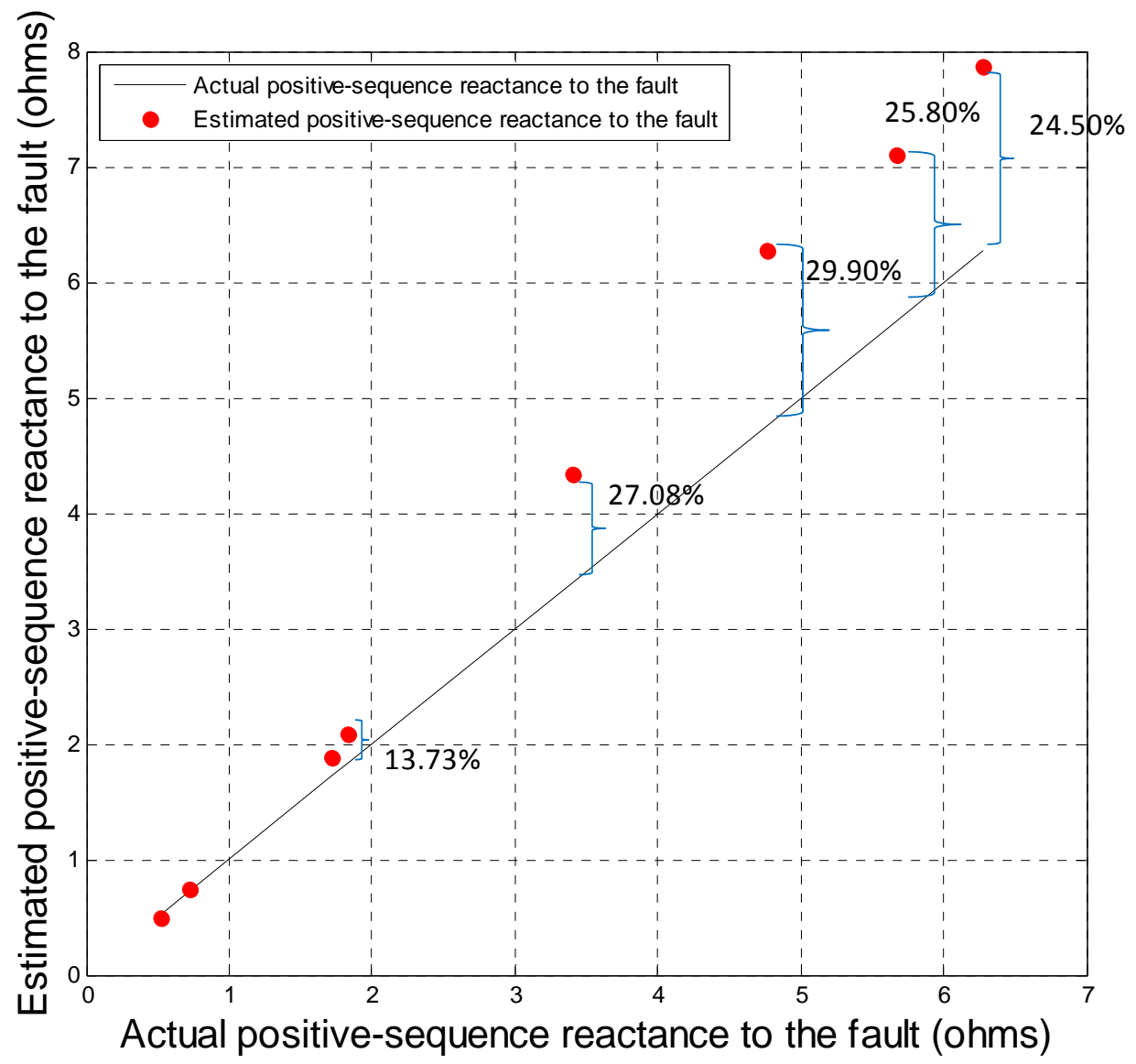

Figure 4.12: Comparison of Estimated versus Actual Positive-sequence Reactance to Fault under Zero Load.

\section{Complementing Estimates from Impedance-based Methods using Short-circuit Fault Current Profile Approach}

In this Section, estimates obtained from impedance-based methods and shortcircuit fault current profile approaches are used together to identify a range in which the fault may be located in.

Reactance estimates using impedance-based methods are tabulated along with estimates obtained using short-circuit fault current profile approach, as shown in Table 4.8. Next the median value of all the estimates is calculated. 
Table 4.8: Computing Median of all Estimates.

\begin{tabular}{|c|c|c|c|c|c|}
\hline $\begin{array}{c}\text { Fault } \\
\text { Bus }\end{array}$ & $\begin{array}{c}\text { Actual } \\
\text { Positive- } \\
\text { sequence } \\
\text { Reactance } \\
\text { (ohms) }\end{array}$ & $\begin{array}{c}\text { Takagi } \\
\text { Method } \\
\text { (ohms) }\end{array}$ & $\begin{array}{c}\text { Positive- } \\
\text { sequence } \\
\text { Reactance } \\
\text { Method } \\
\text { (ohms) }\end{array}$ & $\begin{array}{c}\text { Short-circuit } \\
\text { Fault Current } \\
\text { Profile } \\
\text { (ohms) }\end{array}$ & $\begin{array}{c}\text { Median } \\
\text { (ohms) }\end{array}$ \\
\hline 850 & 0.52 & 0.49 & 0.53 & 0.50 & 0.50 \\
\hline 818 & 0.73 & 0.82 & 0.83 & 0.75 & 0.82 \\
\hline 822 & 1.72 & 2.50 & 2.26 & 1.88 & 2.26 \\
\hline 854 & 1.83 & 1.80 & 1.83 & 2.09 & 1.83 \\
\hline 834 & 3.40 & 3.36 & 3.39 & 4.33 & 3.39 \\
\hline 844 & 4.76 & 4.72 & 4.75 & 6.27 & 4.75 \\
\hline 840 & 5.67 & 5.60 & 5.62 & 7.10 & 5.62 \\
\hline 848 & 6.28 & 6.22 & 6.24 & 7.86 & 6.24 \\
\hline
\end{tabular}

As seen in Table 4.9, the median is found to be very close to the actual distance to the fault. A maximum error of 0.54 miles is observed. If a 0.6 mile radius is built around the median estimate, the fault will lie within that range, as seen from Table 4.9. 
Table 4.9: Error Percentage of the Median Estimate is Close to the Actual Fault Location.

\begin{tabular}{|c|c|c|c|c|}
\hline $\begin{array}{c}\text { Fault } \\
\text { Bus }\end{array}$ & $\begin{array}{c}\text { Actual Positive- } \\
\text { sequence Reactance } \\
\text { (ohms) }\end{array}$ & $\begin{array}{c}\text { Median } \\
\text { (ohms) }\end{array}$ & $\begin{array}{c}\text { Error } \\
\text { (\%) }\end{array}$ & $\begin{array}{c}\text { Path of Fault } \\
\text { Location }\end{array}$ \\
\hline 850 & 0.52 & 0.50 & 3.85 & $1,2,3,4,5,6,7$ \\
\hline 818 & 0.73 & 0.82 & 12.95 & 1 \\
\hline 822 & 1.72 & 2.26 & 31.40 & 1 \\
\hline 854 & 1.83 & 1.83 & 0.00 & $3,4,5,6,7$ \\
\hline 834 & 3.40 & 3.39 & 0.29 & $4,6,7$ \\
\hline 844 & 4.76 & 4.75 & 0.21 & 7 \\
\hline 840 & 5.67 & 5.62 & 0.88 & 6 \\
\hline 848 & 6.28 & 6.24 & 0.64 & 7 \\
\hline
\end{tabular}

\section{SUMMARY}

In this Chapter, impedance-based methods and short-circuit fault current profile approach were used together to locate faults simulated in the IEEE 34 Node Test Feeder under full load and zero load condition. For a fault on the same bus and using the same line impedance parameters, impedance-based methods were more accurate under zero load condition as compared to the full load condition. The short-circuit fault current profile approach gave accurate estimates for faults close to the monitoring location. For faults at the farthest laterals, the accuracy was affected since the circuit model in OpenDSS was not a true representation of the test feeder in PSCAD. The fault current in the real world (PSCAD) was lower than the short-circuit fault current at the farthest bus 
in the OpenDSS model. Hence, to obtain an intersection, the profile was linearly extended. However, error percentage was high and hence the lesson learnt from this analysis is that the short-circuit fault current profile approach should not be used under such circumstances.

In an effort to improve location estimates, estimates from impedance-based methods and short-circuit fault current profile approach were used to calculate a median estimate. It was observed that the median was close to actual fault location. Moreover if a 0.6 mile radius is built around that estimate, the fault will be contained in that range. Most likely, the fault has occurred in one of the equipments lying in that range. This is how the utility can effectively track down a fault. Now the IEEE 34 Node Test Feeder represents a typical distribution feeder and has also been modeled to represent the worst case scenario, i.e. load current is around $51 \%$ of the fault current for the farthest bus. Hence the 0.6 mile radius around the median estimate will hold true for most distribution feeders and will be used when computing the fault range for field case events in Chapter 5. 


\section{APPLICATION OF THE SHORT-CIRCUIT FAULT CURRENT PROFILE APPROACH AND IMPEDANCE-BASED METHODS ON FIELD DATA}

Fault location estimates can be improved by using the short-circuit fault current profile approach together with impedance-based methods, as discussed in Chapter 3 and demonstrated using the modified IEEE 34 Node Test Feeder in Chapter 4. In this Chapter, the above approach is validated against four fault event data provided by the utilities. All the fault datasets have the voltage and current waveforms recorded by the relay. Additionally, the relay has a fault event log which provides the summary of the fault with the maximum recorded current magnitude in each phase.

It is observed that the median estimate calculated from the short-circuit fault current profile approach as well as the impedance-based methods is very close to the actual fault location and the fault is contained in the 0.6 mile radius built around the median estimate. For some events, the voltage waveform recorded by the relay was not useful for analysis. Hence, only the short-circuit fault current profile approach could be used to determine fault location. Estimates were accurate provided the circuit model accurately represented the distribution feeder.

\subsection{UtiLity A}

Utility A circuit model was constructed using OpenDSS, as shown in Figure 5.1. The utility considers this to be a high tech circuit. At about every 1000 feet the line is protected by arrestors which are also fused with either fault tamers or cutouts with current-limiting fuses. There is also a static line which is grounded to the neutral on every pole. This circuit does not serve many customers, and there are no overhead transformers 
on the main line. There are two three-phase tap lines and three three-phase underground dips off of the main line. These dips are protected by electronic reclosers. One of the tap lines serves an underground loop protected by $200 \mathrm{e}$ fuses. The rated voltage at the substation is $23.9 \mathrm{kV}$, while the short-circuit capacity calculated using the circuit model is 239 MVA. An SEL-351S relay present at the substation monitors the system voltage and current for line protection. The relay samples the three-phase line currents and the line-to-neutral voltages at a rate of 16 samples per cycle.

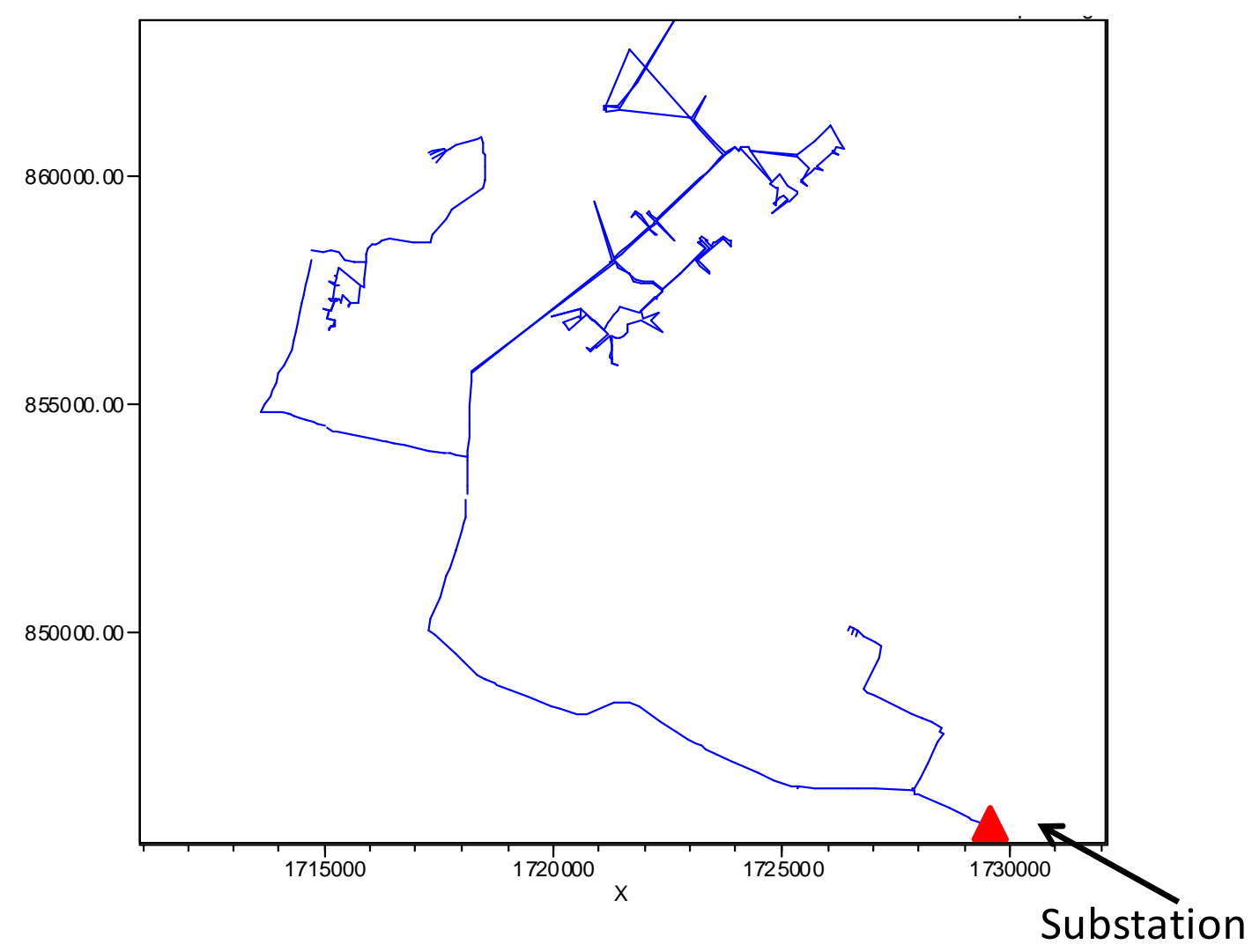

Figure 5.1: Utility A Circuit in OpenDSS.

On $16^{\text {th }}$ June, 2010 at 8:45 pm, several industrial customers called in to complain about a momentary outage. The voltage and current waveforms for this momentary single 
line-to-ground fault on phase $\mathrm{C}$ were recorded by the relay and are shown in Figure 5.2. The fault event $\log$ of the relay is shown in Figure 5.3. From the relay data, the prefault load current is about $200 \mathrm{~A}$. On the other hand, the maximum fault current magnitude recorded by the relay is $1907 \mathrm{~A}$. When investigated, the cause of the momentary interruption was found to be one of the lightning arrestors, which was severely damaged in several places. The cause of the fault was due to squirrel contact. The arrestor did not have a squirrel guard.

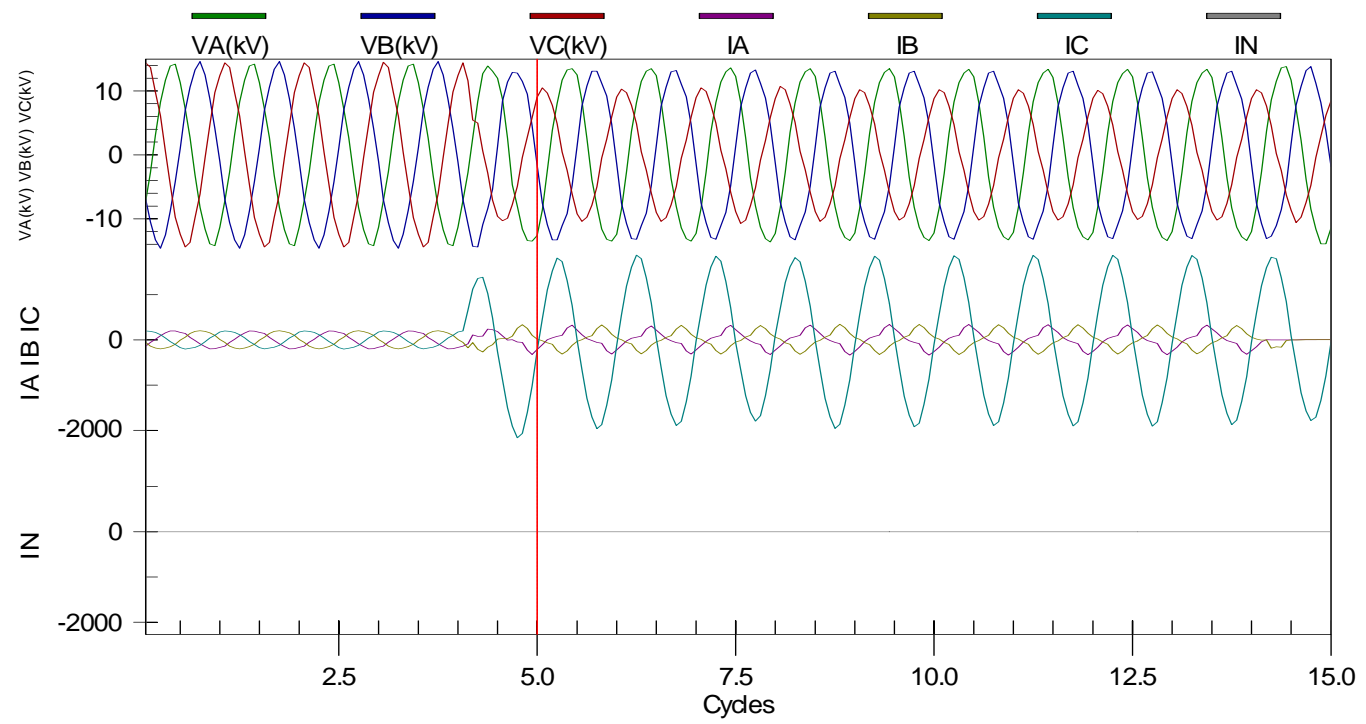

Figure 5.2: Voltage and Current Waveforms Recorded by the Relay During Fault.

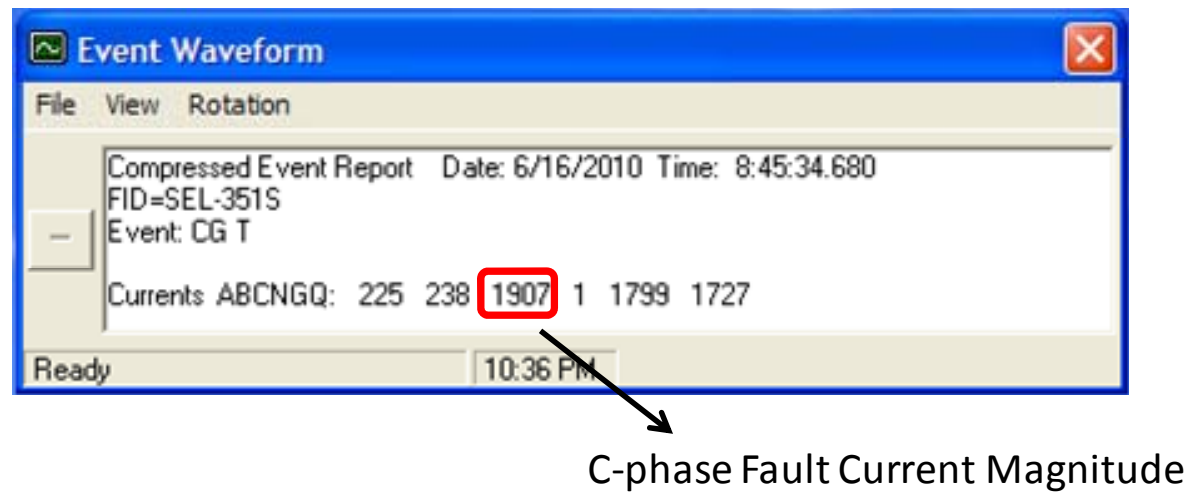

Figure 5.3: Fault Event Log of the Relay 


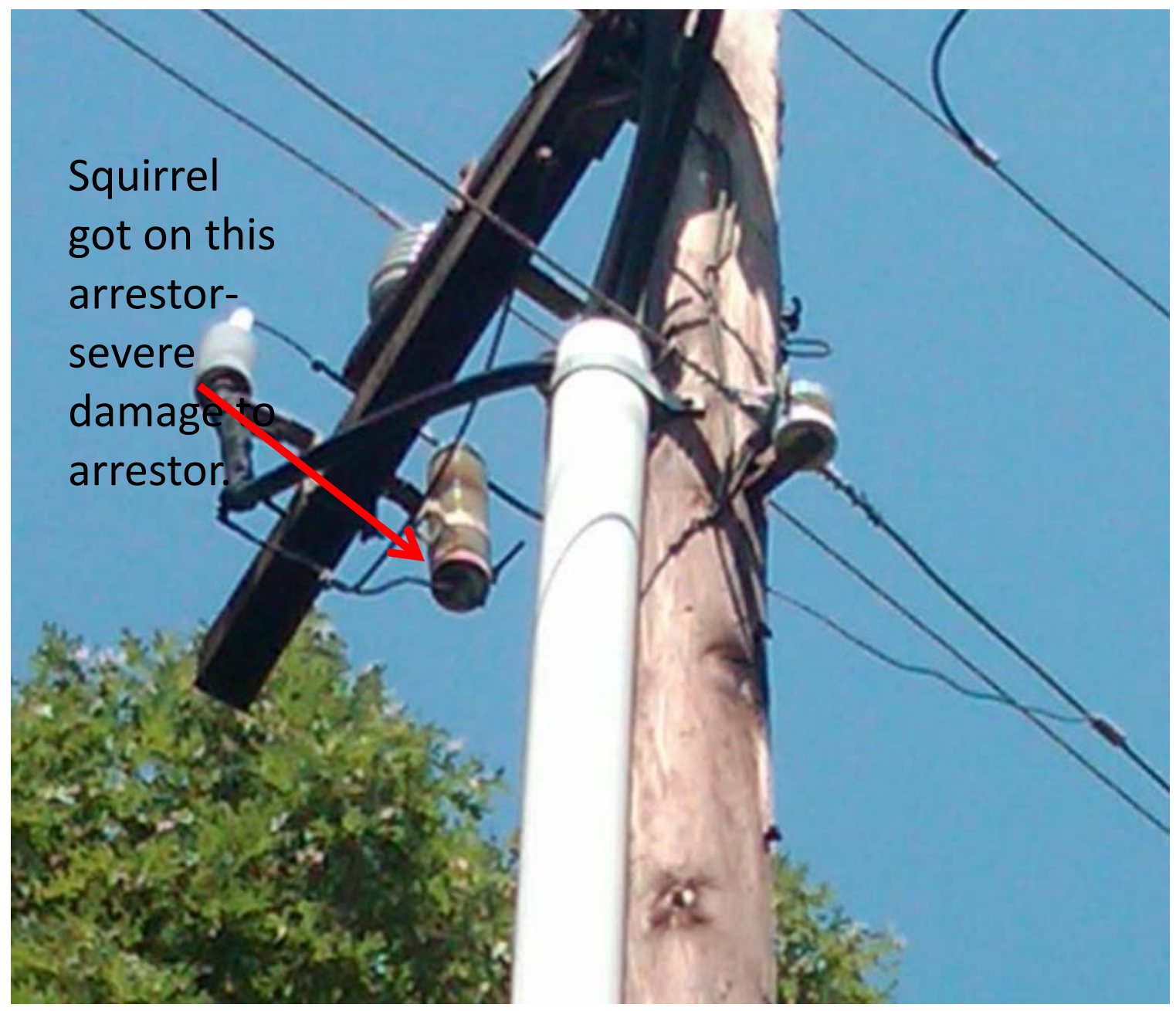

Figure 5.4: The Faulted Lightning Arrestor

Since the utility is aware of the location of the fault, distance to fault from the substation is known to be 5.33 miles. The exact location of the fault is shown in Figure 5.5. Using strategies outlined in Chapters 3 and 4, the location of the fault will be estimated using impedance-based methods and short-circuit fault current profile approach. 


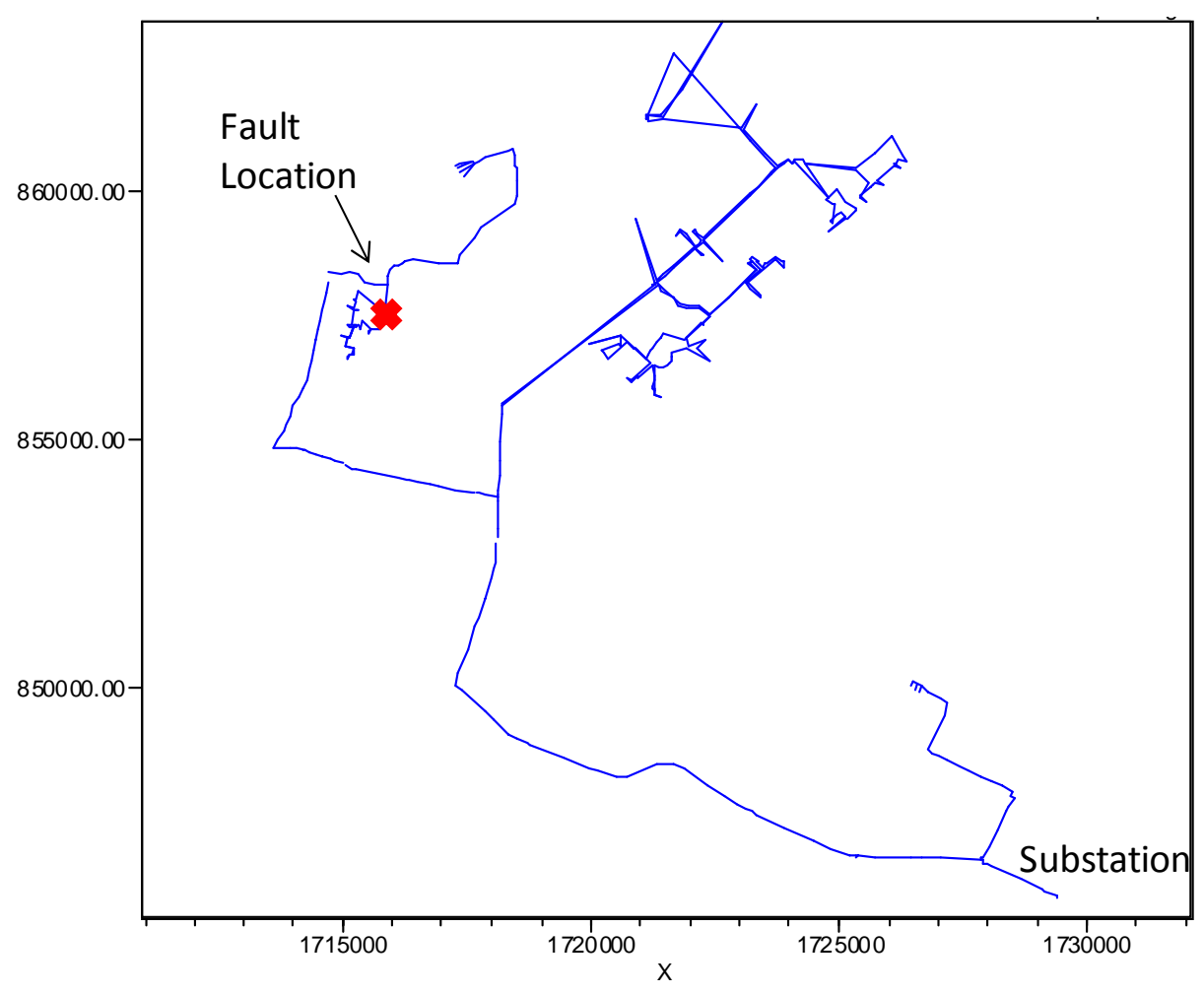

Figure 5.5: Fault Location on the Distribution Feeder.

\subsubsection{Estimation using Impedance-based Methods}

Takagi and positive-sequence reactance methods are used for estimating the distance to fault. As seen from Chapter 2, data requirement of these algorithms are voltage and current phasors during fault as well as prefault current which can be obtained by sampling the voltage and current waveform recorded by the relay and are given as:

$$
\begin{aligned}
I_{\text {phasor }} & =1.87 \angle-93.9^{\circ} \mathrm{kA} \\
V_{\text {phasor }} & =9.98 \angle-28.8^{\circ} \mathrm{kV} \\
I_{\text {prefault }} & =0.20 \angle-34.37^{\circ} \mathrm{kA}
\end{aligned}
$$

The impedance-based methods also need positive- and zero-sequence line impedance per unit length which can be obtained from the line configuration details available in the circuit model of the feeder. The distribution feeder is non-homogenous and the ten 
different line configurations are summarized in Table 5.1. The most commonly occurring conductor configuration in the circuit is code number 2, i.e. "56-556-ACSR-HW, 556ACSR-HW, 556-ACSR-HW, 336-ACSR-HW”, whose positive- and zero-sequence impedances are $z_{1}=0.1680+j 0.6218 \Omega /$ mile and $z_{0}=0.4372+j 1.9305 \Omega / \mathrm{mile}$, respectively. These line parameters are used for the purpose of fault location.

Table 5.1: Line Configuration Types in Utility A Circuit.

\begin{tabular}{|c|c|}
\hline $\begin{array}{c}\text { Code } \\
\text { Number }\end{array}$ & Line Configuration Code \\
\hline 1 & 28-556-acsr-hw556-acsr-hw556-acsr-hw336-acsr-hw \\
\hline 2 & $56-556-$ acsr-hw556-acsr-hw556-acsr-hw336-acsr-hw \\
\hline 3 & $34-556-a a c-h w 556-a a c-h w 556-a a c-h w 336-a a c$ \\
\hline 4 & $56-556-a a c-h w 556-a a c-h w 556-a a c-h w 336-a a c$ \\
\hline 5 & $28-336-a a c 336-a a c 336-a a c 336-a a c$ \\
\hline 6 & $56-2-a c s r 2-a c s r 2-a c s r 2-a c s r$ \\
\hline 7 & $54-2-a c s r 2-a c s r 2-a c s r 2-a c s r$ \\
\hline 8 & $34-2-a c s r 2-a c s r 2-a c s r 2-a c s r$ \\
\hline 9 & $56-336-a a c 336-a a c 336-a a c 1 / 0-a c s r$ \\
\hline 10 & $40-336-a a c 336-a a c 336-a a c 336-a a c$ \\
\hline
\end{tabular}

Takagi method then estimates the distance to be 4.82 miles. Similarly, the positive-sequence reactance method estimates the distance to be 4.75 miles. The branch or lateral in which the fault may be located could not be determined. 


\subsubsection{Estimation using Short-circuit Fault Current Profile Approach}

The short-circuit fault current profile is built using the circuit model available in OpenDSS. The prefault load current recorded by the SEL relay is 200A. To determine the load level in the distribution feeder, a load flow analysis was conducted on the OpenDSS circuit model. The full load current was found to be $400 \mathrm{~A}$, indicating that at the time of fault, the distribution feeder was operating at half-load condition. Hence, to determine fault location, the short-circuit fault current profile should be built under half load condition. Loads in the circuit model are switched off till the desired load level is achieved. From the prefault current seen by the SEL relay, no information regarding which loads were switched off in the real world are available. Hence, in the circuit model, any load is switched off. As seen in Chapter 3, this inaccuracy will not lead to significant error.

Next, to build the fault current profile, four paths have been identified as shown in Figure 5.6. The plot of the short-circuit fault current versus the positive-sequence reactance is shown in Figure 5.7. The fault current magnitude of 1907 A when interpolated on the current profile intersects paths 2 and 3 at positive-sequence reactance value of $2.58 \Omega$ and $2.79 \Omega$. This corresponds to distances of 4.5 and 6.22 miles from the substation along paths 2 and 3 respectively. Hence there are two possible locations, where the fault might be located. 


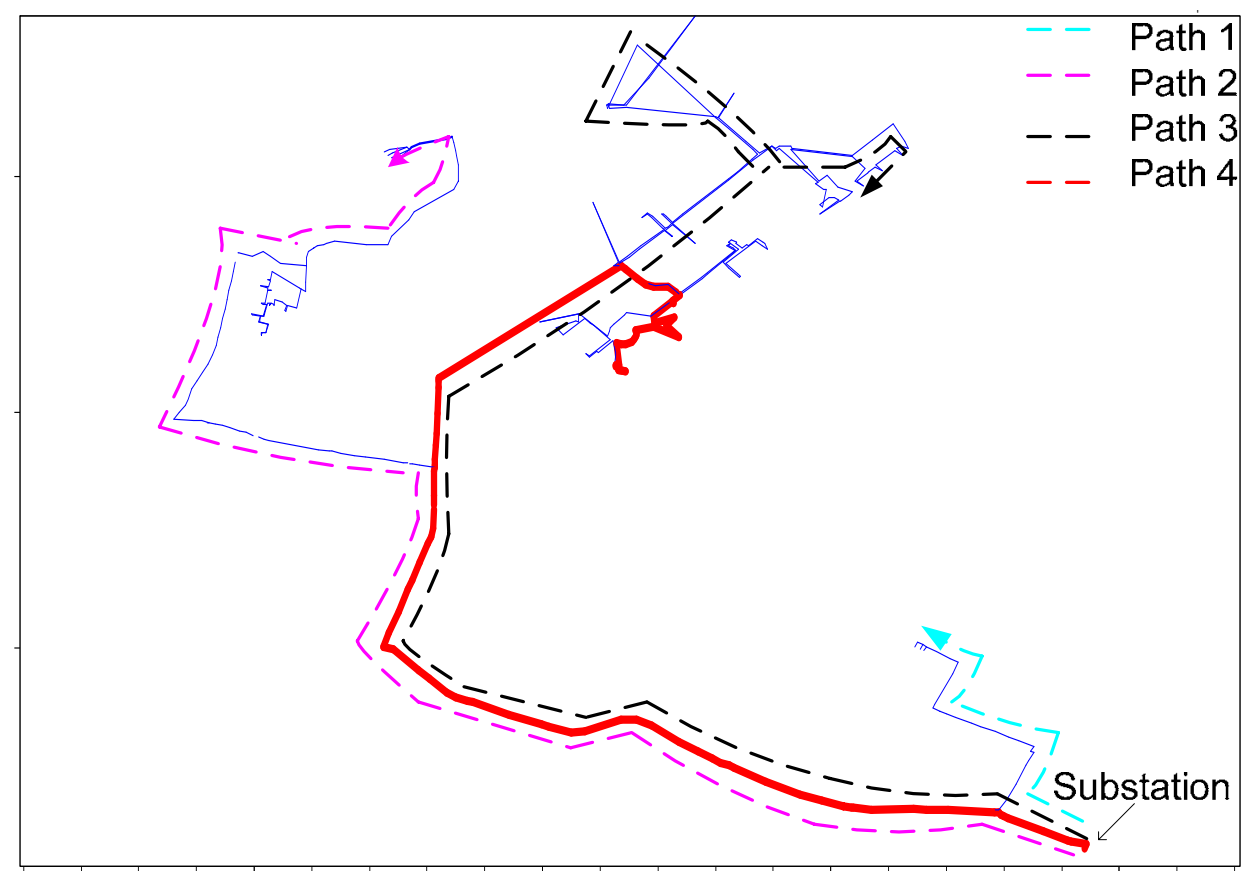

Figure 5.6: Paths for Building the Fault Current Profile.

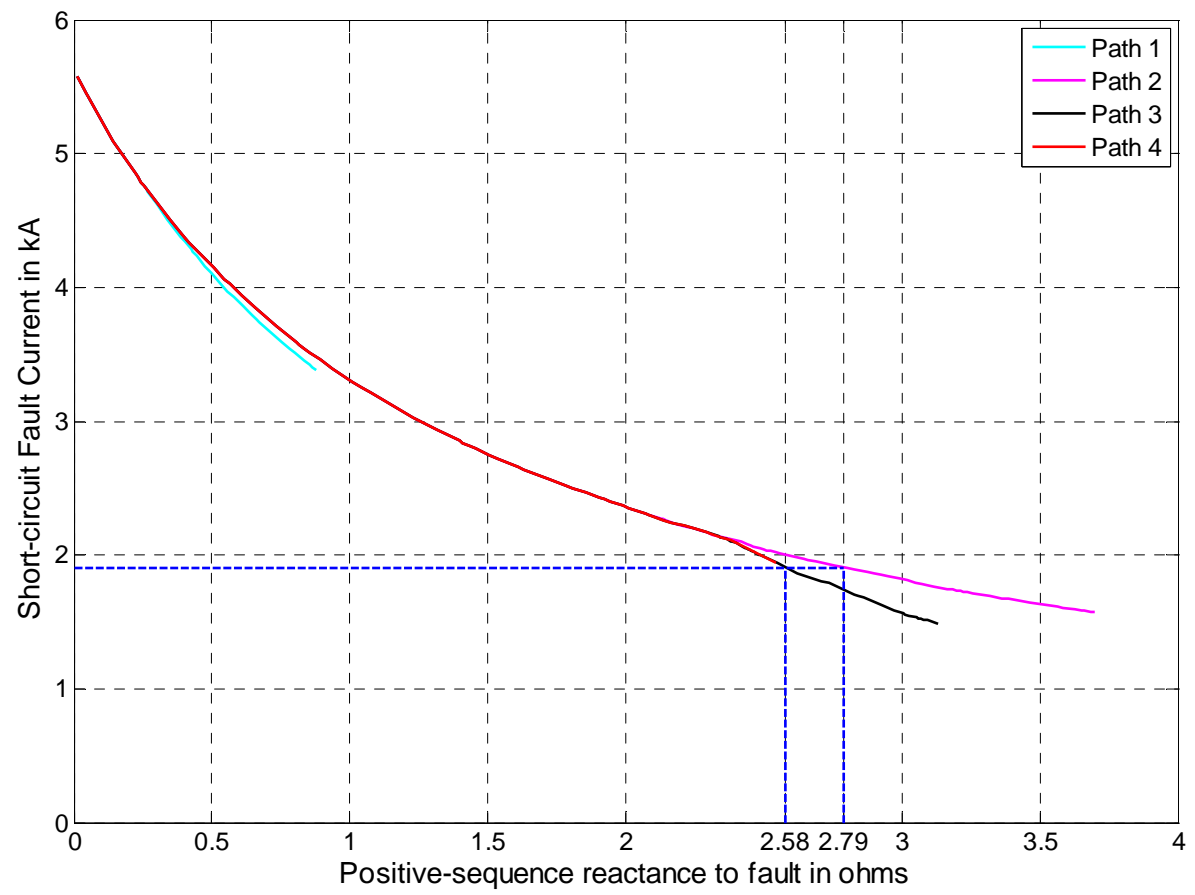

Figure 5.7: Utility A Short-circuit Fault Current Profile. 


\subsubsection{Complementing Estimates from Impedance-based Methods using Short-circuit Fault Current Profile Approach}

Takagi and positive-sequence method estimate the distance of the fault to be 4.8 miles from the substation. Short-circuit fault current profile estimates the fault location to be either 4.5 miles on path 2 or 6.22 miles on path 3 . The estimate of 4.5 miles on path 2 matches closely to that estimated from impedance-based methods and hence is identified as the possible fault location. Now a median of the estimates from Takagi, positivesequence and short-circuit fault current profile is calculated to be 4.75 miles. As in Chapter 4, a 0.6 mile radius is built around the median value of the location estimates. Hence, the fault is estimated to be at $4.75 \pm 0.6$ miles from the substation along path 2 . The actual location is 5.33 miles along path 2 and is contained within the $4.75 \pm 0.6$ mile radius.

\subsection{UTILITY B}

Utility B circuit model was constructed using OpenDSS and is shown in Figure 5.8. The rated voltage at the substation is $34.5 \mathrm{kV}$. A SEL-651R relay is present at the substation for line protection. The relay samples the three-phase line currents and the line-to-neutral voltages at a rate of four samples per cycle. Three fault events occurring on this circuit are analyzed.

\subsubsection{Event 1}

The first fault event occurs on $2^{\text {nd }}$ August, 2010 at 15:09 hours. It is a C-phase to ground fault with duration of about two cycles. No cause for the fault has been determined. The voltage and current waveforms recorded by the relay recorded voltage and current waveforms for this fault are shown in Figure 5.9. The relay fault event log is shown in Figure 5.10. 


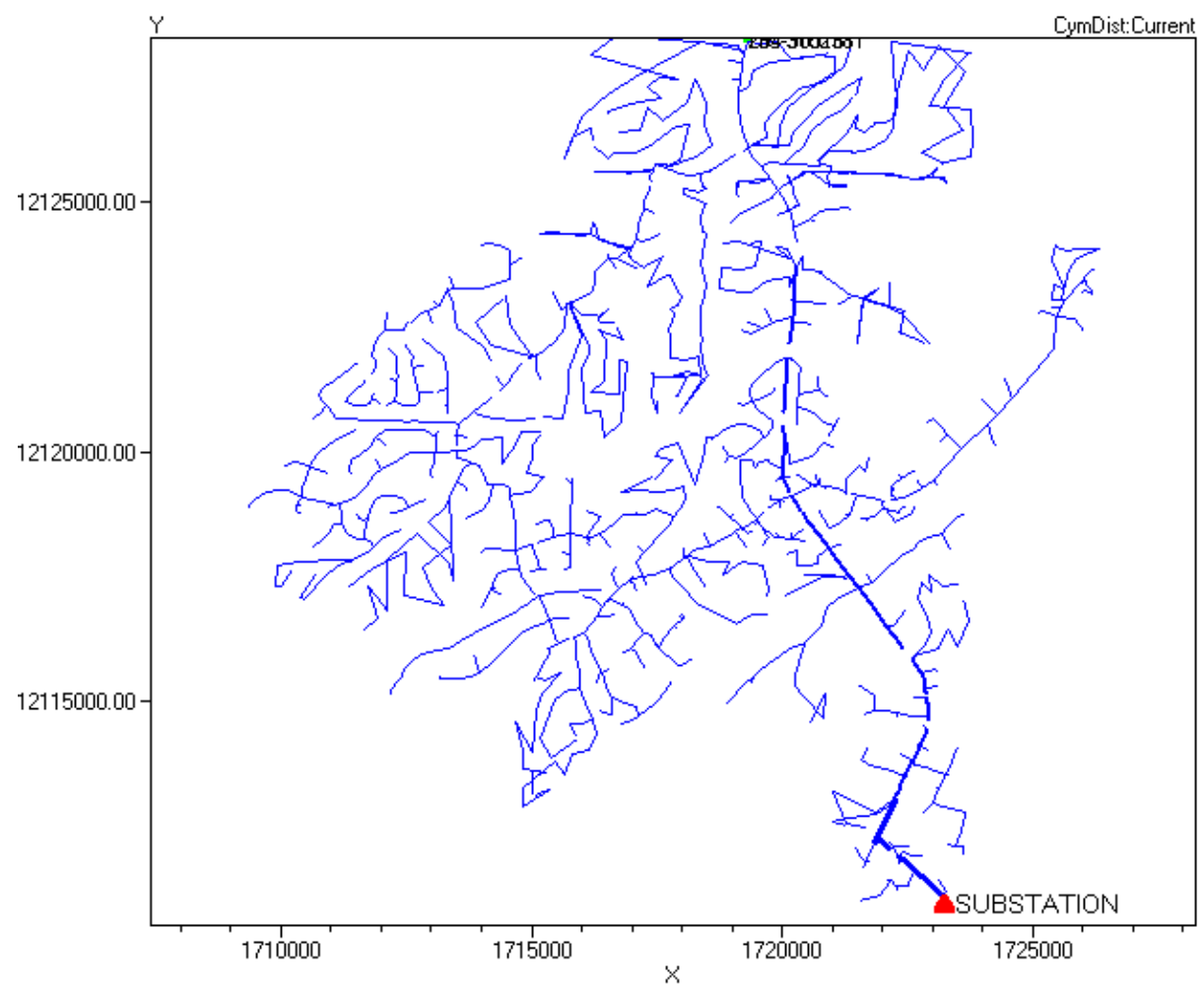

Figure 5.8: Utility B Circuit Model in OpenDSS

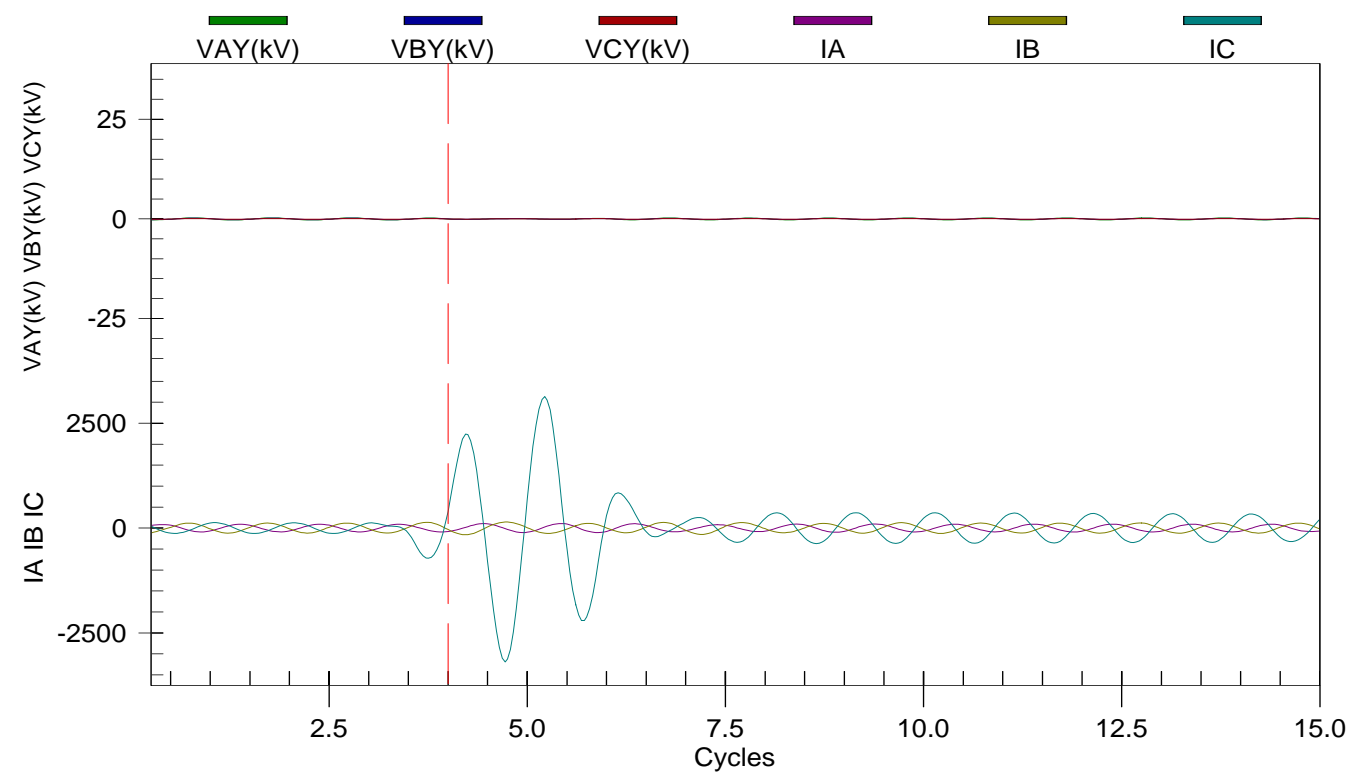

Figure 5.9: Relay Records only Fault Current Waveforms. Voltage Waveforms are Missing. 
Since the location of the faulted equipment is known, as shown in Figure 5.11, the actual location of the fault is known to be 3.07 miles from the substation.

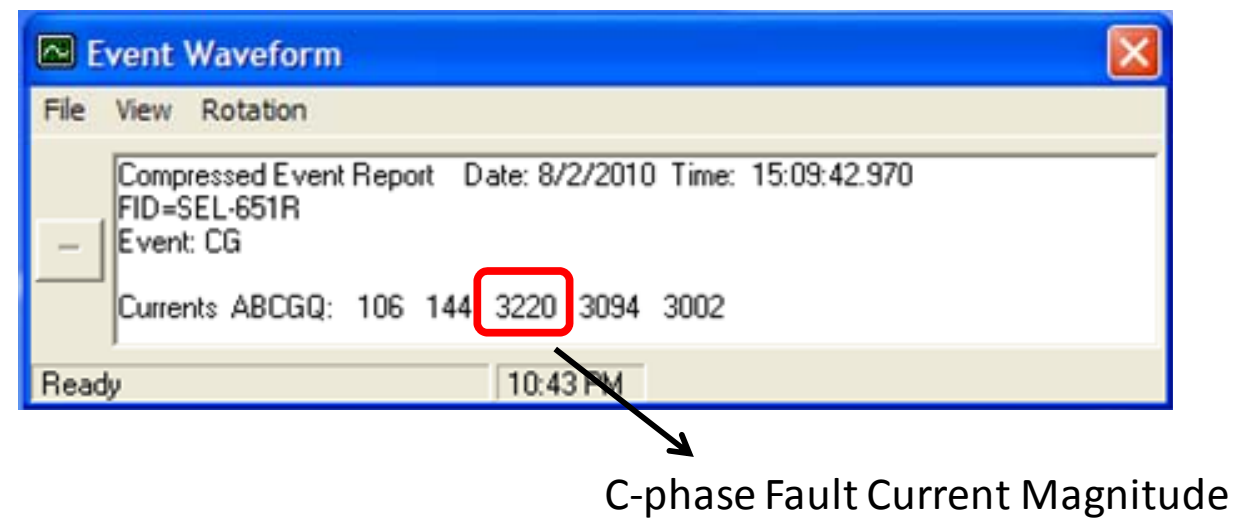

Figure 5.10: Relay Fault Log.

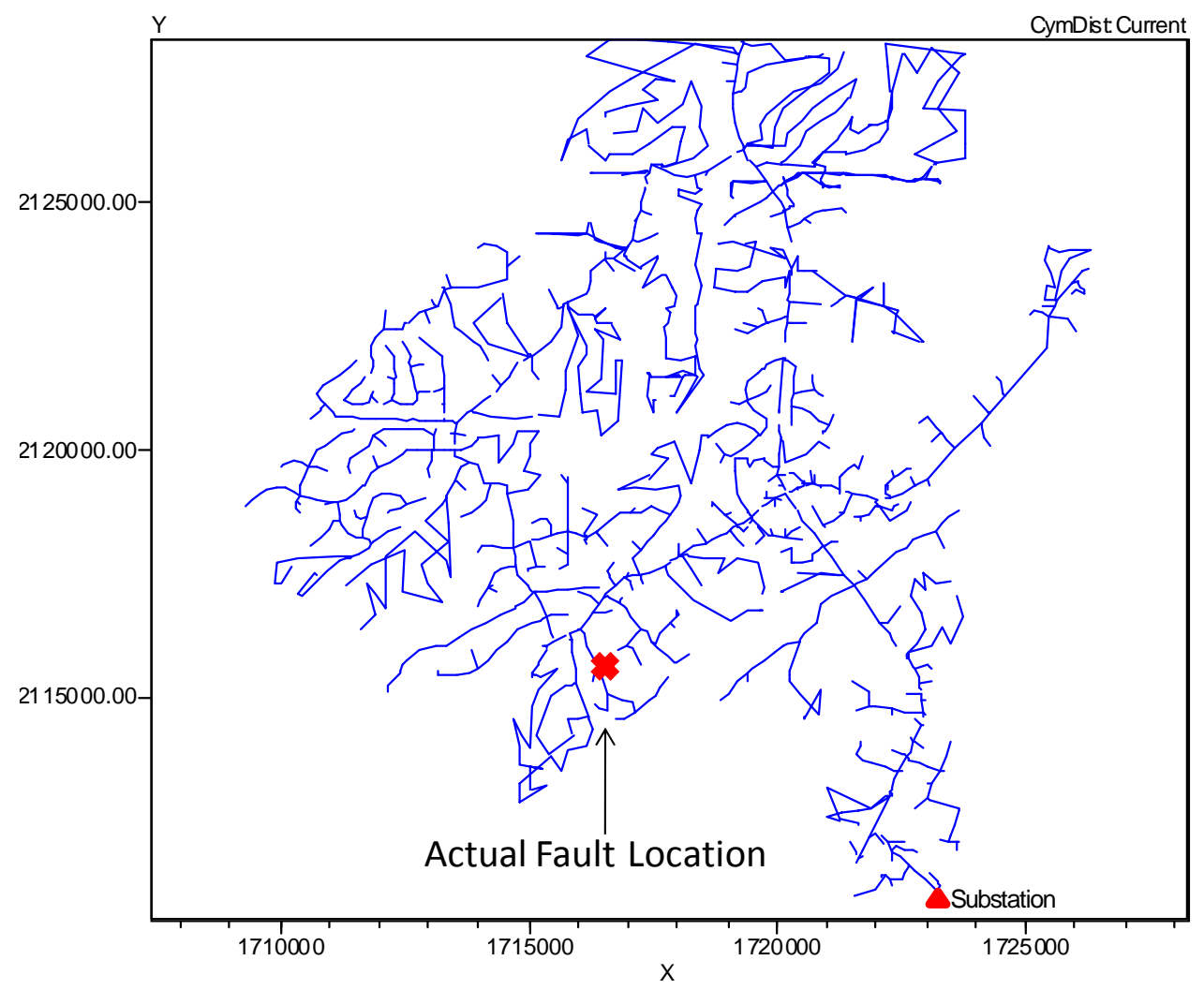

Figure 5.11: Location of the Fault for Event 1. 
As seen from Figure 5.9, the relay records only the current waveform. Voltage waveform data is not useful for analysis. This may be due to malfunction of the voltage transformer or some operational constraint. Whatever the reason may be, voltage waveforms are not available for analysis. Impedance-based methods require both voltage and current phasors to determine distance to fault. Hence Takagi or positive-sequence method cannot be used for fault location. This is the perfect example of the case whereby the utilities can use only short-circuit fault current profile to get a location estimate.

\section{Short-circuit Fault Current Profile Approach}

The maximum fault current magnitude recorded by the relay is 3220 A. Prefault current is 120 A per phase. A load flow analysis was conducted on the circuit model of the distribution feeder in OpenDSS. Full load current is $400 \mathrm{~A}$ per phase. However $120 \mathrm{~A}$ recorded by the SEL relay indicates that the system is operating under one-fourth load condition. To take into account the prefault load current, the current profile should also be built under one-fourth load condition. Loads in the circuit model are switched off till the desired load level is achieved. It should be remembered that from the prefault current recorded by the relay, it is impossible to determine which loads are switched off in the real world. Hence, in the circuit model, any load is switched off to obtain one-fourth load condition.

Now, looking at the circuit model shown in Figure 5.8, there are multiple branches and laterals. Four major paths are identified as shown in Figure 5.12, for building the current profile. The developed fault current profile under one-fourth load

condition is shown in Figure 5.13. The fault current magnitude of 3220 A when interpolated on the current profile correspond to a positive-sequence reactance value of 
$1.625 \Omega$ or 3.14 miles on path $2,1.69 \Omega$ or 3.378 miles on path 3 and $1.763 \Omega$ or 3.352 miles on paths 1 and 4 .

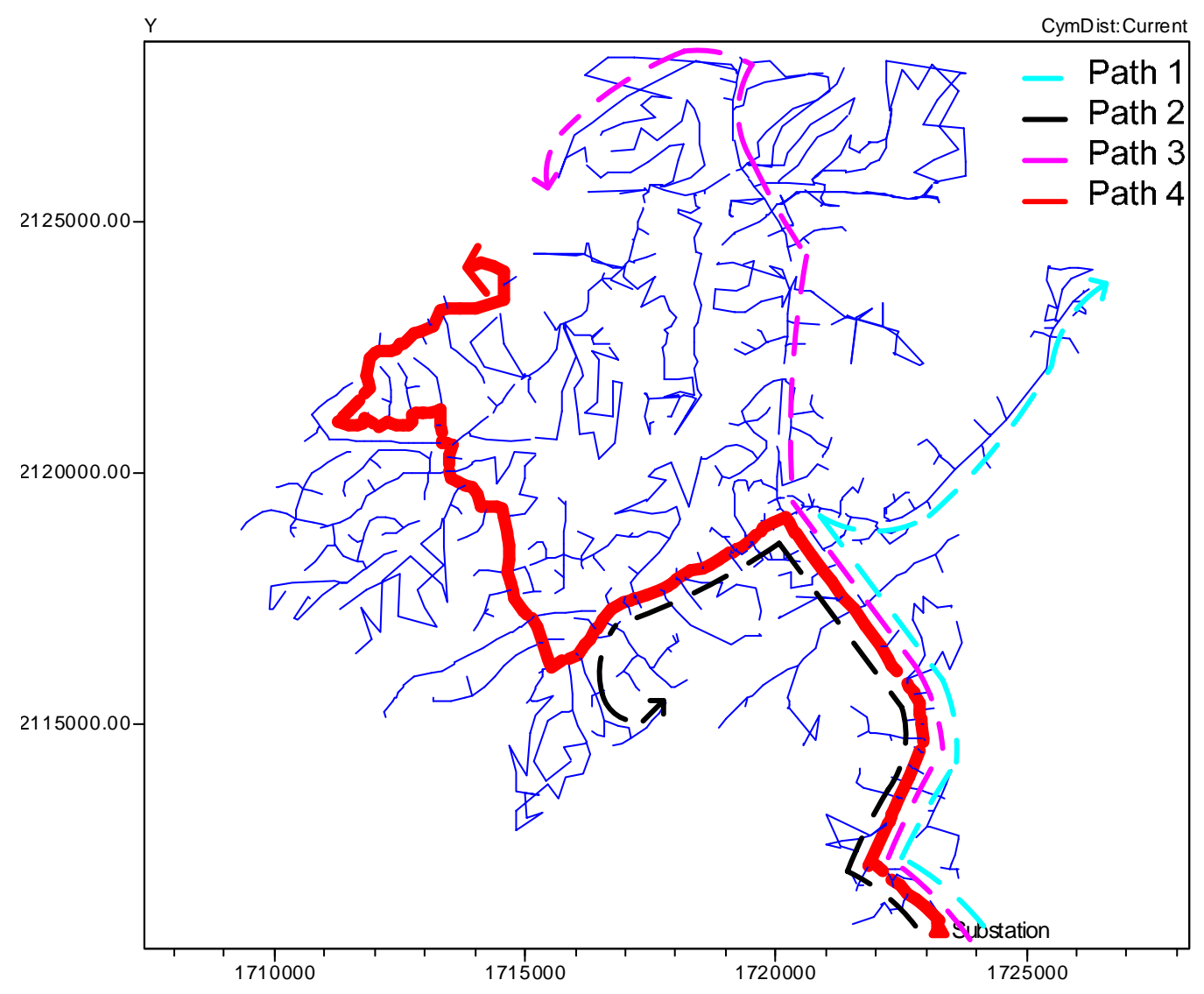

Figure 5.12: Paths for Short-circuit Fault Current Profile.

Now for a fault current magnitude of $3220 \mathrm{~A}$, there are three possible fault locations. Since impedance-based methods cannot be applied, the possible locations cannot be narrowed down. The utility will have to utilize customer outage report or recloser operation status to determine which location has the maximum probability of a fault. The estimate of 3.14 miles on path 2 is reported as the fault location. Actual fault is located on path 2 at a distance of 3.07 miles from the substation. Error in estimation is 0.07 miles or $2.3 \%$ error. 


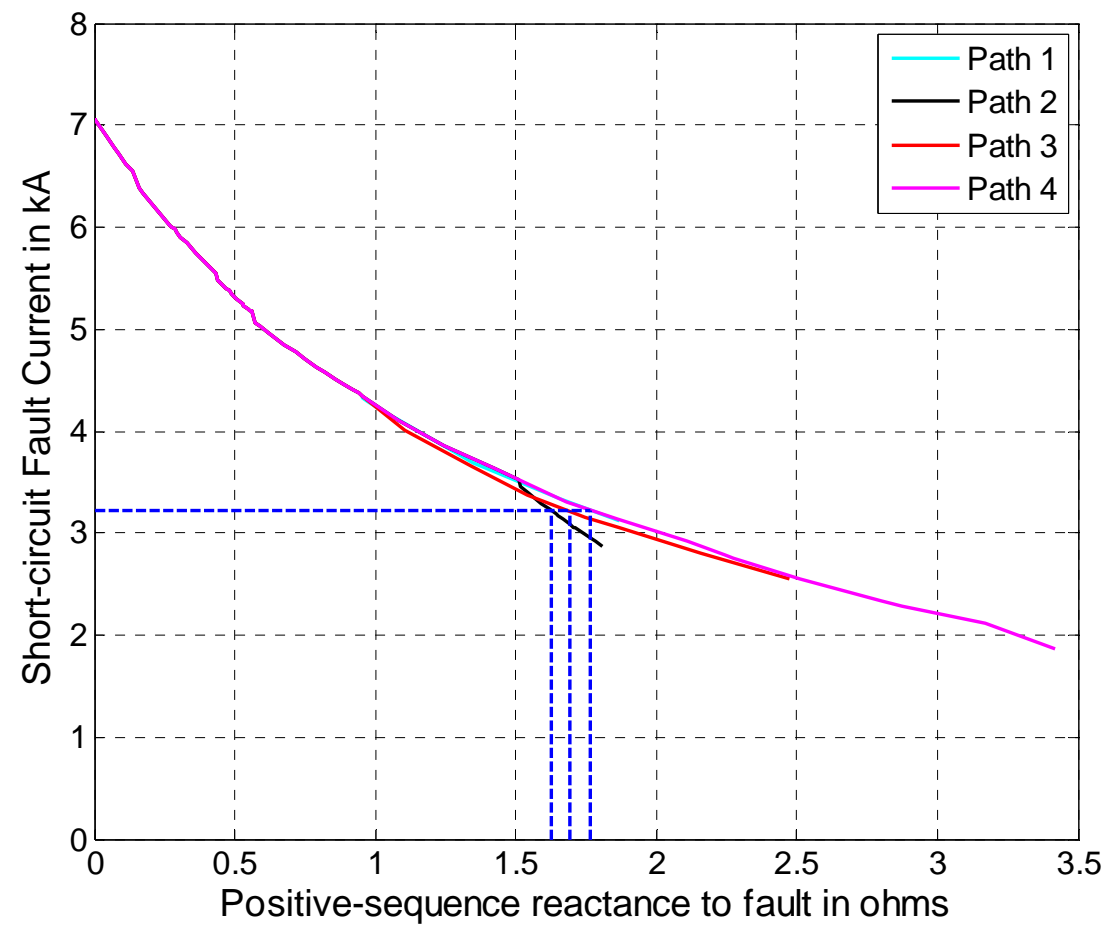

Figure 5.13: Short-circuit Fault Current Profile.

\subsubsection{Event 2}

The second event analyzed occurred on $17^{\text {th }}$ June, 2010 at 17:46 hours. It is a Bphase to ground fault with duration of about two cycles. The fault has occurred in a fuse, which is at a distance of 4.42 miles from the substation. The cause of the fault was due to lightning. Figure 5.14 shows the location of the fault.

The summary of the fault is given by the relay fault event log, as shown in Figure 5.15. The voltage and current waveforms recorded by the relay are shown in Figure 5.16. From the relay data, the prefault load current is about $126 \mathrm{~A}$. On the other hand, the maximum fault current magnitude recorded by the relay is 1014 A. As can be seen from Figure 5.17, the relay has not recorded any voltage data. Hence, impedance-based 
methods which require voltage phasors to determine fault location cannot be used. Only the short-circuit fault current profile approach can be applied to locate the fault.

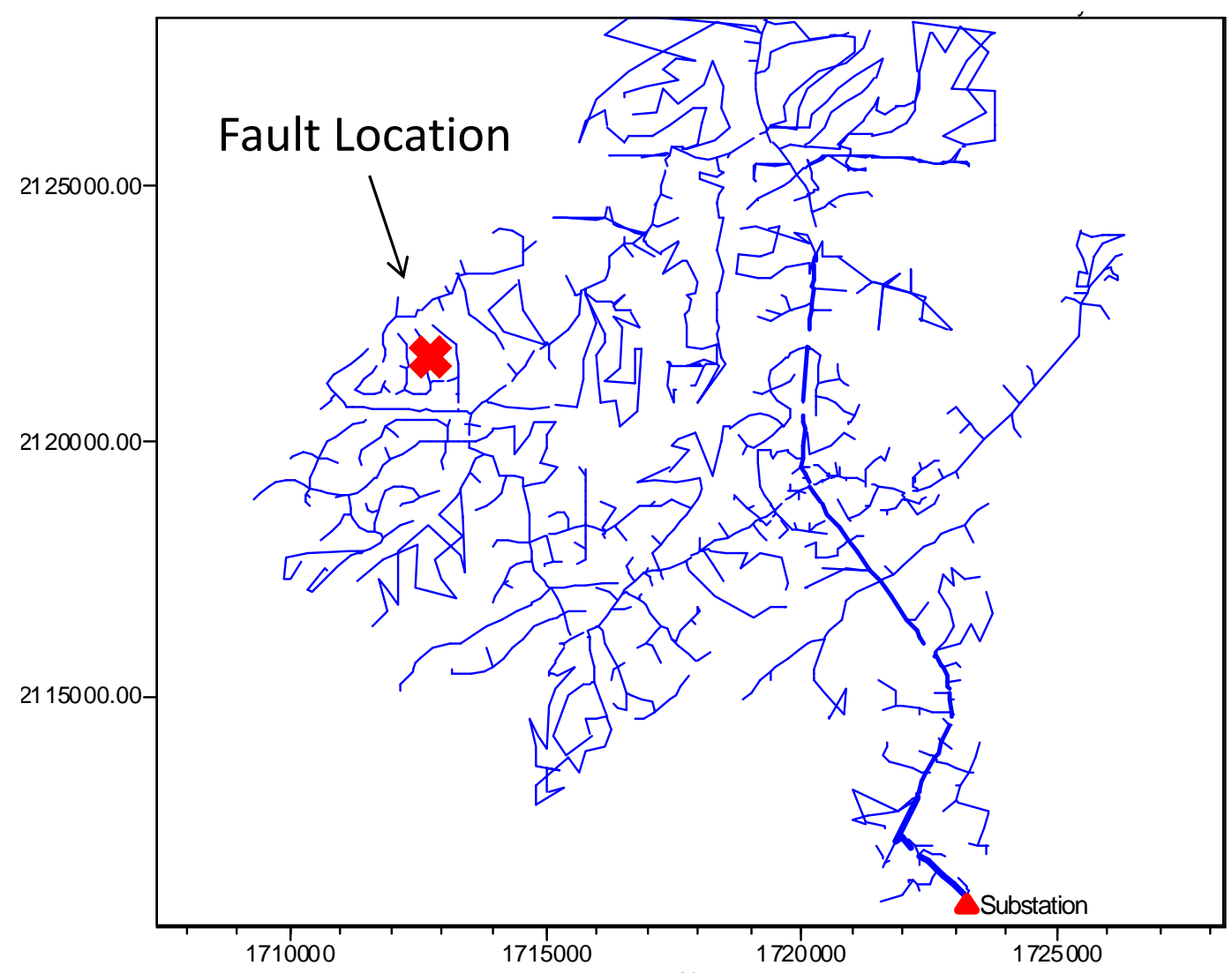

Figure 5.14: Utility B Circuit Model in OpenDSS Indicating Fault Location.

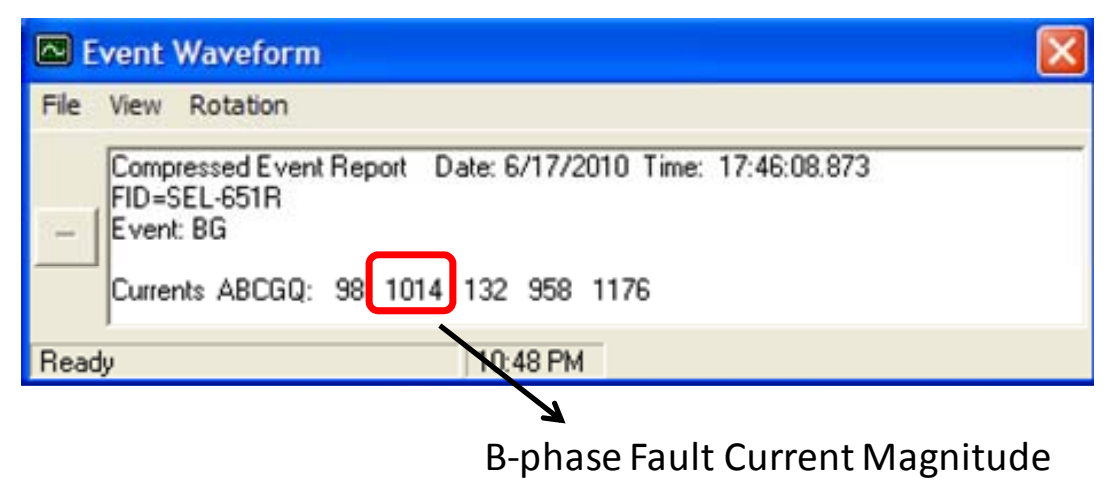

Figure 5.15: Relay Fault Log for Event 2. 


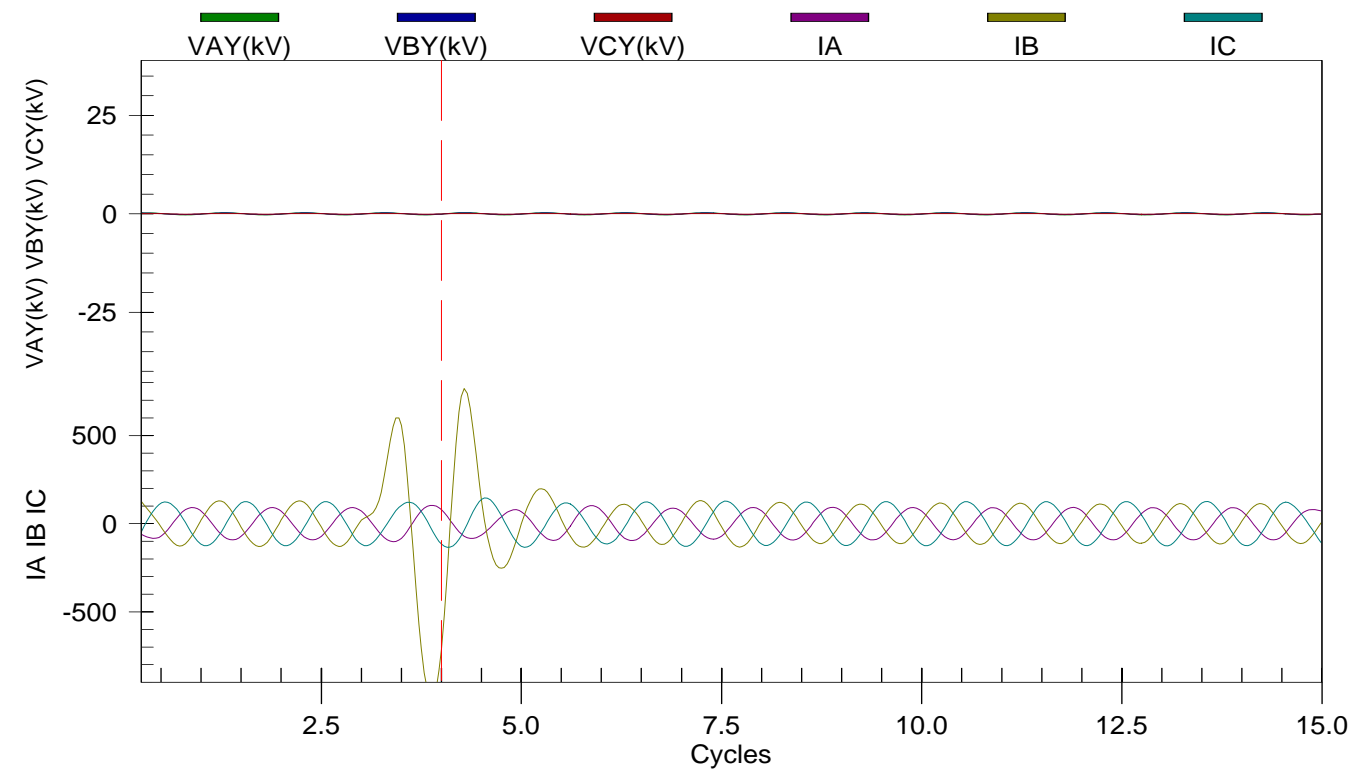

Figure 5.16: SEL Relay records only Current Waveform. Voltage Waveform are Missing.

\section{Short-circuit Fault Current Profile Approach}

The full load current in the circuit model is $400 \mathrm{~A}$, as seen by the load flow analysis carried out on the circuit model in the previous section. Prefault current of $120 \mathrm{~A}$ indicates that before fault, the system was operating under one-fourth load condition. Hence the short-circuit fault current profile developed in the previous section, as shown in Figure 5.13 can be utilized for determining the fault location. Now, when the fault current magnitude of $1014 \mathrm{~A}$ is extrapolated on the current profile, it is seen that this fault current magnitude does not intersect the profile, as shown in Figure 5.17.

As seen from Figure 5.17, the minimum short-circuit fault current from the circuit model is $1864 \mathrm{~A}$ at 5.45 miles from the substation on path 4 . It was previously noted that the maximum fault current recorded by the SEL relay is $1014 \mathrm{~A}$, which lies below this lower threshold of 1864 A. This indicates that the circuit model has not accurately represented the actual distribution feeder. In other words, the circuit model in OpenDSS has modeling errors. In an attempt to address this issue, the current profile is extrapolated 
by using an optimal order polynomial such that it extends to a lower threshold of $1000 \mathrm{~A}$. The extrapolated current profile is shown in Figure 5.18 with a broken line. Using this extrapolated current profile, the positive-sequence reactance to fault for $1014 \mathrm{~A}$ is found to be $4.23 \Omega$ on path 4 . This corresponds to 7.07 miles on path 4 .

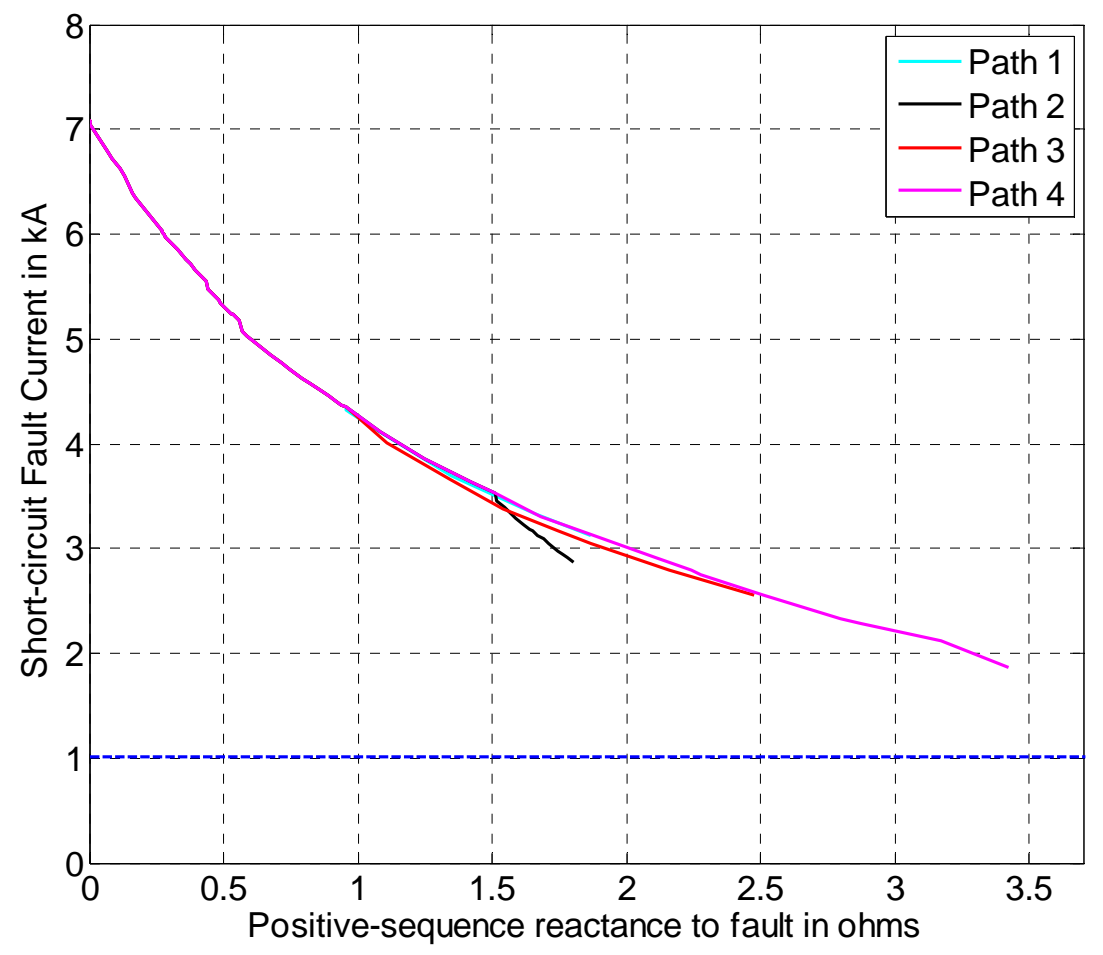

Figure 5.17: Fault Current magnitude of 1014 A does not Intersect the Current Profile.

However, the farthest point in the circuit from the substation is 5.79 miles on path 4. Therefore, distance to fault estimated from the short-circuit fault current profile exceeds the total feeder length. In such a case, the distance to fault is reported as the furthest point on the circuit, i.e. 5.79 miles on path 4. Actual fault is located at 4.42 miles from the substation on path 4 . The error in estimation is $31 \%$ or 1.37 miles. To investigate the cause of the error, a single line-to-ground fault was placed at 4.42 miles. The fault current measured is $2600 \mathrm{~A}$, which happens to be 2.6 times $1014 \mathrm{~A}$, the 
maximum fault current measured by the relay. The short-circuit fault current profile should not be applied under these circumstances.

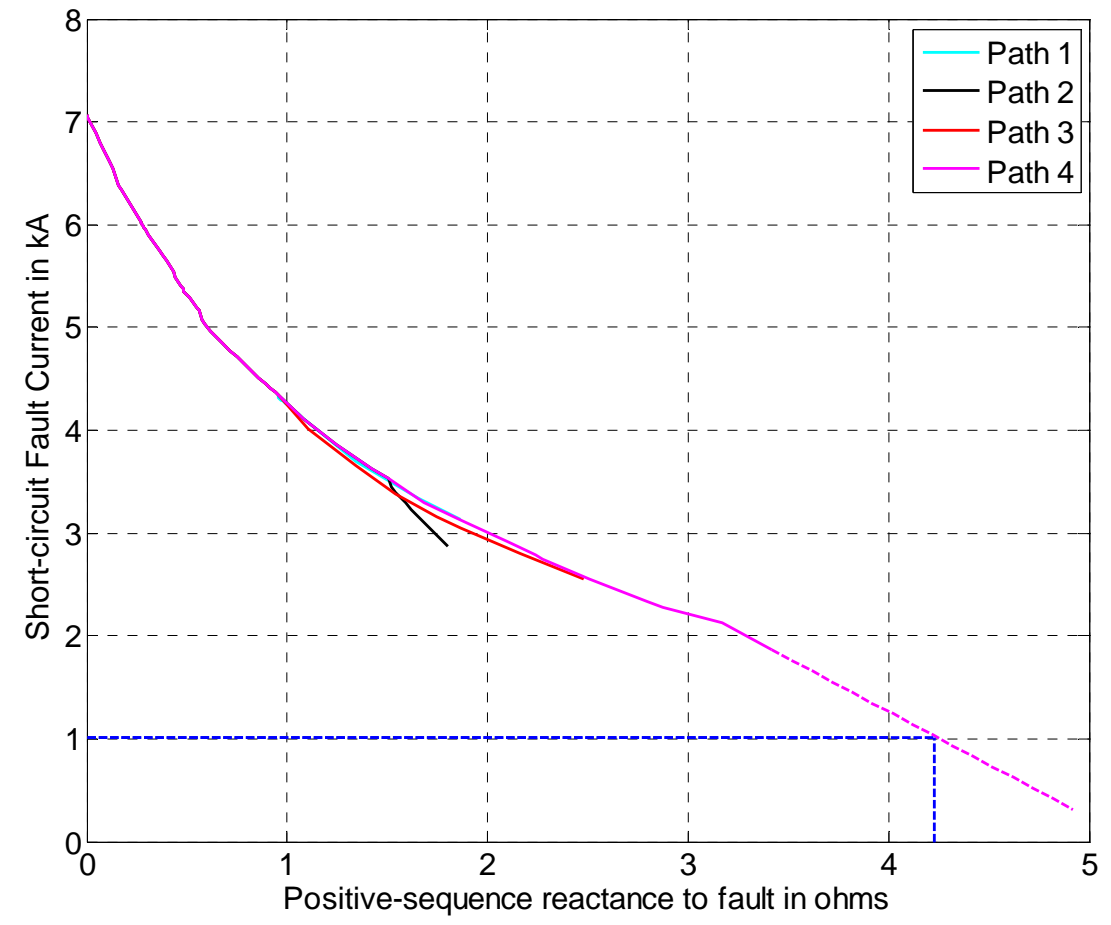

Figure 5.18: Short-circuit Fault Current Profile with Extrapolation..

\subsubsection{Event 3}

The third event analyzed occurred on $21^{\text {st }}$ June, 2010 at 11:37 hours. A C-phase to ground fault occurred in one of the fuses, at a distance of 3.35 miles from the substation. The location of the fault is shown in Figure 5.19. SEL-651 relay is located at the substation for line protection and monitors the system voltage and current at four samples per cycle. The relay fault log is shown in Figure 5.20. The voltage and current waveform recorded by the relay are shown in Figure 5.21. The prefault current is $120 \mathrm{~A}$ per phase while the fault current magnitude is 2166 A. As in the previous two events, voltage waveforms are not usable. Hence, location of the fault can be determined using only short-circuit fault current profile approach. 


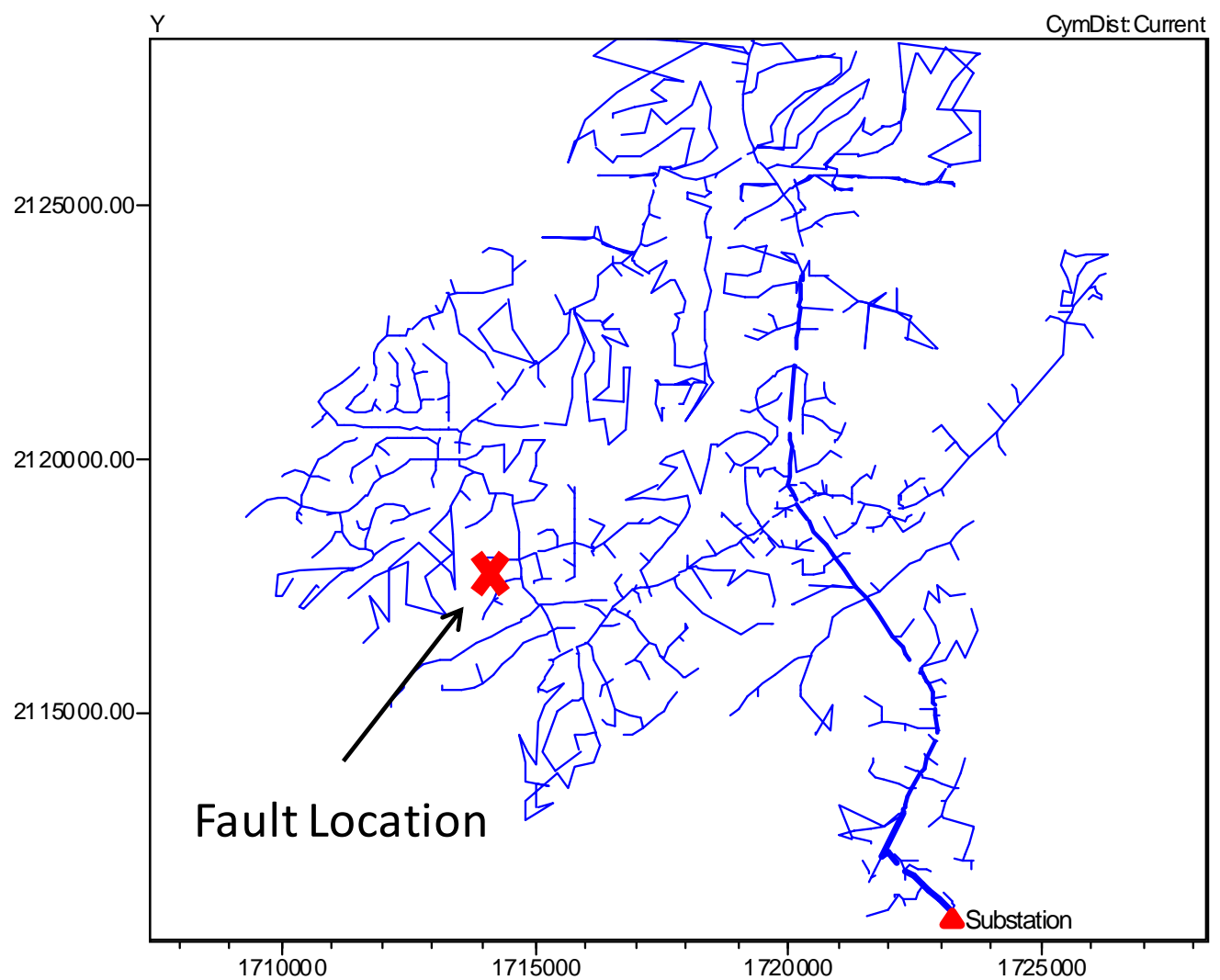

Figure 5.19: Fault Location on the Circuit Model of the Distribution Feeder.

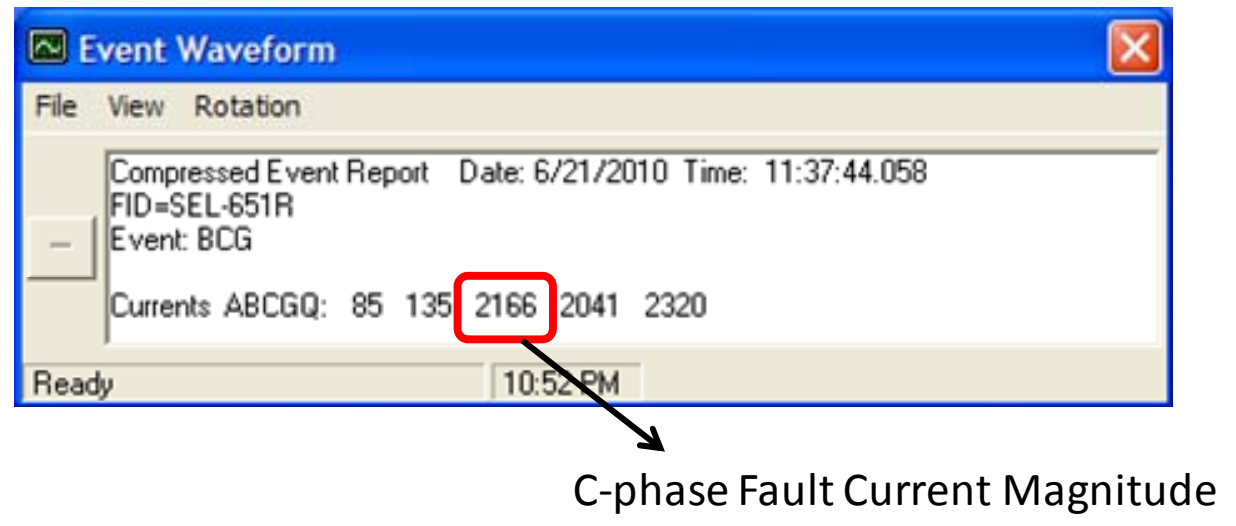

Figure 5.20: Relay Fault Log. 


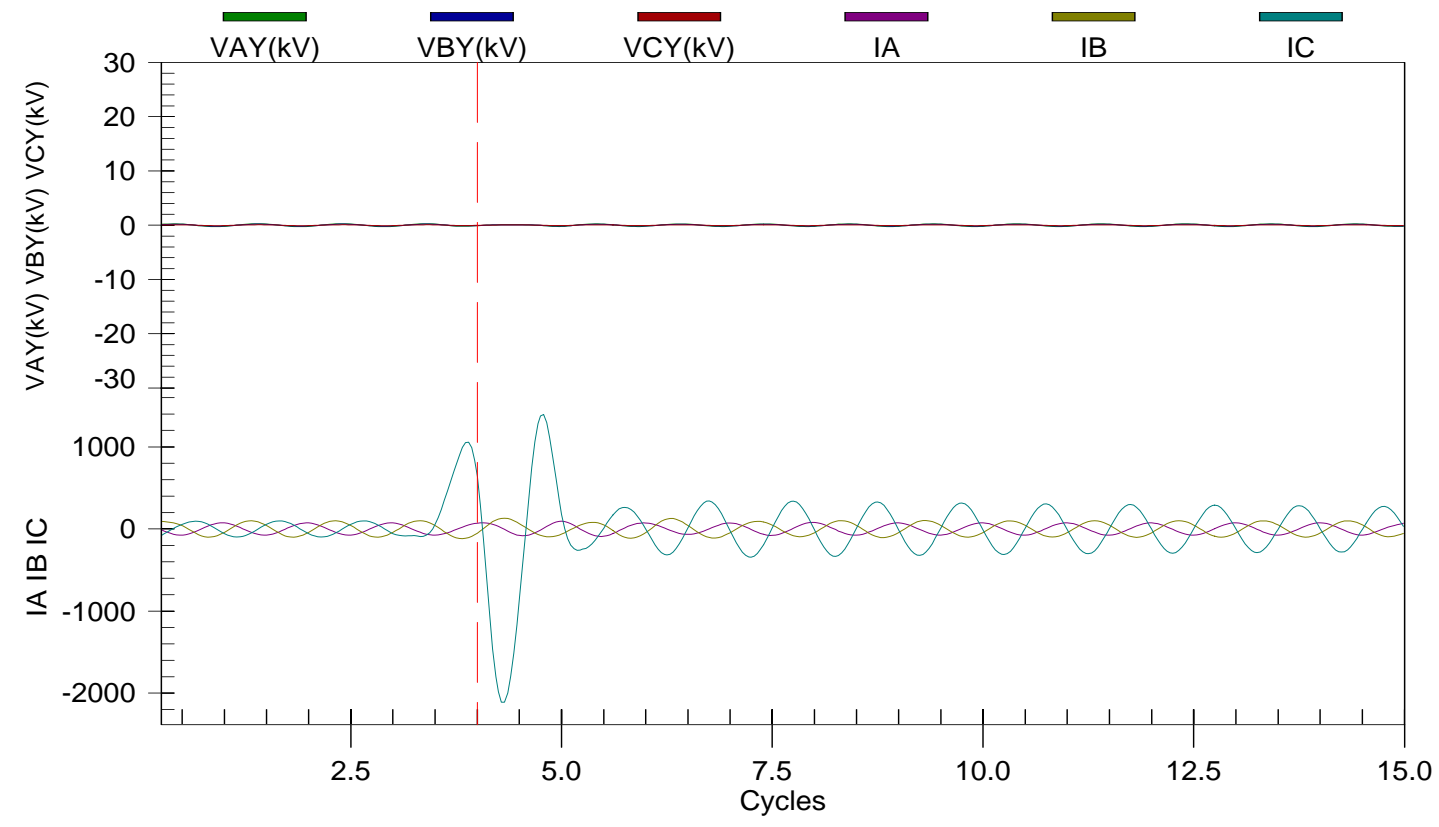

Figure 5.21: Relay Recording only Current Waveform. Voltage Waveform is Missing.

\section{Short-circuit Fault Current Profile Approach}

From the prefault current recorded by the SEL relay, it is evident that before fault the distribution feeder was operating under one-fourth load condition. Hence, shortcircuit current profile developed in the previous section can be used for determining fault location. The fault current magnitude of $2166 \mathrm{~A}$ when extrapolated on the current profile intersects path 4 at a positive-sequence reactance of 3.085 ohms, as seen in Figure 5.22. This corresponds to a distance of 5.33 miles. The actual location of the fault is 3.35 miles on path 4 . The location estimate is off by around 2 miles. The error is due to the fact that the circuit model does not accurately represent the distribution feeder. 


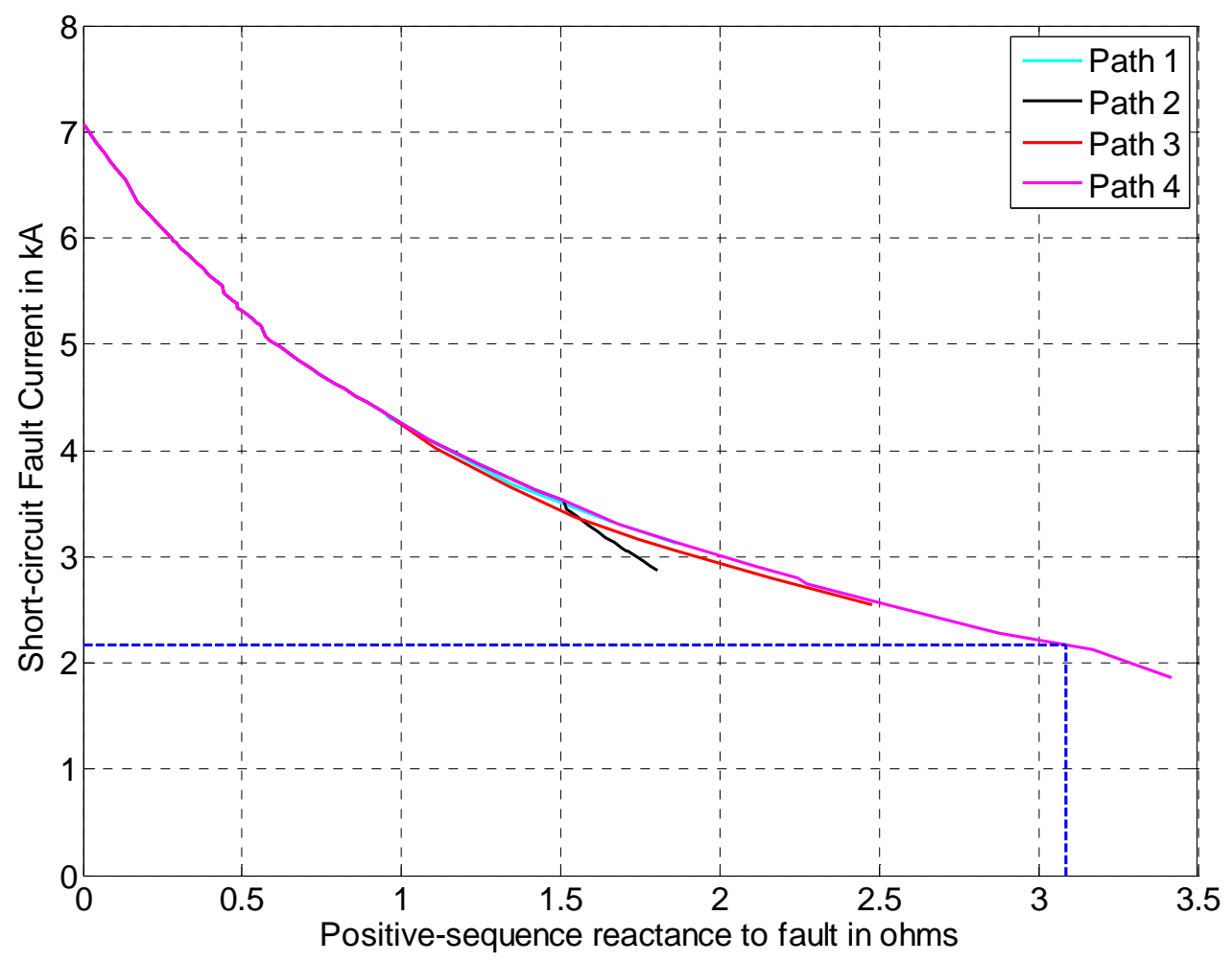

Figure 5.22: Illustrating Fault Location using the Current Profile.

\section{SUMMARY}

In summary, impedance-based and short-circuit fault current profile approach are used together to improve fault location estimates and also identify the path on which the fault may be located. When applied to four field events, the strategy is accurate. Fault path is identified and the fault location lies in the 0.6 mile radius built around the median estimate. In some events, due to unavailability of voltage, the short-circuit fault current profile approach alone was used to determine fault location and the accuracy was within 0.07 miles. The accuracy however is affected when the circuit model is not an accurate representation of the distribution feeder. This discrepancy between circuit model and distribution feeder is evident when the fault current recorded by the relay is less than the minimum threshold short-circuit circuit in the current profile. An approximate estimate 
can be obtained by linearly extending the current profile. However, error percentage of the location estimate is high and hence, short-circuit fault current profile approach should not be used in these cases. 


\section{6 summarz Anp reutrex work}

\subsection{SUMMARY}

The short-circuit fault current profile approach uses the circuit model available to the utilities for building the reference fault current profile. Hence the non-uniform line configuration of the distribution feeder is taken into account. To consider load current before fault, current profile is built for the system under incremental load conditions. Prefault current recorded by relay or fifteen minutes demand data is used to choose the appropriate profile for fault location. This approach also identifies the possible paths in which the fault may be located. When applied to a distribution feeder having multiple laterals and branches, the strategy used is to build current profile along every lateral and branch. As seen from the analysis on the modified IEEE 34 Node Test Feeder as well as field data provided by the utilities, this strategy gives accurate fault location estimates and can complement estimates obtained from impedance-based methods to improve fault location estimates. Median value is computed using estimates obtained from the impedance-based methods and the short-circuit fault current profile method and a 0.6 mile radius is built around that estimate. The value of 0.6 mile radius is obtained from the analysis conducted on the IEEE 34 Node Test Feeder. This test feeder is representative of a typical distribution feeder and has been modeled to represent the worst case scenario wherein the load current is $50 \%$ of the fault current at the farthest bus.

In some field events, voltage data recorded by the relay was not useful for analysis. In such cases, the short-circuit fault current profile approach is the only way to determine fault location. Accurate estimates within 0.1 mile of the actual location of the fault were obtained. The accuracy is however affected when the circuit model is not an accurate representation of the distribution feeder. This discrepancy between circuit model 
and distribution feeder is evident when the fault current recorded by the relay is less than the minimum threshold short-circuit circuit in the current profile. An approximate estimate can be obtained by linearly extending the current profile. However, error percentage of the location estimate is high and hence, short-circuit fault current profile approach should not be used in these cases.

\subsection{FUTURE WORK}

The procedures described above should be integrated in a stand-alone module or integrated as part of existing applications. The inputs to the module would be relay or power quality monitoring data, sequence line impedance, and a circuit model. The output is a range within which the fault is assumed to be located along with equipment names lying within that range. One possible implementation approach is illustrated in Figure 6.1 [4]. The highlights of each component are:

\section{- $\quad$ Event data collection and storage}

This component should collect data recorded by the relay or the power quality monitor and store the event information. EPRI's PQView can be used for such a purpose since it is compatible with SEL and other power quality monitor formats.

\section{- $\quad$ Circuit data importer}

Utilities have circuit model of the distribution feeder in various formats, for example, CYMDIST, ASPEN or FeederAll. The circuit models should be imported and converted to the OpenDSS format, since OpenDSS has a COM object which can be easily interfaced with other development or application programs such as Matlab. Conversion to OpenDSS when done properly is simple and should not involve much effort.

- $\quad$ Fault location system 
This component reads event data recorded by the monitor and identifies the fault event. It also identifies the useful information available for estimation (e.g., both fault voltage and current or fault current phasor or only fault current magnitude). If the relay records both voltage and current, this component applies the impedance-based methods as well as the short-circuit fault current profile approach to locate the faults. Comparing the estimates from both approaches, it identifies the path on which the fault is located and builds a 0.6 mile radius around the median estimate.

\section{- $\quad$ Operator Interface}

The fault location system is interfaced with the operator interface so that it can communicate to the operator about the possible path and a range within which the fault has a higher probability of being located.

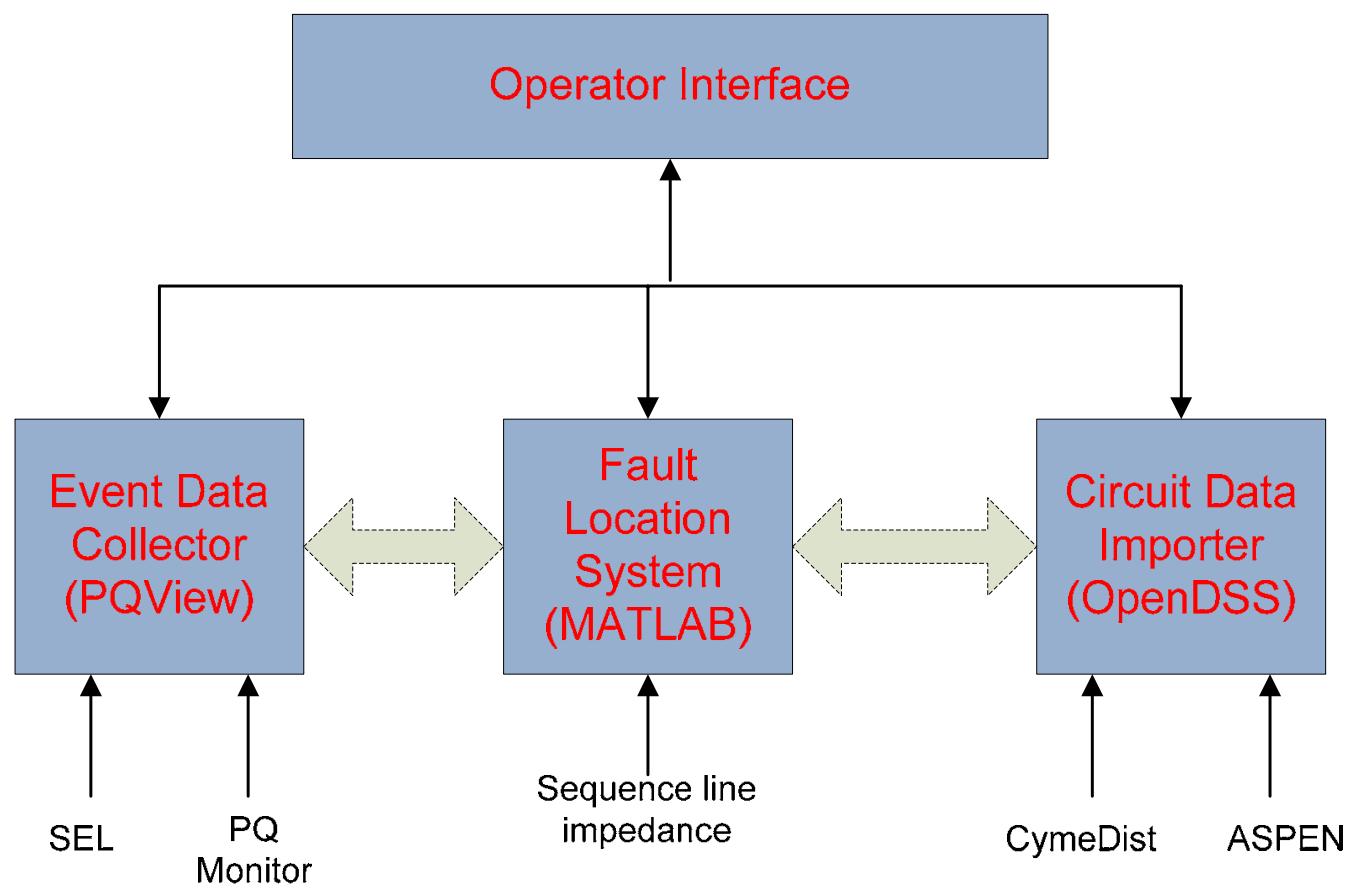

Figure 6.1: Stand-alone fault location module components. 


\section{APPENDIX}

\section{DATASET OF THE MODIFIED IEEE 34 NODE TEST FEEDER}

\section{Line Segment Data}

The IEEE 34 Node Test Feeder has been modified so as to increase the load current and the fault current. Table A.1 summarizes the new lengths of each overhead line segment.

Table A.1: Line Segment Data of the Modified IEEE 34 Node Test Feeder.

\begin{tabular}{|c|c|c|c|}
\hline Node A & Node B & $\begin{array}{c}\text { Length } \\
\text { (feet) }\end{array}$ & Configuration \\
\hline 800 & 802 & 2587.2 & 300 \\
\hline 802 & 806 & 1726.56 & 300 \\
\hline 806 & 808 & 3273.6 & 300 \\
\hline 808 & 810 & 5808 & 303 \\
\hline 808 & 812 & 3273.6 & 300 \\
\hline 812 & 814 & 3273.6 & 300 \\
\hline 814 & 850 & 10.56 & 301 \\
\hline 816 & 818 & 1689.6 & 302 \\
\hline 816 & 824 & 3273.6 & 301 \\
\hline 818 & 820 & 5280 & 302 \\
\hline 820 & 822 & 5280 & 302 \\
\hline 824 & 826 & 3009.6 & 303 \\
\hline
\end{tabular}




\begin{tabular}{|c|c|c|c|}
\hline 824 & 828 & 844.8 & 301 \\
\hline 828 & 830 & 3273.6 & 301 \\
\hline 830 & 854 & 517.44 & 301 \\
\hline 832 & 858 & 3305.28 & 301 \\
\hline 832 & 888 & 0 & XFM-1 \\
\hline 834 & 860 & 4752 & 301 \\
\hline 834 & 842 & 3801.6 & 301 \\
\hline 836 & 840 & 4752 & 301 \\
\hline 836 & 862 & 264 & 301 \\
\hline 842 & 844 & 4752 & 301 \\
\hline 844 & 846 & 4752 & 301 \\
\hline 846 & 848 & 4752 & 301 \\
\hline 850 & 816 & 316.8 & 301 \\
\hline 852 & 832 & 10.56 & 301 \\
\hline 854 & 856 & 5280 & 303 \\
\hline 854 & 852 & 3273.6 & 301 \\
\hline 858 & 864 & 1584 & 303 \\
\hline 858 & 834 & 3273.6 & 301 \\
\hline 860 & 836 & 4752 & 301 \\
\hline 862 & 838 & 4857.6 & 304 \\
\hline 888 & 890 & 3273.6 & 300 \\
\hline
\end{tabular}




\section{Loads}

The test feeder has both spot loads and distributed loads, which are increased to increase the load current. Table A.2 and A.3 summarizes the node at which the load is connected, load model code and the $\mathrm{kW}$ and $\mathrm{kVAr}$ of the load at each phase. The codes for each load have been defined in Chapter 2.

Table A.2: Spot Loads of the Modified IEEE 34 Node Test Feeder.

\begin{tabular}{|c|c|c|c|c|c|c|c|}
\hline Node & $\begin{array}{c}\text { Load } \\
\text { Model }\end{array}$ & $\begin{array}{c}\text { Ph-1 } \\
\mathbf{( k W})\end{array}$ & $\begin{array}{c}\text { Ph-1 } \\
\mathbf{( k V A r})\end{array}$ & $\begin{array}{c}\text { Ph-2 } \\
\mathbf{( k W )}\end{array}$ & $\begin{array}{c}\text { Ph-2 } \\
\mathbf{( k V A r})\end{array}$ & $\begin{array}{c}\text { Ph-3 } \\
\mathbf{( k W})\end{array}$ & $\begin{array}{c}\text { Ph-3 } \\
\mathbf{( k V A r})\end{array}$ \\
\hline 860 & Y-PQ & 100 & 80 & 100 & 80 & 100 & 80 \\
\hline 840 & Y-I & 700 & 800 & 700 & 800 & 700 & 800 \\
\hline 844 & Y-Z & 1000 & 780 & 1000 & 780 & 1000 & 780 \\
\hline 848 & D-PQ & 20 & 16 & 20 & 16 & 20 & 16 \\
\hline 890 & D-I & 800 & 400 & 800 & 400 & 800 & 400 \\
\hline 830 & D-Z & 10 & 5 & 10 & 5 & 25 & 10 \\
\hline Total & & 344 & 224 & 344 & 224 & 359 & 229 \\
\hline
\end{tabular}


Table A.3: Distributed Loads of the Modified IEEE 34 Node Test Feeder.

\begin{tabular}{|c|c|c|c|c|c|c|c|c|}
\hline $\begin{array}{c}\text { Node } \\
\text { A }\end{array}$ & $\begin{array}{c}\text { Node } \\
\text { B }\end{array}$ & $\begin{array}{l}\text { Load } \\
\text { Model }\end{array}$ & $\begin{array}{l}\text { Ph-1 } \\
(k W)\end{array}$ & $\begin{array}{c}\text { Ph-1 } \\
\text { (kVAr) }\end{array}$ & $\begin{array}{l}\text { Ph-2 } \\
(k W)\end{array}$ & $\begin{array}{c}\text { Ph-2 } \\
\text { (kVAr) }\end{array}$ & $\begin{array}{l}\text { Ph-3 } \\
(\mathbf{k W})\end{array}$ & $\begin{array}{c}\text { Ph-3 } \\
\text { (kVAr) }\end{array}$ \\
\hline 802 & 806 & Y-PQ & 0 & 0 & 30 & 15 & 25 & 14 \\
\hline 808 & 810 & Y-I & 0 & 0 & 16 & 8 & 0 & 0 \\
\hline 818 & 820 & $Y-Z$ & 34 & 17 & 0 & 0 & 0 & 0 \\
\hline 820 & 822 & Y-PQ & 135 & 70 & 0 & 0 & 0 & 0 \\
\hline 816 & 824 & D-I & 0 & 0 & 5 & 2 & 0 & 0 \\
\hline 824 & 826 & Y-I & 0 & 0 & 40 & 20 & 0 & 0 \\
\hline 824 & 828 & Y-PQ & 0 & 0 & 0 & 0 & 4 & 2 \\
\hline 828 & 830 & Y-PQ & 7 & 3 & 0 & 0 & 0 & 0 \\
\hline 854 & 856 & Y-PQ & 0 & 0 & 4 & 2 & 0 & 0 \\
\hline 832 & 858 & $\mathrm{D}-\mathrm{Z}$ & 7 & 3 & 2 & 1 & 6 & 3 \\
\hline 858 & 864 & Y-PQ & 2 & 1 & 0 & 0 & 0 & 0 \\
\hline 858 & 834 & D-PQ & 26.7 & 13.30 & 26.7 & 13.30 & 26.7 & 13.30 \\
\hline 834 & 860 & D-Z & 16 & 8 & 20 & 10 & 110 & 55 \\
\hline 860 & 836 & D-PQ & 30 & 15 & 10 & 6 & 42 & 22 \\
\hline 836 & 840 & D-I & 18 & 9 & 22 & 11 & 0 & 0 \\
\hline 862 & 838 & Y-PQ & 0 & 0 & 28 & 14 & 0 & 0 \\
\hline 842 & 844 & Y-PQ & 9 & 5 & 0 & 0 & 0 & 0 \\
\hline 844 & 846 & Y-PQ & 0 & 0 & 25 & 12 & 20 & 11 \\
\hline
\end{tabular}




\begin{tabular}{|c|c|c|c|c|c|c|c|c|}
\hline 846 & 848 & Y-PQ & 0 & 0 & 23 & 11 & 0 & 0 \\
\hline Total & & & 262 & 133 & 240 & 120 & 220 & 114 \\
\hline
\end{tabular}




\section{References}

[1] S. Santoso, Fundamentals of Electric Power Quality. Scotts Valley : CreateSpace, 2009.

[2] Power System Relaying Committee of the IEEE Power Engineering Society., IEEE Guide for Determining Fault Location on AC Transmission and Distribution Lines. New York: , 2005. IEEE Std C37.114 ${ }^{\mathrm{TM}}-2004$.

[3] SEL, AR360 AutoRanger Fault Indicators. 2009-2010.

[4] Distribution Fault Location: Field Data and Analysis. EPRI. Palo Alto: CA, 2006. 1012438.

[5] Distribution Fault Location: Prototypes, Algorithms, and New Technologies. EPRI. Palo Alto, CA, 2008. 1013825.

[6] K. Zimmerman and D. Costello, "Impedance-based fault location experience." 58th Annual Conference for Protective Relay Engineers, April 2005, pp. 211- 226.

[7] N. Karnik, S. Das, S. Kulkarni, S. Santoso, "Effect of Load Current on Fault Location Estimates of Impedance-based Methods," to appear in the Proceedings of IEEE PES General Meeting, Detroit, Michigan, 2011.

[8] Lampley, G. C., "Fault Detection and Location on Electrical Distribution System Case Study," presented at IEEE Rural Electric Power Conference, 2002.

[9] S. Das, S. Kulkarni, N. Karnik, S. Santoso, "Distribution Fault Location using Shortcircuit Fault Current Profile Approach," to appear in the Proceedings of IEEE PES General Meeting, Detroit, Michigan, 2011.

[10] W. H Kersting, "Radial Distribution Test Feeders." 2001 IEEE Power Engineering Society Winter Meeting. Vol.2, pp. $908-912$.

[11] T. Takagi et al., "Development of a New Type Fault Locator Using the OneTerminal Voltage and Current Data." IEEE Transactions on Power Apparatus and Systems, Aug. 1982, Issue 8, Vols. PAS-101, pp. 2892-2898.

[12] Manitoba HVDC Research Centre Inc., Applications of PSCAD/EMTDC. Manitoba HVDC Research Centre Inc. Winnipeg : s.n. User Manual.

[13] W. H Kersting, Distribution System Modeling and Analysis, CRC Press, 2002.

[14] R. C Dugan, The Open Distribution System Simulator (OpenDSS). EPRI. 2009. Reference Guide. 


\section{Vita}

Swagata Das was born in Kolkata, India. After completing her high school from G. D. Birla Centre for Education, Kolkata, India in 2005, she attended SRM College of Engineering, Chennai, India and graduated with a Bachelor of Technology (B.Tech) in Electrical and Electronics Engineering in May 2009. During her undergraduate studies, she has interned with Development Consultant Private Ltd. In August 2009, she entered the Graduate School at the University of Texas at Austin in the Energy Systems track of Electrical and Computer Engineering.

Email address: swagata@utexas.edu

This thesis was typed by Swagata Das. 